\title{
The Life of Language:
}

\section{Saussure and Evolution}

Thesis submitted in fulfillment of the requirements for the degree of Master of

Arts, Philosophy

by

Michael Gilchrist

Victoria University of Wellington

30 June 2009

(C) Michael Gilchrist 2009

Student ID No. 197975710 


\title{
The Life of Language:
}

\section{Saussure and Evolution}

\author{
If we are to discover the true nature of language we must learn what it has in common with all other \\ semiological systems. \\ Ferdinand de Saussure (1974, p. 16)
}

\section{Introduction}

The stimulus for this thesis came from a quite unexpected source. Originally I embarked on a comparative study of the two philosophers primarily responsible for the divergence of the Continental and Anglo-American traditions of language based philosophy: Ferdinand de Saussure and Gottlob Frege. But when I began a careful reading of Saussure's Course in General Linguistics (1974 - the Course) I was struck by the extent to which his synchronic theory of language appeared to reflect an awareness of linguistic evolution as analogous to biological evolution. That seemed to me to be particularly interesting for two reasons. First, I was aware of the empirical success that linguists and biologists have had in the late twentieth century in exploiting this analogy, particularly in tracing the geographical origins of ethnic groups (Cavalli-Sforza, 2000). Second, Saussure is usually identified with a view of language as something essentially arbitrary and conventional - something essentially human (Saussure, 1974, p. 16). By that account linguistic evolution would seem to have little in common with natural evolutionary processes. Yet far from rejecting the analogy, Saussure seemed to be taking a position within it, promoting a view of linguistic evolution that was akin to a contemporary Darwinian understanding, as opposed to a more archaic view, of biological 
evolution (Saussure, 1974, p. 4). The questions then arose: to what extent is Saussure's theory of language a theory that could underpin and explain the linguistic-biological analogy? To what extent should it be such a theory? And what does the linguisticbiological analogy suggest about the philosophical appropriation of Saussure's theory? These are the guiding questions of this thesis. The answers I advance make for what I hope is an interesting and even provocative re-reading of Saussure's theory of language.

Initially, I suggest, we need to recall that Saussure is attempting to theorise the forces that are universally and permanently at work in all languages and to deduce the general laws to which all specific historical phenomena can be reduced $(1974$, p. 6). In other words, historical linguistics - which Saussure also terms "diachronic" or "evolutionary" linguistics - forms the empirical basis for his synchronic theory of language. What Saussure finds in historical linguistics is what he calls a new class of phenomena (1974, p. 83). Here is something without any fixed units, identities or objects on which a science can be based. Instead, the signs or values that make up language manifest a material discontinuity in which change is potentially all pervasive and permanence results from sheer luck $(\mathbf{1 9 7 4}, \mathbf{p}$. 231). There is, nevertheless, a discernible structure to the forces which produce language states. These are the paradigmatic and syntagmatic relations that constitute the mechanism of language. There is also a framework within which that mechanism operates and which ensures its ceaseless evolution. This is the speech-language framework: the relation between the speech that lies within the system of language and the speech that lies outside it. Speakers straddle this framework by means of the unconscious comparisons they make between the collective storehouse of language where productive forms are arranged and the innovations that individual experience seems to 
necessitate. Saussure makes a distinction between everything that participates in this framework - the inner organism $(\mathbf{1 9 7 4}$, p. 21) or evolving system of a language - and everything that is external to it. What we observe in considering the contemporary linguistic-biological analogy is that the analogy holds under just the conditions Saussure defines, with surprising accuracy, for internal linguistics. Broadly, so long as the interaction of language and speech is unhindered, language evolves in a manner analogous to the human genome.

Saussure's theory of language explains and supports the analogy with biological evolution, then, to this extent: it details a conception of language as an evolving system of values within a language-speech framework that is free of external imposition or interference. At the end of the thesis I suggest that there are strong hints that this common evolutionary framework offers a very promising way of re-conceiving key elements in our current metaphysical framework. In the earlier parts of the thesis I consider the way in which Saussure's theory is also elaborated on quite another basis. That basis is the wholly arbitrary nature of the signifier (Saussure, 1974, p. 68). It is this unique feature of language - a feature not shared by other sign systems, especially natural sign systems that is responsible, in Saussure's view, for the manner and complexity of linguistic evolution $(1974$, p. 76$)$. The arbitrariness of the bond between the signifier and the signified is what makes the sign labile, reasons Saussure - and every evolutionary change involves a shift in the relationship between the signifier and signified within the sign (1974, . To the extent that Saussure's theory hangs on his doctrine of the arbitrary signifier, I suggest, it does not support the linguistic-biological analogy. 
The analogy, therefore, drives a wedge between two forms of arbitrariness that are simultaneously at work in Saussure's theory. The first form could be called "system arbitrariness" or "material discontinuity". The character of evolutionary change is such that it makes no difference what material medium a sign system uses so long as it functions on a dynamic of individual innovation and collective conservation - that is, the speech-language relationship. The signifier and signified are inseparable in the values produced by a system evolving in this way. The second form of arbitrariness could be called "signifier" arbitrariness and it is the familiar arbitrariness of names as opposed to objects. The signifier and the signified are essentially separable in the signs produced by arbitrary naming. There is a strong drive in Saussure's thought to connect up these two conceptions of arbitrariness. I suggest that not only is signifier arbitrariness at odds with the linguistic-biological analogy but it contradicts Saussure's critique of language as simple naming. Relying solely on system arbitrariness removes many of the contradictions and aporia that arise from the inclusion of signifier arbitrariness in Saussure's systematics of language.

It could be argued, then, that there are a number of reasons why Saussure's theory should support the linguistic-biological analogy: it is in line with the theory's goal of describing the forces that are at work in language evolution; if the theory supports the linguistic-biological analogy then the analogy, in turn, provides empirical support for the theory; and, unhooking system arbitrariness from signifier arbitrariness frees Saussure's theory from a number of contradictions under which it otherwise labours. But, I suggest, signifier arbitrariness is too strong an intuition to simply relegate to the sidelines. It needs to be accommodated within system arbitrariness and accordingly I argue that it can 
usefully be re-articulated as "systematic latitude" - adapting and developing a concept we already find in Saussure's linguistics. Once that is done, there is no structural division between the signifier and the signified cutting across the values produced by an evolving system of associative and oppositional relations. This re-articulation of arbitrary naming promises, in turn, to loosen the subject-object opposition at the base of our metaphysical framework. It creates the possibility of a meiotic redistribution of key terms and relations associated with that opposition on the axis of the common evolutionary framework i.e. the speech-language relation. This is the potential of the analogy for the philosophical appropriation of Saussure's theory.

In the first two chapters of the thesis I give an exposition of Saussure's theory that provides a basis for an exploration of the linguistic-biological analogy. In particular I emphasise the relationship between the synchronic theory and evolutionary linguistics. For example, I examine the notion that language could be comprised of relations of difference as opposed to relations of similarity and association. Conversely, I question whether the language system could be a kind of limiting of difference precisely by relations of similarity and association. Both of these arguments are present in Saussure's Course, although the former has proved by far the most popular tendency (Belsey, 2002; Culler, 1986). In giving an account of the theory that looks forward to an exploration of the linguistic-biological analogy, I emphasise the inseparability of relations of identity and difference in the evolving language system.

I also note an inchoate theory of truth in Saussure's linguistics. This is later combined with the more developed concept of systematic latitude set out in the fourth 
chapter. The combination provides the basis for an account of the often very subtle relationship between systematic value and the apparently arbitrary naming by which we are free to elaborate systematic value. I use Frege's problems of informative identity statements and intentional contexts to test this account (Frege, 1997). Perhaps we here encounter the palimpsest of the original project of this thesis. However, since these problems form part of Frege's own critique of a simple naming theory of language I suggest that it is both appropriate and useful to use them to test this interpretation of Saussure's theory.

In the third chapter I explore the linguistic-biological analogy in more detail and show that it is a concept that is bound up from the outset with the development of historical linguistics. Saussure's work can be situated firmly within this ongoing dialogue and the extent to which his theory supports the contemporary analogy defined. In the fourth chapter I consider the reasons why Saussure's theory should support the analogy and the way in which this opens the possibility of a fuller philosophical appropriation of his theory. Ultimately, I argue, that appropriation has the potential to change our conceptions of the permanent and the universal as such.

The format of the thesis follows the American Psychological Association style, except that I have had to adopt a different protocol for quotations which here appear two points smaller than the normal text and in bold rather than in quotation marks. This departure is necessitated by the convention in Ballye and Sechahaye's editing of the Course in General Linguistics which uses italics to identify names or signifiers and quotation marks for objects or signifieds. So, for example, Saussure refers to tree and 
"tree" respectively. It is also helpful in distinguishing the large amounts of text that are quoted at some points. When I have already quoted from a source and am using a brief part of the quotation subsequently then this will appear in quotation marks in the normal way. Quotation marks also name expressions that come from the author of this thesis "material discontinuity", for example - or from a writer nearby in context. 


\section{The Life of Language:}

\section{Saussure and Evolution}

\section{Chapter 1: Introducing Saussure}

\section{Section 1: The creation of Saussure's text}

- Saussure's "Course in General Linguistics" (the Course) has an unusual provenance, being based largely on notes taken by students of a course of lectures Saussure gave in three alternate years between 1906 and 1911.

- The Course differs in some respects from the lectures Saussure actually gave. Notably, in the original courses, the account of diachronic linguistics is a prelude to the synchronic theory of language, not a postscript to it.

- The Course gives an account of the accepted views of the time as well as Saussure's own views, without explicitly distinguishing between these.

No-one disputes the influence of Ferdinand de Saussure's theory of language. It has proved extraordinarily fertile across a wide range of disciplines (Gadet, 1986). However, to adapt one of Saussure's own dicta, $(1974$, p. 68), it is often easier to assign a theory its proper place than to discover its truth. The unusual provenance of Saussure's work does nothing to diminish this difficulty. The work in which the theory is contained, 
the "Course in General Linguistics", is a reconstruction, by his editors, Charles Bally and Albert Sechehaye, in collaboration with Albert Reidlinger, of a series of lectures given by Saussure toward the end of his career, between 1906 and 1911. Saussure himself produced no written account of his general linguistics. Indeed Saussure developed what may reasonably be described as a fear of writing, destroying his notes for these lectures and becoming unable to bring to publication any of his considerable number of writing projects (Culler, p. 23). Bally and Sechehaye's reconstruction is based on the notes of students (including those of Charles Bally himself) attending one or other of three series of lectures, together with some notes of Saussure's recovered from his private papers, most notably his "Notes pour un article sur Whitney" of 1894 (Alter, 2005, p.250). The lectures make up the eponymous Course in General Linguistics that Saussure taught three times.

The decisions made by the editors in synthesising the text of the Course have been the subject a good deal of dispute - at least since the publication of original students' notes by Robert Godel in 1957 (Godel, 1957). In his 1976 account of Saussure's work, Jonathan Culler, for example - while acknowledging that the Course in its established form has already been immensely influential - suggests that it does not give enough weight to the primordial importance of the principle of the arbitrary nature of the sign (Culler, 1986, p. 26). Culler contends that the original notes show a greater emphasis on this principle. He bases his account on this principle, locating other key aspects of Saussure's theory as consequences of it. This has the appeal of being a distinctively structural approach to Saussure's work. In a recent article, entitled "Saussure's unfinished semantics", Simon Bouquet develops an account of Saussure' preliminary semantics 
based entirely on student notes of the lectures and on some other unpublished writings of the times (Sanders, 2004, p. 205 - p.218). He makes some strong criticisms of the decisions of the editors, stating, for example, that the last sentence of the Course - the true and unique object of linguistics is language studied in and of itself (Saussure, 1974, p. 232) - is as unfortunate as it is famous. (Sanders, 2004, p. 207) It is completely contradictory and nowhere to be found in Saussure's lectures or writings (Sanders, 2004, p. 207), having been drawn instead from the work of the progenitor of comparative philology, Franz Bopp. Yet it is clear that the dispute that one has with the editors will depend on one's interpretative interests. The echoes, in this phrase, of Saussure's emphasis on what he calls internal linguistics (1974, p. 20) and his frequent emphasis on the need to study language in itself $(\mathbf{1 9 7 4}, \mathbf{p .} \mathbf{1 6})$ and to avoid external (1974, p. 113) aspects of language seem quite appropriate from the point of view of the reading advanced in this thesis, for example. It is also helpful to recall that this pivotal statement would, in the original sequence, appear at the end of the first section of Saussure's course of lectures rather than at the end of the entire course.

For, I suggest - no doubt reflecting my own interpretative interests - that it is very important to note that the original courses of lectures, especially the third course, have a different order from that which they are given in the Course. The plan of Saussure's third Course can be described as follows: from the diversity of languages to "language" (as opposed to "speech") - and from language to linguistics. Bally and Sechehaye, however, begin with language and postpone languages and their diversity (parts 3,4 and 5) to the end. (Gadet, 1986, p. 22) Part 3 is headed "Diachronic Linguistics" and parts 4 and 5 also deal with historical linguistics. It may be said then that the sequence in the Course gives too much prominence to the structural, synchronic aspect of the theory before showing how this arises from 
Saussure's account of evolutionary or diachronic linguistics. Saussure's account of evolutionary linguistics is, I suggest, the prologue to the synchronic theory, not a postscript to it.

For the origins of Saussure's theory of language lie in his understanding of diachronic or evolutionary linguistics. The theory is Saussure's attempt to describe the enduring conditions that make language evolution possible - to determine the forces that are permanently and universally at work in all languages and to deduce the general laws to which all specific historical phenomena can be reduced (Saussure, 1974, p. 6). The fact that Saussure's synchronic linguistics is concerned to describe the structure of language in a stable state does not mean that the subject of his study is not something living - an object constantly being transmitted and reproduced over time within a community of speakers. As Saussure says, there is really no such thing as absolute immobility ... evolution may vary in rapidity and intensity but this does not invalidate the principle (1974, p. 140). Synchronic linguistics does not describe any particular evolutionary trajectory - it does not give any history of the growth of a particular language as diachronic linguistics does. That does not mean, however, that it is not concerned with a living object as the product of an evolutionary process. We should not imagine that, I suggest, any more than we would now seek to understand a biological organism or system of organisms outside its evolutionary context.

It is also important to note what may be called the "geometrical" character of Saussure's theory - a feature which contributed to the difficulty he experienced in writing for publication. What makes the subject difficult, says Saussure, is that it can be approached from various directions, like certain geometrical theorems: everything is the corollary of everything 
else in static linguistics. Whether one is talking of units, differences, oppositions etc., it all comes down to the same thing (Interview with Riedlinger, 1909, quoted in Gadet, 1986, p. 24). In a later interview he says: No one point of departure is more appropriate than another as a foundation for the demonstration (Note from proposed volume, 1894, quoted in Gadet, 1986, p. 25). I will be suggesting that this geometrical character also reflects the essential grounding of Saussure's static linguistics in historical or evolutionary linguistics. The forces that create any stable language state are the same forces that cause it to change.

It is also important to observe that the "Course in General Linguistics" is just that - a long Course of lectures teaching students about linguistics as such. It is a mixture of Saussure's own views and the standard views of the time on the subject. No doubt this fact also emboldened the editors of the Course to add some of their own glosses. The teachings of the Neogrammarian school with which Saussure is most closely associated must be taken into account and, in particular, there is the widespread influence of the American linguist William Dwight Whitney. Whitney is probably the most important single source of ideas for the Neogrammarians as a group and he is particularly important for Saussure (Alter, 2005). The student lecture notes that form the basis of the text of the Course were supplemented by material from Saussure's private papers and much of this is taken from "Notes pour un article sur Whitney". This is a document of some thirty pages Saussure prepared in 1894 on the occasion of Whitney's death, in which he first begins to expound his ideas on the broader questions of linguistics as such. It is not surprising, then, that when the American Leonard Bloomfield reviewed the second edition of Saussure's Course in 1924 he remarked: Most of what the author says has long been 
"in the air" and has been here and there fragmentarily expressed (Bloomfield, 1924, p. 318 in Falk, J.S., in Sanders, 2004, p. 108).

Understanding that the Course is not original in any holistic sense certainly eases some of the contradictions in the text. It is not, I think, facile to attribute many statements in the Course to Whitney and to the accepted views of the time and others to Saussure's distinctive theorizing. Often Saussure uses expressions which are taken almost verbatim from other sources and seem to aim at an accurate reflection of those sources. His differing statements on the role of signification alongside value or on the question of whether there was an implicit original contract between speakers, are good examples of contradictions that may be explained in this way. But perhaps the best illustration one can provide is the most central. Here is John Locke, inspired in turn by Plato's dialogue Cratylus and a long subsequent tradition from Aristotle through St. Augustine (Joseph, J.E. in Sanders, 2004, p. 61). Locke argues that certain words stand for certain ideas not by any natural connexion ... for then there would be but one Language amongst all Men; but by a voluntary Imposition, whereby such a word is made arbitrarily the Mark of such an Idea (Locke, J., Book III, “Of Words," in Essay Concerning Human Understanding (1690) in Alter, 2005, p. 54). The 1853 edition of Websters American Dictionary of the English Language states: Language consists in the oral utterance of sounds which usage has made the representative of ideas. When two or more persons customarily annex the same sounds to the same ideas, the expression of these sounds by one person communicates his ideas to another (Alter, 2005, p. 74). There, in a nutshell, are many of the key elements of Saussure's introductory exposition of the doctrine of the arbitrary nature of the sign in the Course. 


\section{Section 2: The science of linguistics}

- Saussure's "Glance at the history of linguistics" $(1974$, p. 1) reflects his ongoing concern with the definition of linguistics as a science.

- Following the debate between Dwight Whitney, representing a conventionalist tradition, and the continental natural-historical tradition, Saussure is able to take a more nuanced middle ground.

- The primary problem, contends Saussure, is that a science must have a well defined object of study and linguistics has not yet identified such an object nor its method of study.

Despite the "geometrical" character of Saussure's thought, the desire to provide a narrative sequence is very strong in the demonstration of any theory, and no account, including this one, is immune to it. Accordingly, I would suggest that the Course's beginning with A Glance at the History of Linguistics (Sausssure, 1974, p. 1) reflects a theme that is constant throughout the lectures: the definition of linguistics as a science. In fact for some thinkers most influenced by Saussure - Roland Barthes, for example - Saussure is as important a theorist of science as he is a theorist of language (Barthes, 1968). But in this respect also it is important to note that Saussure is continuing a tradition that was particularly strong in the period leading up to his work. Questions about the nature of language were inseparable from questions about the scientific character of linguistics and one concern constantly clouds - as well as informs - the other. If language can be 
characterised as an independent natural organism then the study of language can assume legitimacy as a science alongside the natural sciences. Yet as its confidence grows, linguistics - or comparative philology as it was known earlier in the century - needs to assert its independent and unique characteristics and is more aptly defined as an historical science of voluntary human activity. This latter is the view successfully advocated by Whitney. By the time Saussure takes up the project of defining linguistics as a science there is the opportunity for a more nuanced middle ground - and this is the territory I will be exploring in more detail in the course of this thesis.

From an individual point of view Saussure's continuing preoccupation with the scientific character of his discipline is also not surprising. He was the son of an eminent naturalist and member of a family with a strong tradition of accomplishment in the natural sciences (Culler, 1986, p. 21). His younger brother, Renee, was also a linguist and during the years of the Course achieved renown as a leader of the Esperanto movement, a development in which Saussure often reflects an interest. His other younger brother, Leopold, was also interested in linguistics, linking it to the "scientific racism" of the time in a book published in 1899 (Joseph, J.E., in Sanders, 2004, p. 69). As Joseph puts it: It is certainly interesting, and maybe significant, that Saussure's theoretical path was cut between those of his two younger brothers, one caught up in a racist and the other in a rationalist misunderstanding of language ... (in Sanders, 2004, p. 69).

More broadly it may be remarked that Saussure's birth in 1857 came one year after that of Sigmund Freud and one year before Emile Durkheim. It was also just two years before Darwin's The Origin of the Species was first published in 1859. The affinity 
of Saussure's theory to the writings of Ludwig Wittgenstein (both early and late) is often noted. However, one consequence of the unusual provenance of the Course is that he also resembles the Austrian philosopher in his silence regarding his theoretical influences particularly with regard to his non-linguistic theoretical influences. One line of thought contends that Saussure was directly influenced by Durkheim and subsequently followed closely the debate surrounding Durkheim's ideas. (Barthes, 1968, p. 23) Yet the widespread impact of the Darwinian conception of evolution on historical linguistics must have been particularly keenly felt by Saussure given the intellectual environment in his family. Overall, as Harris puts it, Saussure foresees "the possibility that disciplines such as psychology, physiology, sociology and anthropology might well sponsor forms of linguistic enquiry which would be potential rivals for recognition as the modern science of language (Harris, 1987, p. 6.).

The key problem, as Saussure sees it, for constituting linguistics as a science is that it has not yet sought out and identified the true nature of its object of study. If linguistics could do this then it could go on and develop a method. A key step in this process for Saussure is to set out a history of linguistics that will provide a launching pad for his own theory. The essential element with which he is concerned is the development of the conception of language or "langue". It is this object that Saussure wants to generalize as the object of the science of linguistics. The difficulty for Saussure is that so far the various disciplines that might loosely be termed linguistics have taken all kinds of objects as their raw material and used all kinds of means to study them. In terms of the object of study, Saussure says: Other sciences work with objects that are given in advance and that can then be considered with different viewpoints; but not linguistics. Someone pronounces the French word $n u$ "bare": a superficial observer would be tempted to call the word a concrete linguistic object; but a 
more careful examination would reveal successively three or four quite different things, depending on whether the word is considered as a sound, as the expression of an idea, as the equivalent of the Latin nudum, etc. Far from it being the object that antedates the view point, it would seem that it is the view point that creates the object $(1974$, p. 8). In terms of the method of study Saussure claims that in no other field have so many absurd notions, prejudices, mirages and fictions have sprung up (1974, p. 7). This latter difficulty has mainly to do, as we shall see, with the conception of language as an organism with its own life cycle.

\section{Section 3: A glance at the history of linguistics}

- Saussure gives an account of the history of linguistics which identifies three stages by which historical linguistics develops before finding its true and unique object, language studied in and of itself.

- A key stage in that process is achieved for the Neogrammarians by the refutation of the "life cycle" thesis. This allows for the correct conception of the evolution of language.

- Saussure will be concerned to distinguish that refutation, however, from a simple conventionalist position.

By Saussure's account the science that has been developed around the facts of language passed through three stages before finding its true and unique object (1974, p. 1). These stages are: Grammar (initiated by the Greeks); Philology (which may be traced in 
its contemporary form to Friedrich Wolf in 1777) and Comparative Philology. Comparative Philology then gives way, in Saussure's account, to the Neogrammarians, the to which Saussure is most closely tied. Comparative Philology began early in the nineteenth century when, as Saussure puts it, scholars discovered that languages can be compared with one another, to illuminate one language by means of another, to explain the forms of one through the forms of another (1974, p. 2). This development was given a considerable boost by the discovery of Sanskrit. For example, a comparison of the paradigms of Latin genus and Greek genos reveals nothing. ... But the picture changes as soon as we add the corresponding Sanskrit series. ... Grammatically, then, the Sanskrit paradigm exemplifies the concept of a radical, a unit (ganas) that is quite definite and stable (1974, p. 2).

However, says Saussure, the first mistake of the comparative philologists was also the source of all their other mistakes. They failed to give an account of the meaning of their comparisons or the significance of the relations they discovered (1974, p. 4). This was a mistake because the comparisons should have been used to illuminate the history of language and thus provide some conclusion about language in general, language as such. It is a mistake that is compounded when historical conclusions are sought, says Saussure, - but by an excessively naturalistic method, as for example, whenever the comparative philologists looked upon the development of two languages as a naturalist might look upon the growth of two plants. For example, Schleicher, who always invites us to start from Proto-IndoEuropean and thus seems to be a confirmed historian, has no hesitancy in saying that Greek e and o are two grades (Stufen) of the vocalic system. This is because Sanskrit has a system of vocalic alternations that suggest that notion of grades. Schleicher supposed that each language has to pass through these grades separately and in exactly the same way, just as plants of the same species pass through the same developmental stages independently of one another (1974, p. 2). 
What Saussure is targeting here is the "life cycle" thesis that assumed great importance in earlier $19^{\text {th }}$ Century linguistics and continued in modified forms even after the middle of the century. The assumption is that languages go through a cycle of birth, rapid development that unfolds their latent form and then a prolonged period of subsequent decay. Bopp puts it this way: The grammatical forms and collective organism of the languages are the production of their earliest period of life, when they blossomed forth with the whole strength of youth, like blossoms and fruits from a young stalk (Alter, 2005, p. 217). In a less empurpled vein, Bopp asserts: Languages should be considered organic natural bodies which are formed according to fixed laws and which develop because they have an inner principle of life (Alter, 2005, p. 125). As late as 1871 the linguist Curtius says: That the full forms are prior to the weaker forms is the basic, hardly disputable assumption underlying all of comparative grammar (Alter, 2005, p. 218). Getting historical linguistics quite literally pointed in the right direction - an evolutionary direction - was crucial for the Neogrammarians and we will look in more detail at how this was achieved in Chapter 3 of this thesis. We can note in passing, however, a few of the factors that contributed to the appeal of the life cycle doctrine.

One is that there seemed to be an evidential basis. Looking at earlier versions of languages - Latin as compared to later romance languages, for example - there is a clear loss of much inflectional apparatus and an apparent decline from an original state of grammatical completeness. As Alter says: Few scholars realised at the time that these conclusions were based on limited evidence - those few famous writings that preserved the learned dialect rather than common speech (2005, p. 217). 
A second factor is theological. We have noted that in viewing the growth of language as a natural process comparative philology could lay claim to being a natural science. But this lapsarian view of language also had an obvious theological appeal in suggesting that language could still be viewed as a divine gift bestowed uniquely on Man - as opposed to evolving through a Darwinian process. This could, in turn, be reinforced by appeal to a Kantian argument that abstract thought was a necessary pre-requisite of language and that mental categories of space and time must have preceded the development of language. Enlisting science against Darwinism in this way brought the linguist Max Muller, for example, considerable fame on the Victorian lecture circuit in the early 1860s. (Alter, 2005, p. 63)

So comparative philology first made language the object of study, but with some significant limitations: Not until around 1870 did scholars begin to seek out the principles that govern the life of languages. Then they began to see that similarities between languages are only one side of the linguistic phenomenon, that comparison is only a means or method of reconstructing the facts (Saussure, 1974, p.5). In the 1870 s a number of scholars, including the mainly German Neogrammarians with whom Saussure most closely identified, succeeded in placing the results of comparative studies in their historical perspective and thus linking the facts in their natural order. Thanks to them, language is no longer looked on as an organism that develops independently but as a product of the collective mind of linguistic groups (Saussure, 1974, p.5).

This last sentence sums up what Saussure wants to extract from the development of linguistics in the nineteenth century and use as the object for his theory of language. It is not that linguistics can't be grasped as analogous to the biological study of organisms. On the contrary, Whitney's seminal text of 1875, which Saussure credits (1974, p.5) with 
providing the decisive break with the life cycle thesis, is entitled "The Life and Growth of Languages." Saussure too will continue to talk about the "grammatical organism" (1974, p. 21) and the life of languages. Rather, the distinction Saussure is concerned to make is very similar to one that had already been achieved within biology. That is the distinction between the individual developmental history of organisms and the population based evolution of organisms. The changes that occur in speech are not necessary developmental phases as Schleicher suggests but are random or fortuitous changes - what Saussure calls the chance products of the individual $(1974$, p. 165) - that have become part of the language of a community, just as random, genetic mutations that prove adaptive make their way into a collective gene pool. It is the historical study of language that shows language evolving in this way that Saussure wants to pick out as displaying the object of study of the new science. Likewise, as we will see, the arbitrary nature of the units of language is, in Saussure's view, the condition of this evolution. The arbitrary nature of the sign makes it subject to a wide range of irrational, fortuitous, random and involuntary forces. (Saussure, 1974, p. 75)

\section{Section 4: The object of study for linguistics}

- "Langage" - or the totality of human speech - can be divided into "langue" or language and "parole" or speech. "Language" and "speech" are technical terms that Saussure makes clear that he alone defines.

- Language is first of all the "associative bond" between a sound image and a concept. 
- This bond is formed through the interaction of individuals with other individuals in a speaking circuit.

- Having initially defined the object of linguistics as language studied in itself Saussure introduces his novel solution to the problem of the scientific character of linguistics by proposing a new science of the "life of signs in society", in many respects synthesizing the naturalist and the conventionalist positions.

From a brief history of linguistics Saussure goes on to discuss the object of linguistics - "langue" or "language" in Wade Baskin's translation - in more detail. By language he means broadly "language" in the sense that we think of English, French, Sanskrit and Proto Indo-European as languages. But as the definition of language becomes more precise - particularly in opposition to the term "parole" or "speech" Saussure makes it clear that he is not appealing to the uses of these words in any existing language but defining his own technical terms. He then first defines language in relation to what he calls "langage" - the totality of human speech or the heterogenous mass of speech facts (Saussure, 1974, p. 9). He begins by situating language within what he calls the speaking-circuit.

The speaking circuit - illustrated with some rather quaint diagrams - is not usually the subject of much attention in accounts of Saussure's theory. However it is a vital step in the progress from the broadest definition of language to a more precise and complex one. That is because it is the framework for what might be termed Saussure's "semantic 
immanence”. By this I mean, first of all, that for Saussure, the meaning of a name is not any particular thing in the world but a concept. We have seen that this follows very much the Lockean tradition, which in turn reflects the classical tradition: The Stoics ... explicitly distinguished the semainon, the thing signifying, from the semainomenon, the thing signified and made clear that the latter was incorporeal and not to be confused with the existing thing (Joseph, in Sanders, 2004, p. 61.). The "signified", as Saussure came to call it, can also be distinguished from a Kantian category. Saussure allied himself with Whitney against the mainly German school of linguistics who claimed that some capacity for abstract thought must be present before speech could develop (Alter, 2005, p. 127). It may also be distinguished from the particular designated by a "singular term" in the theories of Frege and then Russell. The signified is generally more abstract (1974, p.66), than the signifier, says Saussure. Nevertheless, both are psychological entities: We have seen in considering the speaking circuit (p. 11) that both terms involved in the linguistic sign are psychological and are united in the brain by an associative bond. This point must be emphasized. The linguistic sign unites, not a thing and a name, but a concept and a sound image (Saussure, 1974, p. 65 - p. 66).

The speaking circuit itself is simple enough - a loop that must include at least two speakers - much as we talk colloquially about "being in the loop". A sequence in the circuit can be imagined to begin with one speaker having the desire to communicate something. As Saussure puts it, a concept unlocks a sound image (1974, p.11). This purely psychological phenomenon is followed by a physiological one in which the brain transmits an impulse corresponding to the sound image to the organs used in producing sounds. Then a physical process occurs as the sound waves travel from the mouth of the first speaker to the ear of the other speaker. The circuit then continues in the reverse order in the other speaker: from the ear to the brain, the physiological transmission of the 
sound-image; in the brain, the psychological association of the image with the corresponding concept. Saussure notes: Among all the individuals that are linked together by speech, some sort of average will be set up: all will reproduce - not exactly, of course, but approximately - the same signs united with the same concepts (1974, p.15). Language can be localised in the limited segment of the speaking circuit where an auditory image becomes associated with a concept (1974, p.14), says Saussure. A little later he notes that the study of speech is then twofold: its basic part - having as its object language which is purely social and independent of the individual - is exclusively psychological; its secondary part - which has as its object the individual side of speech, i.e. speaking, including phonation - is psychophysical (1974, p.18). Most simply, Saussure notes, language is speech less speaking. It is the whole set of linguistic habits that allow an individual to understand and be understood (1974, p. 77).

Language, then, is distinguished from speaking as an individual psychophysical act - including all phonology, speech therapeutic concerns and the like - but language is still speech and it is still situated in the speaking circuit. When we say language is speech, we have of course to note that it is presented in an abstract, schematized form in the work of linguists - as a translation manual drawn from speech, typically in the encounter with a new speech as it lives in a community of speakers or a written record of such a speech. It is then presented as a manual of grammar, syntax and vocabulary. Saussure asks how the social crystallization of language comes about? The answer is: Through the functioning of the receptive and co-ordinating faculties, impressions that are perceptibly the same for all are made on the minds of the speakers $(1974$, p. 13). Associations of sound images and concepts that bear the stamp of collective approval are impressions that are deposited in the brain of each member of a community, almost like a dictionary of which identical copies have been distributed to each individual (1974, p. 19). This last remark reflects what has become known as the 
"Saussurean paradox" (Harris, 1987, p. 227). Language is, in its very essence, the property of a community of speakers - of an inter-subjective "circuit". But it is stored in individuals and can only be accessed through individual versions. A matter of dispute in linguistics is just how idiosyncratic those individual versions might be.

There are many, varying interpretations of the very influential distinction Saussure draws between language and speech. Each account will have its own implications. Before going on to consider how best to make the distinction I think it helps to note that at least part of this ambiguity has to do with the distinctive line Saussure advances in the debate over what kind of science linguistics is - whether natural or human. Bluntly, for Saussure, it is both. We must, he says, call in a new type of facts to illuminate the special nature of language. A science that studies the life of signs in society is conceivable; it would be part of social psychology and consequently of general psychology $(1974$, p. 16). So Saussure begins his account of semiology - which follows on from his initial definition of the object of linguistics as language - with the otherwise rather startling statement that language, once its boundaries have been marked off within the speech data, can be classified among human phenomena, whereas speech cannot (1974, p.15). Most simply, perhaps, Saussure is marking off the purely physiological and psychophysical aspects of speech. But he is also reflecting a central theoretical concern that developed in $19^{\text {th }}$ century linguistics - the role of the conscious human will in language. Simply, if language is a voluntary human activity then it would be thought to belong amongst the humanities or the social sciences. If it is involuntary then it can be thought of as a natural science. The latter view is expounded, for example, in an 1861 lecture by Max Muller which Saussure characterizes as a "brilliant" popularization of historical linguistics $(1974$, p. 3). The following quotation gives the 
flavour of Muller's argument: We can collect them [languages], we can classify them, we can reduce them to their constituent elements, and deduce from them some of the laws that determine their origin, govern their growth and necessitate their decay; we can treat them, in fact. in exactly the same spirit in which the geologist treats his stones and petrifactions - nay in some respects, in the same spirit in which the astronomer treats the stars of heaven or the botanist the flowers of the field." (Muller, M., 1864, in Harris, 1987, p. 7). On the other hand, as Joseph notes: In time a few linguists came to think that the organic metaphor had become so powerful (particularly in the wake of Darwin) that people were forgetting it was a metaphor at all. Resuscitating sign theory was a way to combat it. Saussure's mentor Breal makes a statement precisely to this effect ... 'Our forefathers of the school of Condillac, those ideologists who for fifty years served as target to a certain school of criticism, were less far from the truth when they said, in simple and honest fashion, that words are signs. Where they went wrong was when they referred everything to a reasoning reason .... (Breal, 1900: 249 [1897: 227] in Sanders, 2004, p. 62). It is within this context that we find the solution that Saussure advocates early in the Course - linguistics is a science because it is a part of "semiology" - a broader science of the life of signs within society. If he has succeeded in assigning linguistics a place among the sciences, says Saussure, it is because he has related it to semiology $(1974$, p. 16). But the study of semiology will miss the point so long as it focuses on the consciously willed or voluntary aspects of semiological systems, he contends. The essential mechanism of language is not "reasoning reason" but unconscious comparison (Saussure, 1974, p. 165). The distinguishing characteristic of the sign - albeit the least obvious characteristic - is that it, in some way, it always eludes the individual or social will (Saussure, 1974, p. 17). It is precisely this latter feature that semiological systems should have in common, says Sausssure - and if we are to discover the true nature of language we must learn what it has in common with all other semiological systems (Saussure, 1974, p. 17). Just what Saussure means by saying the sign eludes the will is 
something that, as I have suggested, unfolds in his account of arbitrariness - an account that comes later in the Course.

\section{Section 5: The linguistics of language as opposed to speech}

- Language must be distinguished from speech. Arguably, speech includes the individual, active, transmissive aspect of the speaking circuit as opposed to the social, passive, receptive aspect of the circuit. The relationship between the two is complex, however, as both are situated within the speaking circuit.

- Speech certainly includes any use of a term or any combination of terms by which the speaker expresses his or her own thought but which is yet to become a part of collective usage and so a part of language. Collective combinations or "syntagms" can include sentences and have a unitary, unanalyzed or clichéd character associated with wide circulation.

- I note that there is an inchoate theory of truth within Saussure's theory of language. The truth predicate appears to be a natural candidate for a "sign of collective usage" for sentences and other values.

- The linguistics of language can be divided into internal and external linguistics a distinction which assumes prime importance in relation to the linguisticbiological analogy. 
Having situated language within semiology, Saussure goes back to sharpen his definition of a linguistics of language, as opposed to a linguistics of speaking. I have already cited the distinction between the psychological and the psychophysical. The first purpose of the distinction between language and speech is to disentangle the problem [of the object of linguistics] from anything physiological. There then remains a purely psychological matter (Interview with Gautier, quoted in Gadet, 1986, p. 20). But, then a further distinction must be made within the psychological, as the following remarks makes clear. Speaking, on the contrary, is an individual act. It is willful and intellectual. Within the act, we should distinguish between (1) the combinations by which the speaker uses the language code for expressing his own thought; and (2) the psychophysical mechanism that allows him to exteriorize those combinations (Sausssure, 1974, p.14). (1) is wholly psychological but is still a part of speech as opposed to language. Likewise, when Saussure says: In separating language from speaking we are at the same time separating: (1) what is social from what is individual; and (2) what is essential from what is accessory and more or less accidental (1974, p.14), we need to see that what is individual in (1) includes individual psychology - even if (2) the "accessory and more or less accidental" includes the physical articulation of sounds - and the very use of sound - as a signifier of concepts, as well as what Saussure elsewhere refers to as the chance products of the individual.

But the inclusion of "combinations by which the speaker uses the language code for expressing his own thought" in speech as opposed to language raises some tricky questions. As we will see, associative and syntagmatic relations - where the latter includes all actual combinations of signs - are the essential relations that make up language. And syntagmatic relations are explicitly relations acquired in speaking or discourse (Saussure, 1974 p. 123). How can these two claims be reconciled? Describing 
syntagmatic relations, Saussure says: An objection might be raised at this point. The sentence is the ideal type of syntagm. But it belongs to speaking, not to language (see p.14). Does it not follow that the syntagm belongs to speaking? I do not think so. Speaking is characterized by freedom of combinations; one must therefore ask whether all syntagms are equally free (1974, p. 124). So syntagms originate in the free speech of individuals and become fixed when and as they are accepted into the collective language. The individual speaker then draws on that store of syntagms, by means of unconscious comparisons - before contributing a potentially new syntagm, usually generated by analogy with existing syntagms, to the store. It is just that the passage from speech to language is blurred. But we must realise that in the syntagm there is no clear cut boundary between the language fact, which is a sign of collective usage, and the fact that belongs to speaking and depends on individual freedom (Saussure, 1974, p. 125). Bouquet points out that in the original notes Saussure puts this problem even more strongly: It has to be said that in the field of syntax, a social fact and an individual fact, a putting into practice and a fixed association, get blended rather, end up more or less mixed up (Sanders, 2004, p.215). There is certainly a question then of what counts as an individual innovation and how and when individual speech may be said to become a part of the collective pool.

Yet, it is worth noting, that we may have precisely a "sign of collective usage" in the truth predicate. Is the difficulty around syntagms due to the fact that Saussure's theory of language lacks a theory of truth - at least, a theory of the truth of sentences? Sentences like "God is good" or "If the weather is nice we will go out" are syntagms that are a part of language, says Saussure, because they are general types that are in turn supported in the language by concrete remembrances $(\mathbf{1 9 7 4}, \mathbf{p .}$ 125). These sentences that are syntagms are, in other words, what we call "truisms". But why would we not add such a truism as "snow is white" to this list? 
For there is this inchoate theory of truth in the Course in General Linguistics: the true as the truistic, and truth as a sort of ordinary language theoremhood. A developed theory of truth could play a crucial role in Saussure's larger theory of language by describing the process by which original combinations of signs - and sentences in particular - are incorporated in language. In this way the theory would illuminate the speech-language nexus - what Saussure refers to as the "interdependence" of language and speech.

Such a theory could, too, offer an explanation for many features of the functioning of the truth predicate. It could explain, for example, how characterizing a sentence as true does not alter it but only, in some way, re-presents it - a feature highlighted by disquotational theories of truth. The truth predicate may be said to mark the sentence's entry into general circulation, its passage from speech - and from its place within "quotation" or "speech marks" - into language: ...in the history of any innovation there are always two distinct moments: (1) when it sprang up in individual usage; and (2) when it became a fact of language, outwardly identical but adopted by the community. (Saussure, 1974, p. 89) Perhaps truth promotes speech to the status of language in just the way that Tarski's equivalence thesis reflects, with speech on the left hand side of the equivalence and language - a kind of omniscient narrative voice or system - on the right hand side: "Snow is white" is true iff snow is white. So a proposition becomes a truth - or a truth is demoted, by being considered false, to an historical utterance - in the passage from speech to language or back again. 
As a "sign of collective usage" for values this theory of truth would be consistent across both the authenticity of objects and the veracity of propositions. So an authentic coin, a true Scotsman or a real planet need to be comprehended in the theory as well as true propositions. The same applies to values that lie somewhere in between objects and propositions - a true name or genuine identity as opposed to a false name or fraudulent identity, for example - or expressions and phrases such as "sitting in the sun", "fish and chips", "the thin end of the wedge". These syntagms are all capable of being true or false, authentic or inauthentic. At the least, though, including some conception of truth of this kind in Saussure's theory would mean that a sentence would not need to be so clichéd that, paradoxically, its original, literal meaning has been forgotten, before it could be a part of language.

\section{Section 6: Further ambiguities in the language - speech distinction}

- Another angle from which the distinction between language and speech appears less than clear cut is that of the speaker as amateur linguist - and the linguist as amateur speaker.

- The dominant interpretation of Saussure's distinction is, fairly clearly, the distinction between the underlying system that makes possible various types of behaviour and actual instances of such behaviour. 
- I suggest, however, that we need to resist any tendency to give language a transcendent priority in any causal sense. Language is both the instrument and the product of speech.

- Saussure also emphasises the difference between the internal and the external aspects of the language organism and his exclusive focus on the latter.

Another angle from which the distinction between language and speech appears less than clear cut is that of the speaker as amateur linguist. Language, says Saussure, is constantly analyzing, decomposing and reinterpreting itself - and it is speakers who are performing these operations. We are all folk etymologists, for example, finding motivations for current meanings in earlier meanings. Newspaper columns and radio segments on language enjoy an enduring popularity and we are all keen amateur grammarians and administrators of analogical models. On the other hand, though, Saussure points to what he calls the over-complexity of the linguistics system which means that the very ones who use it daily are ignorant of it $(1974$, p. 73$)$. But, says Saussure, the professional linguist is no more potent a speaker than the enthusiastic amateur: We can conceive a change only through the intervention of specialists, grammarians, logicians etc. But experience shows that all such meddlings have failed $(\mathbf{1 9 7 4}$, p. $\mathbf{7 3})$. Of course language does change - or rather evolve - through speech and so Saussure's position is, perhaps, best represented by his more cautious statements: ... we never know exactly whether or not the awareness of speakers goes as far as the analyses of the grammarian $(1974$, p. 138). 
Equally though, we must acknowledge that classifying the individual, executive side of speech alongside its purely psychophysical aspects, in opposition to language, has been the dominant interpretation of Saussure. In the work of Hjelmslev and others it becomes the distinction between competence and performance (Holdcroft, 1991, p. 44). This accords with Saussure's referring to the executive side of language as speech and language as a product that is passively assimilated by the individual (1974, p. 13). Culler likens the distinction between language and speech to the distinction between the Game of Chess and a particular game of chess: between the underlying system that makes possible various types of behaviour and actual instances of such behaviour $(\mathbf{1 9 8 6 ,}$ p. 44). This view is also supported by Saussure's remarks on analogy and the unconscious comparison that must occur before any new analogy can be introduced by an individual speaker. That requires access to the storehouse of language $(\mathbf{1 9 7 4}, \mathbf{p .} \mathbf{1 6 5})$, he says, and in fact new forms always exist in potentia in the language. The speaker provides an awareness of the productive comparisons that already exist in language - and only the result of this awareness belongs to speaking (1974, p. 165). A major part of the analogical phenomenon is therefore completed before the new form appears (1974, p. 165).

Saussure's best known critic on this point is Chomsky who argues that Saussure downplays the role of individual creativity in language to an excessive degree (Culler, 1986 p. XXIII). But we can take a differing view of the role of the speaker without contradicting Saussure's account of what actually occurs. Many productive speakers creative writers, for example - will happily say that they are inspired by the language itself. Just wielding a pen may be likened, as the poet Kendrick Smithyman puts it, to being a "Dwarf with a Billiard Cue" (1978). But we need only consider Shakespeare's 
contribution to English to observe how much just one speaker can contribute, regardless of what provokes him or her into doing so. However they arise, individual innovations in speech do make their way into the language and this is something Saussure notes at every turn. Indeed immediately following that last quotation, we find an interesting modulation in his position: Speech is continuously engaged in decomposing its units and this activity contains not only every possibility of effective talk but every possibility of analogical formation (Saussure, 1974, p.166).

So, while approving the individual-collective distinction as basic to the speechlanguage distinction, we need to resist a tendency to give language a transcendent priority in any causal sense - to say that it "makes possible" speech, as Culler puts it. This gives an hermetic character to the linguistic system, a feature that emerged in Structuralist literary criticism, for example (Sturrock, (2003), p. 125). It also prompts the question of what makes the underlying system possible - which for Saussure, as we will see, is equivalent to asking what makes it evolve. The answer is, speaking: ... speaking is what causes language to evolve: impressions gathered from listening to others modify our linguistic habits. Language and speaking are then interdependent; the former is both the instrument and the product of the latter (1974, p. 19). If there is any priority, then, it belongs to the speaking circuit itself, in which both language and speech are situated.

Once he has marked the boundary between the linguistics of language and the linguistics of speech Saussure goes on to consider the internal and external elements of language, beginning: My definition of language presupposes the exclusion of everything that is outside its organism or system $(\mathbf{1 9 7 4}, \mathbf{p . 2 0})$. To external linguistics belong the relationship between language and ethnology, language and political history, language and literature 
and such questions as the geographical spreading of languages and their interpenetration. All these must be excluded from the study of language proper because they are contingent and non-systematic. If we arrange these facts according to a system it will be solely for the purpose of clarity. By contrast: In internal linguistics the picture differs completely. Just any arrangement will not do. Language is a system that has its own arrangement. Comparison with chess will bring out the point. In chess, what is external can be separated relatively easily from what is internal. The fact that the game passed from Persia to Europe is external; against that everything having to do with its system and rules is internal.... One must always distinguish between what is internal and what is external. ... everything that changes the system in any way is internal (1974, p.22). As I will show a little later in this thesis, everything that is external to the language system is also everything that negates the analogy between linguistic and biological evolution. This aspect of the definition of language will therefore be considered in more detail then.

\section{Section 7: The units of language}

- The sign is the unit of language - but saying just what a sign is in all cases proves more difficult than might have been expected.

- The sign may be a sentence or a word but does not necessarily coincide with those things - it is best described as a "term" of a system.

- The pervasive evolution of the linguistic system - the unlimited "variability" of the linguistic sign - means that the linguist must use the same method as the 
scientist in other fields while knowing in advance that she will never arrive at the same concrete or material object of study.

The object of study of linguistics is language, asserts Saussure. The next task is to identify the units that make up this object. At one level the answer is simple and has been stated from the outset - signs are the units of meaning. But what exactly is the sign in language as opposed to the sign found in other semiological systems? The problem Saussure faces is very similar to that encountered in defining language as the object of study of linguistics. He puts it this way: In most sciences the question of units never even arises: the units are delimited from the outset. In zoology, the animal immediately presents itself. Astronomy works with units that are separated in space, the stars. The chemist can study the nature and composition of postassium bichromate without doubting for an instant that this is a well defined object. When a science has no concrete units that are immediately recognizable, it is because they are not necessary. In history for example, is the unit the individual, the era or the nation? We do not know. But what does it matter? We can study history without knowing the answer (1974, p. 107).

However, just as Marx's identification of economic classes as the units of history had a huge impact on his "science", so Saussure's identification of the sign as the unit of language has a huge impact on his conception of linguistics. For example, Saussure rules out the sentence as a basic linguistic unit. This is one source of what has become a fundamental division between the Continental and the Anglo-American philosophies of language. Since Frege postulated his context principle, the sentence has been the basic unit of meaning in Anglo-American philosophy. According to the context principle, a word has meaning only in the context of a sentence. The sentence based theory of meaning has dominated (although it has not been adopted by absolutely everyone) in the 
analytic tradition. Witness, for example, the debate between truth-conditional theory of meaning and verificationism, which has occupied a good deal of recent analytic theory of language. On both these views, the sentence is the primary unit of meaning and word meanings are dealt with in terms of how they contribute to the truth or verification conditions of sentences. For Saussure, the problem of the definition of the sentence as a syntagm and hence as a part of language resurfaces: A rather widely held theory makes sentences the concrete units of language: we speak only in sentences and subsequently single out the words. But to what extent does the sentence belong to language? (see p. 124) If it belongs to speaking, the sentence cannot pass for the linguistic unit...(1974, p.106).

A large part of the difficulty Saussure has in thinking of sentences as a part of language is that he associates the sentence with individual rather than collective usage. But Saussure finds that there is a further difficulty in treating the sentence as the basic linguistic unit: sentences are composed of words. He says: In sentences, on the contrary, diversity is dominant and when we look for the link that bridges that diversity, again we find, without having looked for it, the word with its grammatical characteristics ... (1974, p.106). What is the problem with words being the units of meaning? The problem is twofold. First, they don't resolve into concrete units. Are a noun and its plural the same word, for example, in two different grammatical forms? Perhaps. But they are also two different sound slices with two different meanings. So we face a dilemma, says Saussure. We can treat them as distinct words and preserve concreteness. But then we must ignore the obvious relation that binds together words like cheval and chevaux. (Saussure, 1974, p. 105) On the other horn of the dilemma, we can recognize the relation between the two words and treat them as one word in two different forms - but then we must be satisfied with a form or abstraction as our unit of meaning rather than something concrete. 
The second difficulty with words as the unit of meaning is that signs and words are not co-extensive. Signs are often smaller than words. The words painful and delightful, for example, can be seen as complex units: pain-ful and delight-ful. Conversely, signs are sometimes larger than words as with locutions like s'il vous plait. (Saussure, 1974, p. 106)

A third difficulty is that if words were the units of language then they would be able to be classified grammatically as parts of speech. But it seems at times, says Saussure, as if grammar were based on extra-linguistic principles applied to language like the lines of longitude and latitude applied to the earth's surface. Saussure uses the example of bon marche meaning "cheap" as in ces gants sont bon marche "these gloves are cheap" (Saussure, 1974, p. 109). From a logical viewpoint it functions as an adjective - but grammatically this is impossible. It does not function as an adjective (it is invariable, it never precedes its noun etc) - but, even more problematically, it is a group of words and a group of words cannot be one of the parts of speech.

When he is being careful, then, Saussure speaks of "terms" instead of words as the basic unit of language. He says that the use of "term" in this way is preferable because as soon as we substitute term for word, this implies consideration of its relations with others. However, even considered more abstractly, these units resist delimitation as strongly as do words proper, making it extremely difficult to disentangle the interplay of units that are found in a sound chain (1974, p. 106). The interplay of units is described by grammar, then, but not necessarily grammar in the usual linguistic sense. It is rather a grammar in the sense of an internal 
logic. As Saussure puts it: Static linguistics or the description of a language-state is grammar in the very precise and moreover usual sense that the word has in the expressions "grammar of the Stock Exchange" etc. where it is a question of a complex and systematic object governing the interplay of coexisting values (1974, p.134).

It is almost as if, then, a kind of sub-atomic uncertainty principle is at work. Language then has the strange, striking characteristic of not having entities that are perceptible from the outset and yet of not permitting us to doubt that they exist and that their functioning constitutes it. Doubtless we have here a trait that distinguishes it from all other semiological institutions (1974, p.107). The unit of meaning has no isolable, static character. It is always the nexus of a larger dynamic interplay, a point of convergence of linguistic forces. Consequently, evolution of the units of language is capable of intervening between the very letters or sound elements of a word to redefine its component parts, perhaps several times over in the course of time. Saussure provides a vivid demonstration of this process in the case of the word somnolent. Originally the two units in somnolent divided between the $n$ and the $o$. They then divided between the $o$ and the $l$, then between the $l$ and the $e$. At each point there are shifts in meaning. These redefinitions are due to the force of different analogies at work at each point. Originally the meaning of somnolent was "smelling of sleep" from olere, as in vin-olentus, "smelling of wine". Accordingly the division falls between the $n$ and the $o$. In later Latin the word was considered analogous to succu-lentus, with the suffix having a straightforward adjectival effect on the prefix somno or sleep. Somnolent means "sleepy", just as succulent means "juicy". Accordingly the division of units falls between the $l$ and the $o$. In modern French the -ent ending is taken to be a present participle, in a construction analogous with a large number of verbs with an er ending, so 
that there is now a verb - somnoler - to become sleepy. The division now is between the $l$ and the $e$ (Saussure, 1974, p. 170 - p. 171).

Indeed, Saussure goes so far as to suggest that the structure within which the sign is found can equally be seen as preceding the sign: Analogy is therefore proof positive that a formative element exists at a given moment as a significant unit (1974, p. 69). As Saussure emphasizes, language evolves by constantly reinterpreting and analysing its units, by decomposing and redistributing them. An essential stage in this process is always analogy - that is, some equation of two elements, some perception of sameness. It is that perception that yields new oppositions, new articulations. Indeed, analogical creation and the mechanism of speech have a common basis $(\mathbf{1 9 7 4}$, p. 172). The discussion of units goes on to include identities and realities in language, with some well known examples of linguistic identity to which we will refer a little later in the discussion of value. For the notion of linguistic value envelopes, as Saussure puts it (1974, p. 110), the notions of unit, concrete entity, and reality.

Saussure concludes his discussion of the concrete entities of language with a telling observation: the linguist must use the same method as the natural scientist while knowing in advance that she will not arrive at the same concrete or material object of study. Saussure says: To be rid of illusions we must first be convinced that the concrete entities of language are not directly accessible. If we try to grasp them, we come into contact with the true facts. Starting from there we can set up all the classifications that linguistics needs for arranging all the facts at its disposal. On the other hand, to base the classifications on anything except concrete entities - to say, for example, that the parts of speech are the constituents of language simply because they correspond to categories of logic - is to forget that there are no linguistic facts apart from the phonic 
substance cut into significant elements $(\mathbf{1 9 7 4}, \mathbf{p}$. 110). In this paragraph Saussure dramatises his position as an inheritor of the Neogrammarian tradition who is yet acutely aware that language evolves under the influence of all the forces that can affect either sound or meaning (Saussure, 1974, p. 76). As a consequence, any fixed, intentional conception of units of language or parts of speech, of logic or grammar is also subject to evolutionary change. The only option then is an account of language as comprised of something entirely relative that Saussure calls "values". These are the entities that we will explore in more detail in the second chapter of this thesis. 


\section{The Life of Language:}

\section{Saussure and Evolution}

\section{Chapter 2: From convention to system}

\section{Section 1: The arbitrary nature of the sign}

- The signifier and the signified together comprise the sign. The signifier is arbitrary in the sense that it is unmotivated by the signified - it has no natural connection to it.

- Signs gain their meaning through a rule of collective behaviour or convention.

- Linguistic systems evolve in such a way as to render any similarity or difference between the signifier and signified - such as similarity of sound - purely coincidental.

At the end of the previous chapter we had reached the point at which Saussure is poised to expound his doctrine of linguistic value. Before he does this, however, he has been careful to establish that it is a doctrine grounded in something more than the determinedly elusive character of the units of linguistic evolution. It is grounded, too, in the arbitrary nature of the sign. We have already seen when we considered the speaking circuit, that the sign ... is a double entity, one formed by the associating of two terms ... both terms involved in the linguistic sign are psychological and are united in the brain by an associative 
bond (Saussure, 1974, p.65.). When introducing the arbitrary sign Saussure goes on to emphasize this point: The linguistic sign unites, not a thing and a name, but a concept and a sound image ... I propose to retain the word "sign" to designate the whole and to replace concept and sound image respectively by signified and signifier. The last two terms have the advantage of indicating the opposition that separates them from each other and from the whole of which they are parts ... (1974, p.67). The signifier is not just a sound since it can be evoked mentally without any sound occurring, as when we read something written. Saussure uses the term "sound image" to emphasise this abstraction - but there is no doubt that the signifier is just as much a concept as the signified, if only because a phoneme can be the signified of a written signifier. This symmetry appears to be emphasized alongside the central role of the associative bond when Saussure says: The linguistic sign is then a two sided psychological entity... The two elements are intimately united, and each recalls the other. Whether we try and find the meaning of the Latin word arbor or the word that Latin uses to designate the concept "tree" it is clear that only the associations sanctioned by that language appear to us to conform to reality, and we disregard whatever others might be imagined (Saussure, 1974, p.67).

However, the central concept is this: The bond between the signifier and the signified is arbitrary. Since I mean by sign the whole that results from the associating of the signifier with the signified, I can simply say: the linguistic sign is arbitrary (Saussure, 1974, p.67). What does Saussure mean by "arbitrary"? Arbitrary has two basic meanings in Saussure's exposition. One is that it is unmotivated in the sense there is no inner relationship or natural connection between the signifier and the signified (Saussure, 1974, p.67). The second meaning of "arbitrary" for Saussure is also implied in the quotation above but is shown more clearly in what follows. It means collectively based or conventional or fixed by a rule (Sausssure, 1974, p.67). This applies to semiology in general. In semiology in general one 
might think that there will also be natural signs and modes of expression based entirely upon them, such as pantomime - or symbols, where, as Saussure puts it, there is the rudiment of a natural bond. An example Saussure gives is the use of a pair of scales to symbolize justice. But semiology's main concern will still be the whole group of systems grounded on the arbitrariness of the sign. In fact every means of expression used in society is based, in principle, on collective behaviour or - what amounts to the same thing - on convention. Polite formulas, for instance, though often imbued with a certain natural expressiveness (as in the case of a Chinese who greets his emperor by bowing down to the ground nine times), are nonetheless fixed by rule; it is this rule and not the intrinsic value of the gestures that obliges one to use them. Signs that are wholly arbitrary realize better than the others the ideal of the semiological process; that is why language, the most complex and universal of all systems of expression, is also the most characteristic (Saussure, 1974, p. 68).

In language, Saussure argues that apparently onomatopoeic expressions or naturally expressive exclamations and interjections are actually conventional: the sound the French use to represent the sound of a barking dog is different from that which English uses, for example. Or again: Words like French fouet 'whip' or glas 'knell' may strike certain ears with a suggestive sonority, but to see that they have not always had this property we need only examine their Latin forms (fouetis derived from fagus 'beach-tree', glas from classicum 'sound of a trumpet'). The quality of their present sounds, or rather the quality that is attributed to them, is a fortuitous result of phonetic evolution (Saussure, 1974, p.68). The evolution of languages is responsible for terms like 'glas' and 'fouet', not the nature of their signified. That evolution will follow laws derived from the arbitrary nature of the sign in general.

\section{Section 2: From Convention to System}


- Saussure sees his distinctive contribution as a "systematics" of language as opposed to a conventionalist account

- In marking this distinction we must distinguish first of all between simple system and complex, evolutionary system.

- A textual slippage between these two appears at the very outset of the account of the arbitrary sign in the Course in General Linguistics.

The arbitrary nature of the sign has, as Saussure puts it, "primordial importance": No-one disputes the principle of the arbitrary nature of the sign, but it is often easier to discover a truth than to assign to it its proper place. This principle dominates all the linguistics of language; its consequences are numberless (Saussure, 1974, p.68). The most important part of any exposition of Saussure' s theory of language, however, comes in describing how he levers off the extant conception of language as a conventional institution comprising arbitrary signs to his conception of linguistic value. This is the transition from simple, list-type naming what Saussure often calls "nomenclaturism" - to complex, systematic definition. It is also the movement from a conventionalist account of language to what we could call a systematic or post-conventionalist account. This is what Saussure sees as constituting his distinctive contribution.

Saussure believed that the American linguist Dwight Whitney had placed linguistics on its true axis by identifying language as a genuine human institution that was arbitrary and conventional in all its parts (Saussure, 1974, p.76). But in Saussure's view Whitney does 
not go far enough. First he does not tie the arbitrariness of the sign to its unique lability. But he [Whitney] did not follow through and see that the arbitrariness of language radically separates it from other institutions. This is apparent from the way in which language evolves. Nothing could be more complex (Saussure, 1974, p.76). Second, Whitney does not see that the arbitrariness of the sign and its complex evolution reflect its essentially systematic character: Whitney, whom I revere, never said a single word on the same subjects [concerning 'a theoretical view of language'] which was not right; but, like all the others, he does not dream that language needs systematics (Cited by Falk J., in Sanders, 2004, p. 108).

Of course, if Whitney did not make the transition from convention to system that is at least in part because such a transition is not entailed by the arbitrariness of names. On the contrary that arbitrariness is more likely to be associated with the isolability of signs and a pre-existing signified. As Whitney says in his seminal 1875 work, "The Life and Growth of Languages": In common phrase, we first have our idea and then we get a name for it (Alter, 2005, p. 250). Yet many accounts of Saussure's theory elide this very point, suggesting that the arbitrary nature of the bond between the signifier and the signified somehow in itself necessitates a system of signs - as if only a complex system can explain how the signifier and the signified are, as it were, held together. But we can imagine a system that comprises a simple, arbitrary one to one mapping in any order or arrangement. We can even, as Saussure puts it, conceive of the job of language as maintaining the parallelism (Saussure, 1974, p. 121) between the two planes of the signifier and the signified without supposing that the signs so formed constitute any complex, evolving system or network of terms and relations. In addition, we can imagine that names have a complex, contextual value or sense alongside their arbitrary naming. Such a theory of 
language was developed at much the same time as Saussure's by Gottlob Frege and expounded in his article "On Sense and Reference" (Frege, 1892).

But whether or not there is any logical necessity to the transition from simple convention to complex, evolving system, it is undoubtedly the innovation that Saussure seeks to enact. Saussure ties the arbitrariness that Whitney championed to both the systematic character of language and the complexity of its evolution. It is that process which is at stake: Signs that are wholly arbitrary realize better than the others the ideal of the semiological process (Saussure, 1974, p.68).

At a textual level, the transition from convention to system does not get off to a great start, however. In the Course in General Linguistics, Saussure begins his account of the Nature of the Linguistic Sign with the following words: Some people regard language, when reduced to its elements, as a naming process only - a list of words, each corresponding to the thing that it names. For example:

This conception is open to criticism at several points ... (1974, p.65)

It seems obvious that it is after the For example: that the subsequent exemplary illustrations of a tree and horse, listed alongside their corresponding names, should be inserted. These illustrations show the popular conception. But instead For example: is followed immediately, as we see above, by the continuation of the written text. That text goes on to outline Saussure's critique of the popular conception of the naming process. It is only after that critique, in which Saussure introduces his own conception of the sign, that the illustration of simple naming appears - suggesting that it illustrates Saussure's conception of the sign as well. The point is just that the truth which this rather naïve 
approach (Saussure, 1974, p. 65) of simple naming brings us near - and the key element that Saussure wants to preserve in his own conception of the sign - is not illustrated by the parallel lists of a horse and a tree and their corresponding names, and especially not by those "etc" terms at the bottom of each column. It is illustrated by the later bisected ovoid form and reversible arrows showing that the linguistic unit is a double entity, one formed by the associating of two terms (Saussure, 1974, p.65) and the systematic relations those ovoid forms enter into. In the developed theory, as we will see, it is the relationships between the ovoid forms that assumes primacy and which motivates what is to be found within the ovoid forms.

Simple naming includes, then, a simple list ontology and language conceived as a simple conventional system of names for that ontology. Simple naming includes any system in which objects and their names may be listed or "piled up" in any order - or where the arrangement of the elements is just for clarity of exposition rather than being intrinsic to them. Saussure says: We must not begin with the word, the term, in order to construct the system. This would be to suppose that the terms have an absolute value given in advance and that you only have to pile them up one on top of the other in order to reach the system (Saussure, 1911, lecture of 30 June). Saussure's emphasis on convention must be understood, then, with this crucial qualification in mind.

Indeed, failing to understand that Saussure's concept of complex system marks a decisive step on from conventionalism is the source of a lot of misunderstanding between Anglo-American and Continental theories of meaning. For if there is no dispute about the arbitrary sign, then there is equally little dispute about the conventional character of the 
system that is needed to support arbitrary naming. If the conventional character of language systems is supposed to be Saussure's distinctive insight, then, from the point of view of Anglo-American theorists, it is an insight that appears to have little novelty or significance. On the other hand, we can see that ruling out a list or inventory type of ontology has considerable implications for traditional metaphysics as well as theories of language. For this approach to ontology is still dominant. It is, effectively, the assumption that an object is separable from the system of signifying properties and relations in which it is embedded. For Saussure language is not a simple system of names for pre-existing objects because the object is never found outside a complex linguistic system.

\section{Section 3: The complex system as a system of values}

- Difficulties in translation reflect the fact that signs are values in a complex evolving system in which units reciprocally delimit each other.

- This reciprocal delimitation or articulation of units is often thought to be constituted by relations of difference enacted in a kind of arbitrary "decoupage" or "cutting out" of units of meaning.

- There are a number of passages in the Course that appear to support the view that "the pairing of a certain number of acoustical signs with as many cuts made from the mass of thought engenders a system of values" but these need to be treated with the greatest care if we are not to take away only half of the story. 
With the distinction between convention and system firmly in mind, we can describe in more detail what Saussure means by complex system. This complexity is expressed in the notion of linguistic value. Terms in language do not simply name things or express existing ideas. They have a value due to their place within a complex system of signs. Saussure says: The characteristic role of language with respect to thought is not to create a material phonic means for expressing ideas but to serve as a link between thought and sound under conditions that of necessity bring about the reciprocal delimitation of units $(1974$, p. 112) ... Language in a manner of speaking is a type of algebra consisting solely of complex terms $(1974, p$. 122). The content or value of a term is really only fixed by the concurrence of everything that exists outside it... Language is a system of interdependent terms in which the value of each term results solely from the simultaneous presence of the others (1974, p. 115).

One way we can tell that signs are terms with a value rather than simple names for pre-existing ideas is that terms do not have exact equivalents across languages - hence the difficulty we often have in translating from one language to another. If language were a simple naming process then there would be no exception to the situation illustrated by cases like boeuf and $o x$, in which the same signified, "ox", has different signifiers on different sides of a geographical border. But we do not have to look far to find that this is not the case, says Saussure. The English word sheep does not have the same value as the French mouton just because the English sheep has another term alongside it - namely mutton - whereas mouton in French signifies both the living and the butchered animal. Much larger differences in value between languages exist that than this however. Different tenses, reflecting quite different conceptions of time, exist in different languages and may be quite irreconcilable. 
It has to be noted that for Saussure, as we saw also for Locke, the very existence of different languages proves arbitrariness $(\mathbf{1 9 7 4}, \mathbf{p . 6 8})$ as in the case of boeuf and ox. So ease in translation proves arbitrariness - difficulties in translation prove systematicity. In what has turned out to be a potent pun on the term "articulate" - meaning both to speak and to differentiate in a sequence - Saussure contends that languages articulate thought in this way: In Latin, articulus means a member part or subdivision of a sequence. (1974, p.10) Language might be called the domain of articulations using the word as it was defined earlier. Each linguistic term is a member, an articulus, in which an idea is fixed in a sound and a sound becomes the sign of an idea (1974, p. 113). Language can also be compared with a sheet of paper; thought is the front and the sound the back; one cannot cut the front without cutting the back at the same time (1974, p. 113). The notion of articulation unites the actions of making a horizontal division and a vertical unity. The two come into being at the same time. Articulation is the reciprocal delimitation of units - and languages are constantly rearticulating their units as a change in one part of the system resonates through the other parts.

But the cutting out or "decoupage" of meaning has to be carefully understood. It seems to go hand in hand with the notion of Saussure's system as a system solely of differences. As Barthes puts it: The sound is considered immediately significant, as if the act of speech itself delimited signs (Barthes, 1968, p. 34). Then, between these elements arbitrarily differentiated from each other by a cutting out process, we assume that there is a relation of arbitrary signification - particularly as suggested by that first illustration referred to above. 
There are a number of passages in the Course that seem to further support this view. For example, when Saussure first states that the conception of simple naming is open to criticism at several points, the editors refer us directly to his account of linguistic value: Psychologically our thought - apart from its expression in words - is only a shapeless and indistinct mass. Philosophers and linguists have always agreed in recognizing that without the help of signs we would be unable to make a clear-cut, consistent distinction between two ideas. Without language, thought is a vague uncharted nebula. There are no pre-existing ideas and nothing is distinct before the appearance of language (Saussure, 1974, p. 111 - p. 112). Saussure goes on to explain how the signifier and signified come into being at the same time: A linguistic system is nothing but a series of differences in sound combined with a series of differences in ideas; but the pairing of a certain number of acoustical signs with as many cuts made from the mass of thought engenders a system of values (1974, p. 120).

We can see how these passages could encourage the view that the articulation or cutting out of meaning itself entails a simple mapping of signifier and signified. The term "engendered" certainly suggests this view here. But when we read of "the pairing of a certain number of acoustical signs ..." we need to hear the adjective "systematic" before the word "pairing". The pairing in any language state is the product of a system of values, not the origin of it. Likewise the notion that sounds are immediately significant in language is basically antithetical to Saussure's thesis that they are precisely mediated by the system in which they are found.

Again, a simplistic view appears to be reinforced by the horizontal ladder type of diagram by which Saussure illustrates the delimitation of units of meaning in synchronic or static linguistics. (Saussure, 1974, p. 104) However, as soon as we include an evolutionary 
perspective, Saussure shows the diagram complicating, with forked and angled mappings reflecting the evolutionary forces that constitute units of meaning (Saussure, 1974, p. 179). In the same vein, it often seems as though Saussure endorses the conception of the linguistic system as a system solely of differences: Everything that has been said up to this point boils down to this: in language there are only differences. Even more important: a difference generally implies positive terms between which the difference is set up; but in language there are only differences without positive terms (Saussure, 1974, p. 120). A little before this passage Saussure notes that Arbitrary and differential are two correlative qualities (Saussure, 1974, p. 118). But that "up to this point" is significant in the quotation above. This is not the whole story.

\section{Section 4: Opposition and association}

- Differences are the product of the linguistic system not the origin of it.

- The systematic mechanism of language rests on the associative bond, including association by analogy, and works through paradigmatic and syntagmatic relations.

- There are logical, as well as interpretative, reasons for rejecting the notion that cutting out is the actual mechanism which articulates and rearticulates units in a language system rather than the result of that mechanism.

First, Saussure makes it clear that when we speak of differences this can only apply to the signifier or the signified considered apart from each other. We must first of all note 
that in the system of values, the meaning as counterpart of the image and the meaning as counterpart of co-existing terms merge (Saussure, 1911, Chap. V). Then, he says: Although both the signifier and the signified are purely differential and negative when considered separately, their combination is a positive fact (Saussure, 1974, p. 120).

Second, as I have argued above, differences are a product of the system, not the immediate cause of it: Whether we take the signified or the signifier, language has neither ideas nor sounds that existed before the linguistic system, but only conceptual and phonic differences that have issued from the system (Saussure, 1974, p. 120, my emphasis).

Third, once we are considering the sign as a whole it is only appropriate to speak of oppositions rather than differences (Saussure, 1974, p. 121). And, more than this, oppositions depend on similarities: ... one must also compare it [a word] with similar values, with other words that stand in opposition to it (Saussure, 1974, p. 115).

Simply, in this account of Saussure's theory of language I want to emphasise that the arbitrary relation between the signifier and the signified - and equally between signs - is a mutable relation but it is not a relation of difference as such. Nor is it just a relation of opposition, as Saussure characterizes this relation when he is being more precise. It is, fundamentally, an associative bond. It is a bond that can be - and often is - "loosened" under various evolutionary forces so that it is always susceptible to change. These forces include apparently arbitrary phonetic changes - or associations based on arbitrary phonetic similarities. On the other hand, what holds these bonds in place is a larger system of associations and oppositions. The emphasis on difference - and even on oppositions - is only one phase in the unfolding of Saussure's theory of language. In this 
phase Saussure is considering language apart from its functioning, apart from its mechanism - and this is a distinction that must be noted. Two signs, each having a signified and signifier, are not different but only distinct. Between them there is only opposition. The entire mechanism of language, with which we shall be concerned later, is based on oppositions of this kind and on the phonic and conceptual differences which they imply (Saussure, 1974, p. 121). When we do come to consider the mechanism of language - which is at once how language functions and how it evolves - we find that relations and differences between linguistic terms fall into two distinct groups, each of which generates a certain class of values (Saussure, 1974, p. 122).

We find, in other words, that difference lies within syntagmatic and associative relations. And a little later: The set of phonic and conceptual differences that constitutes language results from two types of comparisons: the relations are sometimes associative, sometimes syntagmatic ... this set of common relations constitutes language and governs its functioning (Saussure, 1974, p. 122). Then we come to the full blown account of linguistic system: Up to this point units have appeared as values, i.e. as elements of a system and we have given special consideration to their opposition; now we recognize the solidarities that bind them; they are associative and syntagmatic and they are what limits arbitrariness ... (Saussure, 1974, p. 133).

Yet even before these stages we must imagine that in the sequence of the original Course the emphasis on difference itself follows on from extensive discussions of analogy, agglutination and other "solidarities" considered as part of diachronic linguistics. So, even originally, the emphasis on relations of difference in Saussure's synchronic linguistics stands in relief to that earlier discussion. 
In summary, Saussure registers the fact that difference or opposition plays a key role in defining values and at times he suggests that difference on its own, as opposed to sameness, is responsible for structure. But it is difference alongside sameness or identity - a kind of originary being together of the two - that creates the point of convergence (Saussure, 1974, p. 126) that is a linguistic value. Delimitation is accomplished by the paradigmatic and syntagmatic relations that constitute the mechanism of language. This is the latent system that makes possible the oppositions necessary for the formation of the sign ... in this process, which consists in eliminating mentally everything that does not help to bring out the desired differentiation at the desired point, associative groupings and syntagmatic patterns both play a role (Saussure, 1974, p. 130). The ultimate product of systematic associations appears as a "differentiation" for Saussure, or an "opposition", because it has no inner substance or matter. It appears to be cut out, as he says in an interview, literally by a pair of scissors, snip, snip, snip (Interview with Gautier, 6 May, 1911, in Gadet, 1986, p. 20) because there is no preexisting object or positive content to limit this process of systematic definition. Division may occur anywhere. It is entirely determined by the system, from the outside in, as it were. Saussure marks this wholly different approach to individuation by his preference for the term "delimitation" for this process rather than "definition".

Apart from interpretative considerations, however, there are compelling logical reasons for thinking of associative relations as inseparable from oppositions in building linguistic systems. If "cutting out" were all that was involved in the linguistic system we would have a strangely two dimensional system - a sort of absolute, level playing field. We could not imagine any system of objects that includes a generic - as opposed to a specific - level. We could not have any taxonomy of objects. Similarly, pure relations of 
difference would yield only an array of objects that could be arranged in any order with no object having any particular relation to any other. How, in that case, would mutton come to be "alongside" sheep or one term come to be the "neighbour" of another, as Saussure puts it? David Holdcroft explores the logical possibilities and argues convincingly that: ... if Saussure' s claim that signifieds are purely negative entities is true we have completely failed to capture any sense in which it is. Indeed I have argued that only differences which give rise to oppositions are relevant to the determination of a signified's content, and that oppositions presuppose similarities. Moreover, it seems that some of the ways in which signifieds call for positive characterization do not in any natural sense involve oppositions ... Holdcroft asks: ... is Saussure's system not then in ruins (Holdcroft, 1991, p. 129)? He answers this challenge by arguing that Saussure's system is not in ruins because it does not require the arbitrariness of systematic or structural relations. Rather it requires only the view that a value is determined by the relations that it enters into with other values in a system: ... hence Lyons' claim that the 'defining characteristic of modern "structural" linguistics is as follows: linguistic units have no validity independently of their paradigmatic [=associative] and syntagmatic relations with other units' (Holdcroft, 1991, p. 130).

\section{Section 5: Synchronic and Diachronic linguistics}

- Saussure distinguishes between diachronic linguistics - the study of language on the axis of successions over time - and synchronic linguistics - the study of language on the axis of simultaneities.

- Saussure emphasizes the distinction of the synchronic viewpoint in order to open up space for his systematics of language. 
- Given its lack of natural data or any material continuity language must be understood as a system of pure values functioning in accordance with the relations between its terms - their synchronic solidarity - at any given moment in time.

Following his distinction within the totality of human speech of language and speech Saussure is concerned to make a further important division within language. This is the distinction between diachronic and synchronic - or evolutionary and static linguistics. Saussure seeks to clarify the difference between these two approaches as an essential part of the definition of linguistics as a science before he can go on to describe in detail the syntagmatic and associative relations that constitute the system of language.

Saussure says: But the thing which keeps language from being a simple convention that can be modified at the whim of interested parties is not its social nature; it is rather the action of time combined with the social force. If time is left out, the linguistic facts are incomplete and no conclusion is possible (Saussure, 1974, p. 78). The intervention of the factor of time creates two quite different - but complementary - orders of linguistic phenomena, argues Saussure, and a corresponding division within the science of linguistics. For two different axes can be distinguished:

(1) the axis of simultaneities, which stands for the relations of co-existing things and from which the intervention of time is excluded; and

(2) the axis of successions (Saussure, 1974, p. 80).

The first axis concerns language states. The second axis concerns the evolution of language states over time. The first kind of linguistic science, concerned with the first 
axis, the axis of simultaneities, may be termed "synchronic linguistics". Saussure also uses the term "idiosynchronic", because language states can be distinguished down to the level of idiomatic usage: Synchronic study has as its object, not everything that is simultaneous but only the totality of facts corresponding to each language; separation will go as far as dialects and subdialects when necessary (Saussure, 1974, p. 90). Saussure argues that for a science concerned with values the distinction is a practical necessity. Scholars must consider both co-ordinates and make a distinction between the system of values per se and the same values as they relate to time (1974, p. 80). Saussure gives concise definitions of the two kinds of linguistics when he summarises his discussion of the terms toward the end of his account of synchrony and diachrony. Synchronic linguistics will be concerned with the logical and psychological relations that bind together coexisting terms and form a system in the collective mind of speakers (Saussure, 1974, p. 100). Diachronic linguistics, on the other hand, will study relations that bind together successive terms not perceived by the collective mind but substituted for each other without forming a system (Saussure, 1974, p. 100).

The synchronic linguistics Saussure envisages has a certain place in the history of linguistics, a place that Saussure himself initiates from a broader Neogrammarian position in defining the space he wants for his systematics of language. The old grammarians worked synchronically but they saw the original synchronic structure or system as being, just by reason of its precedence, the true structure or system. The analogies that yielded changes in grammar were viewed as false analogies. The historical linguistics that developed rapidly in the nineteenth century, had by the time of the Neogrammarians, come to a more genuinely evolutionary and scientific view of linguistic change. In so doing, that linguistics "revealed a new class" of phenomena. In the return to synchrony, then, the consequences of that discovery must be incorporated. The old 
grammar saw only the synchronic fact; [historical, diachronic] linguistics has revealed a new class of phenomena. But that is not enough; one must sense the opposition between the two classes of facts to draw out all its consequences (Saussure, 1974, p. 83).

To incorporate diachronic linguistics - to draw out its consequences - requires the awareness of a certain opposition. What does Saussure mean by this? The consequence of diachronic linguistics Saussure has in mind is the potentially all pervasive nature of evolutionary change. The unlimited variability of language over time creates a causal break on the axis of successions. It makes language a system of pure values generated solely by the synchronic solidarity of signs, "the momentary arrangement of terms". Saussure notes that some other sciences, such as economics, treat of values and so confront the disciplinary duality necessitated by "the intervention of the factor of time". But, this distinction has to be heeded by the linguist above all others (i.e. other disciplines) for language is a system of pure values which are determined by nothing except the momentary arrangement of terms. A value - so long as it is somehow rooted in things and in their natural relations, as happens with economics (the value of a plot of ground, for instance, is related to its productivity) - can to some extent be traced in time if we remember that it depends at each moment on a system of co-existing values. Its link with things gives it, perforce, a natural basis and the judgments that we base on such values are therefore never completely arbitrary; their variability is limited. But we have just seen that natural data have no place in linguistics (Saussure, 1974, p. 80).

It is in the exposition of the arbitrary nature of the sign that we "have just seen that natural data have no place in linguistics". And that arbitrariness, must, I suggest, be understood from this angle, the angle of what we might call its "material discontinuity" over time. It is this that makes the linguistic sign wholly arbitrary and it is this way into the systematics of the sign that I want to emphasise in this account of Saussure's theory. 
Yes, we can observe arbitrariness in the conventional conception of simple naming. The arbitrariness of the relation between signifier and signified - in which there is "no natural connection" - is certainly one point of entry to the arbitrary nature of the sign. No doubt it is, too, part of what Saussure has in mind when he refers to the absence of natural data in language. In particular, we will see that this is because evolutionary change always involves a shift in meaning which, for Saussure, can be conceived as a shift in the relationship between the signifier and the signified. But I want to suggest that it is the character of evolutionary change as revealed by diachronic linguistics that is the real root by which Saussure's "radical" arbitrariness enters the system. It is material discontinuity, the exhaustive nature of the potential transformations in the evolution of language that explodes the natural object of study and opens up the space of Saussure's fully realized conception of linguistic system. That system is arbitrary in the sense that it is not predictable over time on the basis of any irreducible form or natural enduring element. No element is reserved from the random impact of the evolutionary process - there is no unit that may not be fractured for use in a different structure: ... we must defend our principle: there are no unchangeable characteristics. Permanence results from sheer luck; any characteristic that is preserved in time may also disappear with time (Saussure, 1974, p. 230).

\section{Section 5: The synchronic-diachronic distinction examined further.}

- Any language state will contain some evolutionary movement but that does not prevent a sharp distinction between the two methods of study. 
- Synchronic linguistics allows us to think about language in a manner that is appropriate to the ever fortuitous nature of its states.

- A simple way of understanding the synchronic-diachronic opposition, then, is to observe that it is the difference between studying a single term and studying the "contract" between two or more terms of the kind that yields linguistic value.

- It is the very nature of diachronic linguistics that necessitates the distinction and gives synchronic linguistics its character. There is a scientific unity between the two forms of linguistics - a unity with its empirical basis in diachronic linguistics.

Synchronic linguistics studies language states - that is, states of linguistic evolution. The "momentary arrangement of elements" is a moment in an evolutionary process, not a fleeting interval. It is a period in which there are no significant evolutionary changes. The linguist discards unimportant changes in much the way that a mathematician discards infinitesimal quanta, says Saussure. The actual time period involved may vary between several centuries or a decade, depending on how much change takes place in a language. In any case it will be more of a chunk of time than a mere moment. It is similar, says Saussure, to the study of the structure of a plant stem. If we took a wafer thin cross section for study without having some idea of the longitudinal structure - the tubes and fibres which are arranged in that section - it would make little sense to us. Saussure's often quoted remarks at the beginning of his account of diachronic linguistics are relevant: There is really no such thing as absolute immobility. Every part of language is subjected to change. To each period there corresponds some appreciable evolution. Evolution may vary in 
rapidity and intensity, but this does not invalidate the principle. The stream of language flows without interruption, whether its course is calm or torrential is of secondary importance (Saussure, 1974, p. 140). So it is not that diachronic linguistics is excluded - both kinds of linguistics are needed. But the unprecedented character of the object of study necessitates a distinction between the two approaches at the descriptive level: Again, the more complex and rigorously organized a system of values is, the more it is necessary, because of its very complexity, to study it according to both co-ordinates (Saussure, 1974, p. 80).

As a part of the linguistics of language, diachronic linguistics takes language as its object. But at a sub-specific level, the diachronic may be distinguished from the synchronic by its association with speech. For language evolution is a phenomenon driven by speech. Nothing enters language without having been tested in speaking and every evolutionary phenomenon has its roots in the individual ... Before "honor" could become a rival strong enough to replace "honos", one speaker had to coin the new word then others had to imitate and repeat it until it forced itself into standard usage (Saussure, 1974, p. 168).

A change that becomes a part of a language state always begins unintentionally by a purely fortuitous mechanism. Speakers then take advantage of a difference to impregnate it with significance. At that point, the solidarity between elements of the language state the complex equilibrium of terms that mutually condition each other (Saussure, 1974, p. 122) - is affected and the state as a whole changes. It is as if one of the planets that revolve around the sun changed its dimensions and weight: this isolated event would entail general consequences and would throw the whole system out of equilibrium (Saussure, 1974, p. 85). Diachronic linguistics is capable of giving a detailed account of language evolution and its mechanisms. So, in introducing the diachronic-synchronic distinction Saussure further illuminates both the 
language-speech distinction and the fundamental role of arbitrariness in the creation of linguistic value. His favoured examples are binary differences: The opposition of two terms is needed to express plurality: either foot;foots or foot:feet; both procedures are possible, but speakers passed from one to the other, so to speak, without having a hand in it. In a fortuitous state (foot:feet), speakers took advantage of an existing difference and made it signal a distinction between singular and plural; foot;feet is no better for this purpose than foot: foots. In each state the mind infiltrated a given substance and breathed life into it. Neither was the whole replaced, nor did one system engender another; one element in the first system was changed, and this change was enough to give rise to another system. (Saussure, 1974, p. 84 - p. 85)

As we've noted, this new perspective - the ever fortutitous nature of a state - is, as Saussure says, inspired by historical linguistics and is unknown to traditional grammar which could never acquire it by its own methods. Likewise, most philosophers of language are equally ignorant of it yet nothing is more important from the philosophical viewpoint (Saussure, 1974, p. 85). For Saussure, we take advantage of fortuitous comparisons, importations, mutations and the like in language but we don't create these in order to express something external. A conventionalist view of language recognizes the arbitrariness of names and suggests that as a result some convention or contract between speakers must be necessary to ensure names refer to objects. In no way do diachronic facts aim to signal a value by means of another sign ... A diachronic fact is an independent event; the particular synchronic consequences that may stem from it are wholly unrelated to it (Saussure, 1974, p. 84). In contrast to the false notion that we readily fashion for ourselves about it, language is not a mechanism created and arranged with a view to the concepts to be expressed. We see on the contrary that the state which resulted from the change was not destined to signal the meaning with which it was impregnated (Saussure, 1974, p. 85).

A simple way of understanding the synchronic-diachronic opposition, then, is to observe that it is the difference between studying a single term and studying the 
"contract" between two or more terms of the kind that yields linguistic value. The contract or convention involved is one between two terms - and the essence of the linguistic mechanism is the unconscious comparison of terms (Saussure, 1974, p. 165). Diachronic changes are wholly unintentional while the synchronic fact is always significant. It always calls forth two simultaneous terms. Not 'Gaste' alone but the opposition 'Gast:Gaste' expresses the plural. The diachronic fact is just the opposite: only one term is involved and for the new one to appear (Gaste), the old one (Gasti) must first give way to it (Saussure, 1974, p. 85).

The difference between synchronic and diachronic linguistics is also closely related to the difference between internal and external linguistics. Both branches of linguistics can discover laws, but the difference between the two types of laws is crucial. Vowel shifts or consonantal changes over time, when they are regular, can be described by diachronic laws and may come about as a result of all sorts of external influences. Synchronic laws - such as those that express the relation between a word-unit and its accent or a word-unit and its ending - describe an internal relationship, a sort of contract between co-existing terms (Saussure, 1974, p. 92).

At the factual level it is vital not to confuse the two approaches, says Saussure. But at the general level, the level of scientific law, what Saussure calls a panchronic viewpoint is possible and this is important for any philosophical study of his theory of language (1974, p. 95). Saussure has some interesting things to say about synchronic and diachronic laws in language. If a law has the two key features of being both imperative and general then diachronic laws are imperative in the sense that diachronic change cannot be stopped - but they are not general. The change has a specific contingent - even random - form in each case. On the other hand, synchronic law describes a general arrangement of parts. 
But that arrangement is not imperative, it could change at any time. It is imperative in the sense that it is imposed upon individual speakers - but in language no force guarantees the maintenance of a regularity when established on some point (Saussure, 1974, p. 92).

Saussure goes on to say: But cannot the term (law) also be used in language as in the physical and natural sciences, i.e. in the sense of relations that are everywhere and forever verifiable? In a word, cannot language be studied from a panchronic viewpoint? Doubtless. In linguistics as in chess there are rules that outlive all events. But they are general principles existing independently of concrete facts (Saussure, 1974, p. 95). I think we can go a little further and say that it is at the crossing, the intersection of the two axes that the general mechanism or functioning of language is located. The "momentary arrangement of terms" is just that - momentary. But it has a general structure which Saussure envisages quite literally being reproduced in each speaker's mind, even if it is more or less unconsciously. That structure is syntagmatic and associative. And it is through the expansion of that structure that the chance productions of speech which prove useful are included in language.

Undoubtedly Saussure's strong injunction not to confuse synchronic with diachronic linguistics has helped produce a tendency to read his synchronic linguistics apart from his diachronic linguistics. But as he says: This is really unnecessary; one truth does not exclude the other (Saussure, 1974, p. 96). In fact, as we've seen above, as a system of values, language must be studied according to both co-ordinates. Further, I think we need to see that it is the very nature of diachronic linguistics that necessitates the distinction and gives synchronic linguistics its character. That character is in some vital sense immaterial and the distinction is necessitated by material discontinuity. But this doesn't mean there is not a scientific unity between the two forms of linguistics - a unity with its 
empirical basis in diachronic linguistics. It just means that it is not a unity based on material units. This is not easy to see because the material object as such - as the typical scientific object - does not admit of its own arbitrariness, its own lack of necessity. But in synchronic linguistics, I suggest, Saussure is trying to provide a linguistics that is a systematics of the evolutionary process - and he is doing so in the only way that is appropriate to the subject matter.

\section{Section 6: Paradigm and syntagm}

- A linguistic sign is a point of convergence of syntagmatic and paradigmatic associations.

- Syntagmatic or linear combinations occur "in praesentia" in discourse and can be conceived as relations of opposition. Paradigmatic relations are constituted "in absentia" and can be thought of as associative relations.

- These two are interdependent and work together in the mechanism of language.

The mechanism of language is constituted, says Saussure, of a latent system of unconscious comparisons. Comparisons are sets of terms that are, in our colloquial expression, "the same but different". As we have seen, association or sameness is inseparable from opposition or difference because neither has logical priority. Terms must be brought alongside each other before they can be contrasted and defined most precisely by being what the others are not (Saussure, 1974, p. 117). On the other hand they must 
be distinct before their association can be a meaningful activity. Within language we find a metonym of this relation in our use of the term "para" meaning both "with" and “against". For example, a paramedic is most precisely what a medic is not, doing what a medic does not do - the converse is also true. But less precisely - at the next level of generality - a paramedic is doing the same work as a medic, with and alongside medics. That is, they can both be contrasted with hospital administrators. Hospital administrators are not, we would say, directly involved in the care of patients. But at the next level all three categories of worker may be thought to be involved precisely in caring for patients when we speak of them in opposition to the local body politicians who open and close hospitals, and set their funding and waiting lists.

Again, we use a parachute against falling - but using a parachute is also the nearest thing to falling. As Saussure puts it: For it is obvious that analysis, because it results from a set of comparisons, depends constantly on the associative environment of the term (Saussure, 1974, p. 170). If the associative environment of a sign changes the sign itself changes. This is reflected in Saussure's account of the mechanism of language. There are two contrasting ways in which the sameness that yields difference is achieved. The first is in a sequential chain. This is the syntagm. In discourse, on the one hand, words acquire relations based on the linear nature of language because they are chained together (Saussure, 1974, p. 123). It consists of two or more consecutive units, including both complex words and groups of words: compounds, derivatives, phrases, whole sentences. Syntagms form one complex unit that is more than the sum of its parts. As Barthes points out, the syntagm can be seen as the initial raw material of any analysis of a code or semiological system. (Barthes, 1968) It is the largest repeated and therefore recognizable unit in speech that must be then 
decomposed into mutually delimiting units. Outside discourse, on the other hand, words acquire relations of a different kind. Those that have something in common are associated in the memory, resulting in groups marked by diverse relations (Saussure, 1974, p. 129). These are paradigms or associative groupings. They are one or more associative series comprising units that have an element in common with the syntagm (Saussure, 1974, p. 129). These are the associations that are "in absentia" in relation to discourse, that form an unspoken background to any syntagm. The common element in these groupings can vary from the meaning of the terms, as in groups of synonyms to inexact homonyms, based on phonic similarity. One example Saussure uses is the simple syntagm "de-faire" (to undo). The "de" element evokes decoller, deplacer, decoudre etc. The "faire" element recalls faire as such, refaire, contrefaire, etc. It is worth quoting Saussure at length, however to give a fuller picture: Through its grasp of the nature of the relations that bind the terms together, the mind creates as many associative series as there are diverse relations. For instance, in enseignment 'teaching', enseigner 'teach', enseignons 'we teach' etc. one element, the radical, is common to every term; the same word may occur in a different series formed around another common element, the suffix (cf. enseignment, armament, chagement, etc); or the association may spring from the analogy of the concepts signified (enseignment, instruction, apprentissage, education, etc); or again simply from the similarity of the sound images (enseignement and justement 'precisely'). Thus there is at times a double similarity of meaning and form, at times only similarity of form or meaning. A word can always evoke everything that can be associated with it one way or another ... we are unable to predict the number of words that the memory will suggest or the order in which they appear. A particular word is like the centre of a constellation; it is the point of convergence of an indefinite number of co-ordinated terms (Saussure, 1974, p. 126).

Paradigmatic and syntagmatic relations work together simultaneously to create meaning. There is a bond of interdependence; they mutually condition each other. In fact, spatial 
(linear, syntagmatic) coordinations help to create asssociative co-ordinations which are in turn necessary for analysis of the parts of the syntagm (Saussure, 1974, p. 123). We can imagine this happening in a fairly straightforward manner: the syntagm, "nous marchons aujourd'hui" provides the subject, the first person plural pronoun "nous". That selects "marchons" from the paradigm "marche, marches, marche, marchons, marchez, marchent". That agreement of the verb stops us hearing the "ons" sound as an "en" and analyzing the syntagm incorrectly. In some cases it is difficult to analyse the ribbon of sound because the paradigms are not distinctive enough. Saussure uses the example of "Si je l'apprends" (If I learn it). This has the same phonological profile as "Si je la prends" (If I take it). In these cases a larger syntagm - that is, more context - will be required.

All this is happening in an interplay that resembles the operation of a machine, says Saussure. Indeed, the meaning of a term and its function are identified in the system (Saussure, 1974, p. 161). If we look up a word in a dictionary we find first of all its part of speech and its closest synonyms. We might find its etymology and derivation. Then we will be given a citation, a syntagm to finally sharpen the definition. All these relations go to define a term and its meaning says Saussure. That dictionary definition is, however, but the tip of an iceberg of latent paradigms brought to a certain point of convergence by the syntagm. We are seeing one instance and one instant of a system.

\section{Section 7: The interaction of analogy with paradigmatic and syntagmatic relations}

- Although the traditional divisions of grammar may be useful in practice, they do not correspond to natural distinctions, says Saussure. Grammar should be 
constructed around the natural co-ordinates of syntagmatic and paradigmatic relations.

- Analogy interacts with paradigmatic and syntagmatic relations. Signs are best conceived as syntagms, as decomposable combinations of signs which are productive of new forms through syntagmatic solidarity i.e. relations of analogy.

- Saussure ties the productivity of terms through analogy to their complexity or decomposability - apparently forgetting his assertion that there are no simple terms in language only complex ones. He appears, in particular, to forget the linear or discursive relations in which terms are delimited.

But we must note that there is a good deal more to associative and syntagmatic relations than traditional grammar and syntax respectively, although those are certainly included. In short, although the traditional divisions of grammar may be useful in practice, they do not correspond to natural distinctions. To build a grammar, we must look for a different and higher principle ... only the distinction established above between syntagmatic and associative relations can provide a classification that is not imposed from the outside ... the whole subject matter of grammar should be arranged along its two natural co-ordinates (Saussure, 1974, p. 137). In particular Saussure is struck by what he calls "syntagmatic solidarities". For, there is another, complementary mechanism at work in language, one which we might characterize as the relation between elements that are "different but the same". This mechanism has a number of forms, the most important of which are analogy and agglutination. Changes in interpretation, no matter how they start always become apparent through the existence of analogical forms, (1974, p. 170) says Saussure. These two processes work together. Differences that are 
the same create the potential for new samenesses that are different and vice versa. Saussure devotes a good deal of time to discussing the role of analogy in evolution, including the way in which it counteracts the disruptive effect of phonetic change. I will describe analogy in more detail in the next chapter. At this point I want to highlight its interaction with syntagmatic and paradigmatic comparisons. In this regard Saussure provides the following image - vividly evocative of cultural traditions more generally, as well as of language. But one thing in particular interests the linguist. In the enormous mass of analogical phenomena built up through centuries of evolution, almost all elements are preserved; they are only distributed differently. Analogical innovations are more apparent than real. Language is a garment covered in patches cut from its own cloth (Saussure, 1974, p. 172).

We have seen a number of examples that Saussure cites of analogy in action, but to improvise an example we may take the term "aggro". "Aggression" is analogous to "aggravation" by way of the first four letters and to "anger" by way of the first and third letters. As Saussure says at several points, analogy with respect to meaning is also required - whether or not we think of that as a "false analogy" because "aggravation", strictly speaking, has nothing to do with anger or aggression. But in many contextual or syntagmatic usages aggression and anger are associated with the worsening or aggravation of a situation. So a new sign "aggro", both an adjective and a noun, with new shades of meaning, evolves: a person is "so aggro", there is "too much aggro" in a given situation, particularly when the person involved may also be addressed as "bro". This is the evolutionary force of time in action - the chance resemblance of phonemes combines with some equally contingent coincidence of meaning. 
Saussure advises that Analogy supposes a model and its regular imitation. An analogical form is a form made on the model of one or more other forms in accordance with a definite rule. (Saussure, 1974, p. 161) Syntagms provide the rules for selecting terms from within paradigms. But there is another element of analogy at work that results in different models - three different syntagm models in the case of "somnolent" - being selected on an unpredictable basis from the larger mass of signs. These activate different paradigms in accordance with their different divisions or analyses of "the original". We need to note, too, that all the terms in associative or paradigmatic groupings can be thought of as analogs. They just take different elements of the term as the element in common with the term - that is, as the positive analogy.

Syntamatic solidarity is so important partly because most terms, says Saussure are syntagms. They are analysable and therefore capable of being decomposed in an entirely unpredictable way. There are exceptions: To be sure, language has independent units that have syntagmatic relations with neither their parts nor other units. Sentence equivalents like yes, no, thanks etc are good examples. But this exceptional fact does not compromise the general principle. As a rule we do not communicate through isolated signs but rather through groups of signs, through organized masses that are themselves signs. In language everything boils down to differences but also to groupings (Saussure, 1974, p. 128). There is a contradiction here, though, with what Saussure says elsewhere about simple terms. For simple terms can only be used in syntagmatic contexts. Saussure points out that the sign "sun" has different values in different languages - in some languages one cannot sit "in" the sun for example. In another example, the expression "Gentlemen!" may be used by him several times in the course of a lecture with several different meanings. That can be due to the sound of the voice, its intonations, he says. But any specific intonation is just an element in another set 
of associations and analogies, interacting with the linear chain of sounds and signs. It is perfectly admissible to the system. And in any case there are syntagms that fall within Saussure's narrower definition, combinations that will incorporate isolated signs into something that is more than the sum of their parts: "Thanks but no thanks", "yes and no", etc.

It is also important to consider the sign as originally a syntagm insofar as it is comprised of an opposition of signifier and signified. That composition of a sign tells us, says Saussure, that change is potentially all pervasive. It can intervene in any sign and always results in what Saussure describes as a shift in the signifier-signified relation. No sign is indivisible - the delimitation of signs is not technically their individuation because there is no indivisible object for Saussure: A word is apprehended simultaneously as a unit and as a syntagm, and is preserved to the extent that its elements do not change (Saussure, 1974, p. 172).

At times, however, Saussure seems to forget the broader systematic nature of signs and display a curiously limited conception of linear or discursive context. The irony in this is that, as I will argue later, if we consider a sign or object in isolation we effectively take its systematic definition or delimitation for granted. It becomes unquestioned and unconscious. Saussure's project is to make that system of unconscious comparisons conscious. Yet the linear combination of signs - the syntagm - has almost to be reified, for Saussure, to be admissible to language. It has to be alienated from the individual speaker and have a concrete, unified character. Consequently there sometimes seems to be too little appreciation, as has been often remarked, of how speech realizes the potential 
of language, how it selects from its potential combinations and focuses speakers on specific signifieds.

The issue goes a little further for Saussure as we will see when we come to consider absolute and relative arbitrariness. For compound, decomposable terms are more productive in an evolutionary sense: Words can be rated for capacity to engender other words to the extent that they themselves are decomposable. Simple words are, by definition, unproductive ... Each language then has both productive and sterile words in varying proportions. This takes us back to the distinction between "lexicological" and "grammatical languages" languages (see p. 133). In Chinese, most words are not decomposable; in an artificial language, however, almost all words are. An Esperantist has unlimited freedom to build new words on a given root (Saussure, 1974, p. 166). Words are productive through analogy and syntagmatic solidarity. But those relations of identity can only be partial - if they were complete, the need for the differentiation of signs would not be met. This, at least, is how Saussure appears to reason. So Saussure concludes that it can only be the parts of words that are used to make others by analogy - and hence, words are potentially productive of other words to the extent to which they are decomposable into parts. Some words are perhaps more isolated and unproductive than others depending on how simple and unanalysable they are: ... the only forms left untouched by analogy are of course isolated words like proper nouns, especially place names (Saussure, 1974, p. 173).

The problem is that we can't tell in advance how or where a term will be redelimited or rearticulated. It doesn't have any inherent boundary, any necessary delimitation. An example is "Mt Cook", the highest mountain in New Zealand, a place name that doesn't look promising in terms of productivity. Yet now it is Aoraki/MtCook 
- a new name and a new value - but also one that will provide a form for other such names.

Thinking of terms more broadly - including terms in discursive contexts - allows us to see that analogy also works with terms as a whole, whether they are simple or complex. Terms may be productive of other terms whether that is visible in the words or not. Pre-existing signs may be placed in a new discursive system. The atrium of our heart, for example, is also the spacious entrance chamber of a Roman house. The ventricle to which it is joined is literally a little belly, a diminutive version of an element in an earlier - but somehow no less foreign - anatomy. There is a certain shock in discovering analogy at this level. Who would have thought the human body was so originally synthetic? Yet the heart gained these associations when it ceased to be just a core or centre of the body and was rearticulated as part of a circulatory system. And we see again in this example that relations of association and analogy - sameness and identity - are essential to differentiate objects. Likewise, the evolving, reciprocal delimitation of units yields ever more and more specific values - more complex points of convergence of various coordinations.

\section{Section 8: Absolute and relative arbitrariness}

- In some ways, relative arbitrariness appears as the culmination of Saussure's account of linguistic system - but it also appears to invoke a number of significant contradictions. 
- What Saussure wants to articulate, I suggest, is system arbitrariness: Signs cohere - that coherence is arbitrary in the sense that it has no external basis. Its logic is always immanent to the system.

- Relative arbitrariness, however, does show that there is a complex interplay between the arbitrary and the systematic in Saussure's conception of language as an evolving system.

In some ways, relative arbitrariness appears as the culmination of Saussure's account of linguistic system: Everything that relates to language as a system must, I am convinced, be approached from this viewpoint, which has scarcely received the attention of linguists: the limiting of arbitrariness (1974, p. 133). Broadly speaking, syntagmatic and associative relations limit arbitrariness because they bind a sign, however arbitrary the signifier may seem in relation to its signified, into a complex of relations in which that sign is rational and necessary - in which it resists, as Saussure says, arbitrary substitution. Syntagmatic and associative relations are the structures and the structural rules, respectively, by which a language functions and which yield its relations of difference and analogy: Motivation is explained by the principles stated in Section 2. The notion of relative motivation implies: (1) analysis of a given term, hence a syntagmatic relation; and (2) the summoning of one or more terms, hence an associative relation. It is the mechanism through which any term whatever lends itself to the expression of an idea, and it is no more than that (Saussure, 1974, p. 132). That last phrase is curious. The mechanism by which a term lends itself to the expression of an idea seems to be just about all we would want to describe in a theory of language. These relations "govern the functioning" of language - and meaning and function are apprehended as identical within the linguistic system (Saussure, 1974, p. 161). 
But there are also a number of contradictions in Saussure' s account of relative motivation that mean the conception as a whole requires very careful handling. When, for example, Saussure says: There is no language in which nothing is motivated and our definition makes it impossible to conceive of a language in which everything is motivated. Between the two extremes - a minimum of organization and a minimum of arbitrariness - we find all possible varieties (1974, p. 133), he seems to mean that at the most basic level all languages as systems are motivated because even basic oppositions are systematic. It is just that some may be more elaborated - i.e. analysable - than others. But Saussure also seems to say that some individual signs are motivated and others are not: At any rate, even in the most favourable cases motivation is never absolute. Not only are the elements of the motivated sign themselves unmotivated (cf. dix and neuf in dix-neuf) but the value of the whole term is never equal to the sum value of its parts. Teach + er is not equal to teach $\mathrm{X}$ er ... Dix-neuf is supported associatively by dixhuit, soixant-dix etc. and syntagmatically by its elements dix and neuf. (1974, p. 132) It is hard not see this latter view as inconsistent to the point of being anomalous. Just because dix is not part of a syntagm it doesn't mean that it is not fixed by "the concurrence of everything around it". It may be less systematically elaborated than dix huit - but it can't be absolutely arbitrary in the manner of a simple name. It must at least be a part of a binary opposition since we would have to suppose that dix on its own "is radically incapable of coming to consciousness". In fact we would think it was "supported associatively" by a number of paradigms - the set of natural numbers, for example. In the section preceding we have considered a number of Saussure's injunctions against the isolated sign - but we have also noted a certain limitation in his conception of context. In this case again it seems that he sees dix as not being part of a syntagm. There is a further puzzling feature 
in this passage: by Saussure's argument the complexity of the constitution of signs like teacher or dix-huit is not an argument for their arbitrariness but against it.

With these points in mind, it is not surprising that for a commentator like Roy Harris, the concept of relative arbitrariness is simply a muddle (1987, p. 132). Indeed Harris reacts in vivid terms to the whole suggestion of relative arbitrariness: Here Saussurean synchronic theory lies agonizing on a bed of nails of its own manufacture. Having accepted arbitrariness as a 'first principle' Saussure is at loss to explain why the principle fails to capture the most significant and characteristic properties of linguistic structure (Harris, 1987, p. 132). We have seen, of course, that arbitrariness as difference - difference as such - cannot account for any structural or systematic properties. But Harris suggests further that Saussure has confused questions of arbitrariness with questions of systematicity. For Harris, if dix is arbitrary then dix-neuf is no less arbitrary. He applies the principle to Saussure' s commercial analogy for language: ... the fact that the price of a loaf of bread is arbitrarily fixed at five francs does not mean that charging two and half francs for half a loaf is only relatively arbitrary. This is simply a gross non-sequitur. Both prices are equally arbitrary and that arbitrariness has nothing to do with the systematicity that relates them $(1987$, p. 132).

Harris certainly has a point. It really doesn't seem helpful to make a division between signs within any given system. The properties of a sign within a system are systematic properties. The sign does not also have isolable properties - at least not within the system. To the extent that it does have isolable properties it is simply not a part of the system under consideration. As Saussure says: To consider a term as simply the union of a certain sound with a certain concept is grossly misleading. To define it in this way would isolate the term from its system; it would mean assuming that one can start from the terms and construct the 
system by adding them together when, on the contrary, it is from the interdependent whole that one must start and through analysis obtain its elements $(\mathbf{1 9 7 4}, \mathbf{p .}$ 113). This, as I argue in the fourth chapter of this thesis, is the key aspect of Saussure's theory which the linguisticbiological analogy exposes: the arbitrariness of signs considered in isolation - signifier arbitrariness - is incompatible with the systematic character of signs. Signifier arbitrariness implies some opposition of signifier and signified that transcends any system of oppositions and associations. Harris is suggesting that Saussure could still maintain signifier arbitrariness on a of bi-planar basis, as the distinction between the orders of the signifier and the signified. But Saussure also conceives of linguistic value, like the economic system, as a system for equating things of different orders - labor and wages in one and a signified and signifier in the other (Saussure, 1974, p. 79). So there is bound to be confusion so long as Saussure maintains a concept of signifier arbitrariness. What I will suggest Saussure needs to do is maintain the immanence - the systematic character - of all linguistic relations. Signs in a system cohere. That is what being in a system means. They stand or fall together. But - and this is what is so difficult to theorise - the basis of their coherence, including the material medium of the system, is arbitrary. It could be anything. It is immanent to the system. The grammar of the stock exchange is not the simple logic of division, for example, that makes half a loaf of bread half the price of a whole loaf. The logic of the system - its exchanges of agreed equal value between speakers - is immanent to the system and varies and evolves by the mechanism of language that Saussure describes. Signifier arbitrariness seems to Saussure to subvert any fixed structure of reference and cause semantic variation and evolution. The problem is that it also reasserts a trans-systematic structure of reference. In the concept of relative arbitrariness this structure is identified with systematicity itself: A language constitutes a 
system. In this one respect (as we shall see later) language is not completely arbitrary but is ruled to some extent by logic; (Saussure, 1974, p. 133). But having developed his conception of linguistic value, Saussure cannot now refer simply to logic itself, or to the principle of order and regularity introduced by the mind into the disordered mass of signs (1974, p. 133).

However, what we can observe in the doctrine of relative arbitrariness is that Saussure's conception of language as an evolving system involves a complex interplay between the arbitrary and the systematic. The former is associated with the individual, the innovative and the differential - the latter with the collective, the regular and the equal. If the mechanism of language were entirely rational, it could be studied independently. Since the mechanism of language is but a partial correction of a system that is by nature chaotic, however, we adopt the viewpoint imposed by the very nature of language and study it as it limits arbitrariness (Saussure, 1974, p. 133). The interaction between the arbitrary and the systematic maintains the energy - dare one say, the vitality - of the whole. Within a language all evolutionary movement may be characterized by continual passage from motivation to arbitrariness and from arbitrariness to motivation; this see-saw motion often results in a perceptible change in the proportions of the two classes of signs (Saussure, 1974, p. 133). In this conception the arbitrary has come to stand opposite the rational in place of the natural or necessary. That shift is subversive. In place of a pre-existing natural object we encounter the irrational or chaotic - including those "shapeless masses" of thought and sound - from which values are created. 


\section{The Life of Language:}

\section{Saussure and Evolution}

\section{Chapter 3: Exploring the linguistic-biological analogy}

\section{Section 1: Introducing the analogy}

- Mathematical theories developed to describe biological variation in space can be used to describe variation in language evolution.

- This is surprising since the arbitrariness of the sign - and the role of human agency in language which that implies - would lead us to expect that Saussure's theory would reflect only a superficial correspondence between linguistic and biological evolution

- Equally surprising is that Saussure's theory of language appears to offer some explanation in terms of the internal mechanism of language for this analogy.

- A number of points of analogy have already emerged from the exposition of Saussure's theory in the previous two chapters and these are listed as a prelude to a deeper exploration of the analogy. 
The stimulus for this thesis came from reading Saussure's Course in General Linguistics and being struck by the extent to which his synchronic theory appeared to reflect an awareness of linguistic evolution as analogous to biological evolution. That was striking to me because I was aware of the success that linguists and biologists have had more recently in exploiting this analogy. The questions then arose: to what extent is Saussure's theory of language a theory that could underpin and explain the linguisticbiological analogy? To what extent should it be such a theory? And what does the linguistic-biological analogy suggest about the philosophical appropriation of Saussure's theory? These are the guiding questions of this thesis.

One of the pioneers in the application of biological models to linguistic evolution, Luigi Luca Cavalli-Sforza, describes the process in this way: Theories of biological variation in space, developed in the middle of the twentieth century by several different mathematicians, resulted in very similar models. They have the generic name of "isolation by distance" and show that genes vary randomly in geographic space, following exact rules derived from statistics and probability. The most significant regularity is the relation between genetic distance (calculated from averaging a number of genes) and geographic distance. We have seen that genetic distance increases regularly (but always more slowly) as geographic distance increases until it reaches a maximum. The shape of the theoretical and empirical curves is determined by two measurable variables: the mutation rate, which increases genetic differences between two places, and the rate of genetic exchange between neighbours due to migration, which tends to increase genetic similarity between them - so these forces are opposed, to a certain extent and balance each other.

The same mathematical theory can be applied to linguistic evolution: the equivalent of mutation (which produces new forms of genes, or alleles) is innovation, which in linguistics is the generation of new sound, meaning or grammar. Migration propagates these changes in space. William Wang and I 
have applied this genetic theory of isolation-by-distance to linguistic variation in Micronesia (CavalliSforza, 2000, p. 196).

Cavalli-Sforza is phlegmatic about this analogy. The explanation, he says, is quite simple: How is it possible for these two very different systems to follow parallel evolutionary trajectories, or to "co-evolve"? The explanation is quite simple. Two isolated populations differentiate both genetically and linguistically. Isolation, which could result from geographical, ecological, or social barriers, reduces the likelihood of marriages between populations, and as a result, reciprocally isolated populations will evolve independently and gradually become different. Genetic differentiation of reciprocally isolated populations occurs slowly but regularly over time. We can expect the same thing to happen with languages: isolation diminishes cultural exchange and the two languages will drift apart (2000, p. 150).

By this account, linguistic exchange and evolution are a subset of cultural exchange and evolution: sexual intercourse goes along with cultural intercourse. Are the guiding questions for this thesis otiose then? Or does Cavalli-Sforza's account leave the question of the underlying, internal mechanism of language evolution and its analogy with biological evolution unanswered? I think the answer is that the analogy at the mechanistic level - the "inner organism" of language - is indeed yet to be explored. Further, I think this exploration is worth undertaking because the popular expectation is not exactly as Cavalli-Sforza represents it. It may be obvious that as populations drift apart genetically they will drift apart linguistically. It is rather startling, however, to learn that mutation in genes is, in some sense, mathematically equivalent to innovation in language. That is because we think of language as an arbitrary product of our conscious intention which transcends natural processes. Biological evolution, on the other hand, is a natural process which we are, or have been, powerless to control. Based on this conventional - and 
conventionalist - understanding of language we would expect the two forms of evolution to differ at any but the most superficial level.

Reading Saussure, then, and noting first of all how often the term "arbitrary" is used as a synonym for "random", "fortuitous" (1974, p. )or "unmotivated" (1974, p. 69) - and how often language is said to escape the will of both the individual and the community (1974, p. 17) - suggests that in this theory we may find some explanation for the unexpected depth of the linguistic-biological analogy. It may be, of course, that as a result of exploring these questions further we find suggestions about the mechanisms of biological evolution as well - but that is something that lies beyond the scope of this thesis. Learning more about the analogy may, however, provide new perspectives on the broader philosophical appropriation of Saussure's theory.

One virtue of these guiding questions is that we soon find that they are a good way of revisiting the challenge Saussure poses for himself. There is, first of all, the semiological ideal: If we are to discover the true nature of language we must learn what it has in common with all other semiological systems $(1974$, p. 17). Saussure was not able to think of biological evolution as a genetic phenomenon and so he would not, we might suppose, be as inclined as we are now to think of it as a semiological phenomenon. Indeed we have now, in Biosemiotics, a biology that interprets living systems as sign systems (Emmeche, Kull, Stjernfelt 2002: 26). More fundamentally, though, the scope of linguistics should be, says Saussure, a) To describe and trace the history of all observable languages, which amounts to tracing the history of families of languages and reconstructing as far as possible the mother language of each family. b) To determine the forces that are permanently and universally at work in all 
languages, and to deduce the general laws to which all specific historical phenomena can be reduced. c) To delimit and define itself. $(1974$, p. 6)

Saussure's theory deals with b) and c) of these aims: to theorise the common and enduring features of the evolution of language; and, to define language as a scientific object and linguistics as a scientific enterprise. As we have noted in the first part of the thesis and see again in this formulation, historical linguistics is intertwined from the very outset with natural scientific and especially biological theories. Here, for example, the history of languages is thought by Saussure to be primarily phylogenetic - having to do, that is, with family trees of languages.

In the first two chapters of this thesis I have attempted to introduce and expound Saussure's theory in a way which I hope is both reasonably comprehensive but which also bears the first of our guiding questions in mind. The elements of positive analogy between linguistic and biological evolution that emerge in that exposition are already so numerous that it is a little risky to attempt a comprehensive summary. Before focusing in more detail on the analogy, however, the main points might be listed as follows:

a) Language is a population-based phenomenon.

b) Language is an holistic system like an organism.

c) Languages, like species, don't grow through a life cycle but rather evolve continuously.

d) The development of languages like species can be traced through family trees to ever more common origins. 
e) The linguistic system is comprised of heritable units called signs.

f) The sign is exposed to alteration because it perpetuates itself $(1974$, p. 74$)$.

g) Changes in signs are arbitrary in the sense of being chance products and fortuitous innovations.

h) Change enters the system by way of the individual.

i) Changes in signs may only be initiated by individual speakers but survive or perish according to whether or not they are adopted by the group and in this way become a part of the system.

j) Change is potentially all pervasive.

k) The system escapes the will of both the individual and the collective.

1) For both systems, meaning is function

In this chapter I want to explore the analogy between biological and linguistic evolution in more depth - both historically and in its contemporary usage - and examine how Saussure situates his own work in relation to it. Then I think we can go on in the next chapter to better answer our second and third guiding questions.

\section{Section 2: A metaphor with a long history}

- The linguistic-biological analogy can be traced to the beginning of the comparative philology tradition in the late eighteenth century. 
- In its earlier stages the argument was used to argue for the natural scientific character of linguistics because its development appeared to escape human volition.

- Soon after the publication of the Origin of the Species, Muller modifies this view, arguing that language development combines in one the two opposite elements of necessity and free will.

The analogy can be traced to the beginning of the comparative philology tradition. At this stage it was mainly focused on the question of common origin but we will see how it remained essential in the development of the Neogrammarian position.

The analogy was first prompted by the theory advanced in 1786 by the English judge Sir William Jones - and subsequently developed by the German Franz Bopp (Saussure, 1974, p. 2) - that Sanskrit, Greek and Latin, and possibly Celtic and Gothic (the ancestor of Germanic languages) appeared to have a common origin (Cavalli-Sforza, 2000, p. 166). In perhaps its earliest expression, Friedrich Schlegel in 1808 called on philologists to study the inner structure of languages or comparative grammar, which will give us altogether new insights into the genealogy of languages, in a manner similar to that in which comparative anatomy has shed light on the higher natural history (Alter, 2005 p.124). Schlegel noted that the affinity of Sanskrit with ancient Greek and Latin consists not only in a great number of [word-] roots which it shared with them, but it extends to the innermost structure and grammar. The agreement is accordingly not one of chance, which might be explained by mixture, but rather an essential one which points to common descent from an ancestral tongue (Alter, 2005 p.125). 
Stephen Alter notes that what Schlegel called "mixture" of languages resulted from contingent historical processes such as migrations, conquests and culture contact and mainly produced similar vocabularies. Parallel grammars, on the other hand, pointed to an inherited genealogical connection. By focusing on comparative grammar, the researcher filtered out mere accidental factors and tested whether a given sets of languages had a common ancestor (2005, p.125). By 1861 Max Muller was able to take this natural - historical tradition of language theory a step further. Muller sought to argue that philology was a science because it was a natural science. The criterion of demarcation Muller used between natural and historical science still has intuitive appeal today. It accounts, I think, for what we find startling in the precise level of analogy that has been exploited in contemporary science. That criterion was the mode of causality that normally operates amongst its phenomena ... the natural sciences have nothing to do with the products of human volition (Alter, 2005, p.127). Muller argues that language is not the product of human volition and so its study belongs among the family of natural sciences. Changes in language occur gradually but irresistibly, and, what is most important, they are completely beyond the reach or control of the free will of man ... Though the individual seems to be the prime agent in producing new words and new grammatical forms, he is so only after his individuality has been merged in the common action of the family, tribe or nation to which he belongs (Alter, 2005, p.127).

Muller highlights this paradox: The process by which language is settled and unsettled combines in one the two opposite elements of necessity and free will (Alter, 2005 p.128). Then, in a second series of lectures, in 1862, having digested Darwin's Origin of the Species, he produces a surprising solution to this contradiction: We want an idea that is to exclude caprice as well as necessity - that is to include individual exertion as well as general co-operation - an idea applicable neither to the unconscious building of bees nor to the conscious architecture of human beings, yet combining within itself both these operations and raising them to a new and higher 
conception ... It is the idea of natural Selection ... (Alter, 2005 p.128). It appears that this was the earliest application, even if only rhetorical in character, of a Darwinian concept to a socio-cultural phenomenon (Alter, 2005, p.128).

It is not quite accurate, then, for Saussure to say that a crucial feature of language, though the one that is least remarked, is that it escapes both the individual and collective will (1974, p. 17). It was much remarked, at least in the period when Saussure was growing up and before he became precociously active as a linguist. By emphasizing this feature himself Saussure aligns himself in an important way with the natural-historical tradition. But Saussure's position in relation to philologists such as Muller and Auguste Schleicher, who both appeared to embrace Darwinian evolution, is nuanced in an unexpected way. That is because of the persistence of the life cycle thesis - and various associated notions - alongside the more progressive tendencies of these theorists. For the Neogrammarians, who provide the primary basis for Saussure's theoretical work, the priority had been to establish a more fundamental, genuinely evolutionary, perspective. That is provided by the work of Dwight Whitney and others and involves two central theses. These are: uniformitarianism and analogy as a creative force.

\section{Section 3: Uniformitarianism and analogy as a creative force}

- Establishing a genuine evolutionary perspective in historical linguistics requires the rejection of the life cycle thesis and the incorporation of two alternative theses: uniformitarianism (which includes an assumption of gradualism) and analogy as a creative force. 
- Saussure's theory registers the full force of these theses. His theory gives a central role to analogy, for example, saying it occupies a preponderant place in the theory of evolution.

- His careful account of the analogical process leaves room for a mechanism of selection - based, for example, on a rule of economy. This possibility is not developed however.

- There is a double movement in analogy. It is responsible equally for the conservation of terms as for their transformation.

The life-cycle thesis, as I have said, was the view that some prehistoric or primeval period of growth in languages precedes their subsequent decay. Grammatical fullness is to be found only in the earliest periods of a language. Decay then follows naturally but inevitably by means of phonetic and grammatical change - "lazy" speech, for example that disrupts regularity in the language. The uniformitarian principle articulated by Whitney was first popularized by the geologist Charles Lyell. The subtitle to his Principles of Geology $(1830$ - 33) is indicative: "An Attempt to Explain the Former Changes of the Earth's Surface by Reference to Causes Now in Operation" (Alter 2005, p. 89). Whitney put it this way in his lectures: It is but shallow philology, as it is shallow geology, which explains past changes by catastophes and cataclysms (Alter, 2005 p. 89). 
Whitney's view is that current processes can be projected back to the earliest times, making it unnecessary to invoke unknown causes: The nature and uses of speech, and the forces which act upon it and produce its changes, cannot but have been essentially the same during all the periods of its history, amid all its changing circumstances, in all its varying phases; (Alter, 2005 p.219). As Saussure puts it: There had to be a reaction against the aberrations of the old school, and the appropriate slogan was this: Observe what happens in the everyday speech of present-day languages and attribute to older periods no process, no phenomenon that is not observable today (1974, p.184). Whitney acknowledged that the Indo-European languages had lost much of their inflectional apparatus since the time of ancient Sanskrit, Greek and Latin. Even so, he found the larger trend to have been one of increasing complexification. As we noted earlier in the thesis, this understanding develops alongside the attention in linguistics to the full range of speech phenomena rather than just to literary texts. As Saussure says: People attach even more importance to the written image of a vocal sign than to the sign itself. A similar mistake would be in thinking that more can be learned about someone by looking at his photograph than by viewing him directly (1974, p. 24). Simply: Language is constantly evolving, whereas writing tends to remain stable (1974, p. 27).

In some ways, perhaps, Saussure embraces uniformitarianism to an even greater extent than Whitney. For Saussure it is matter of principle that originary conditions are always present. In the chapter entitled Immutability and Mutability of the Sign (1974, p. 71) he argues against Whitney and the conventionalist view by emphasizing that language is always the heritage of the preceding period and that, despite the arbitrariness of the sign, there can have been no simple convention or contract by which names were assigned to things or concepts to sound images: The so-called primitive contract merges with what happens every day. There is no moment at which genesis differs characteristically from the life of language, 
and the essential thing is to have understood the latter (Saussure, n.12 in Gadet 1986, p. 36). In the Course Saussure puts the matter in this way: That is why the question of the origin of speech is not so important as it is generally assumed to be. The question is not even worth asking; the only real object of linguistics is the normal regular life of an existing idiom. A particular language state is always the product of historical forces ... (1974, p. 120).

Whitney, on the other hand, had engaged with Darwin on the question of the genesis of language itself. He expresses some sympathy for Darwin's views that the imitation of animal cries as warnings or to attract mates might have formed a protolanguage before these became conventionalized. Saussure's statements above seem to rule out this kind of theory, as does Saussure's tendency to think of signifier arbitrariness as essential to linguistic evolution. Evolution is an origin but not in the sense of being a starting point on a linear timeline - it is a present condition that illuminates the structure of linguistic phenomena: The form of a word at a particular moment stands for a moment in its enforced evolution (1974, p. 31).

Gradualism is also an essential element of the uniformitarian thesis. The realisation in the mid 1850 s that human pre-history stretched back much further than previously thought allows Whitney and thence Saussure to suppose that changes occurred gradually over very long periods of time. This strengthens the analogy with geological change and biological evolution. For change to be uniform it must be gradual and that in turn requires plenty of time. When Saussure refers to time as a force in language evolution, then, he is imagining this gradualist, uniform force. As Alter notes the revolution in ethnographic time which Whitney registered so fully supplied the theory of essential continuity ("without a break, being of one piece") on which Neogrammarian doctrine would be based and on which historical linguistics 
has been based ever since (2005, p. 219). The analogy with biological evolution is perhaps increasingly striking from a contemporary perspective as the gaps in the fossil record to which Darwin referred are filled in. Indeed it can be argued that these gaps are now most notable by their absence, with an abundance of transitional forms available for all the major lines of descent (Prothero, 2008).

The doctrine of uniformitarianism, then, is crucial in paving the way for a description of language evolution as having a steady, uniform path of gradual development - thus securing a crucial component of the analogy. The other critical element in the development of the Neogrammarian position is the revision of the role of analogy. Saussure's own account is perhaps the clearest: The first linguists did not understand the nature of the phenomenon of analogy, which they called "false analogy". They thought that in inventing honor, Latin "had made a mistake" concerning the prototype honos. For them, everything that deviated from the original state was an irregularity, a distortion of an ideal form. The fact is that, through an illusion characteristic of their time, they saw in the original state of the language something superior and perfect, with the result that they did not even ask themselves whether this state had been preceded by another. Every liberty with respect to this state was then an anomaly. The Neogrammarian school was the first to assign analogy to its proper place by showing that it is, along with phonetic changes, the prime force in the evolution of languages, the procedure through which languages pass from one state of organization to another (1974, p. 162).

The Neogrammarian argued that the sound laws that seemed to govern phonetic change were, by definition, exceptionless. Exceptions to such rules actually follow an additional rule of their own - namely analogical regularity (Alter, 2005, p. 220). Saussure teaches: That phonetic evolution is a disturbing force is now obvious. Wherever it does not create alternations, it helps to loosen the grammatical bonds between words; the total number of forms is 
uselessly increased; the linguistic mechanism is obscured and complicated to the extent that irregularities born of phonetic changes win out over the forms grouped under general patterns; in other words, to the extent that absolute arbitrariness wins out over relative arbitrariness. Fortunately analogy counterbalances the effect of phonetic transformations. To analogy are due all normal, non phonetic modifications of the external side of words (1974, P. 161). As Whitney puts it in "The Life and Growth of Languages": When phonetic corruption has disguised too much or has swept away the characteristics of a form, so that it becomes an exceptional or anomalous case, there is an inclination to remodel it on a prevailing norm. The great mass of cases exerts an assimilative influence upon the smaller (Alter, 2005, p. 222).

Saussure emphasizes that the process has three stages. First, the analogical innovation must be created. Second, it coexists with its rival. Third it eliminates its rival. Many innovations do not make it to the second stage - the typical example is the regularities that children produce on learning the rule but not the exception: the comparative "badder" in place of "worse", for example. Analogical innovation is a process Saussure calls "paraplasm" and can be contrasted with "metaplasm". He brings out this contrast by noting that: the analogical fact is a play with a cast of three: (1) the traditional, legitimate heir (e.g. honos) (2) the rival (honor); and (3) a collective character made up of the forms that created the rival (honorem, orator, oratorem, etc). Honorem itself came into being by the phonetic process of rhotacisation by which the intervocalic $r$ replaced the $s$ in honosem. In a sense that creates two roots, honor and honos: After that the radical had a double form. This duality was eliminated by the new form honor, created on the pattern of orator: ortatorem (Saussure, 1974, p. 161). Saussure is at pains to separate out the stages of analogical change and allow for the co-existence of the two forms in language: One might readily suppose that honor is a modification, a "metaplasm" of honos and say that it drew most of its 
substance from honos. But the only form that has no part in the production of honor is this very honos $(1974$, p. 163)!

It is because of this process that, he says: ... it is evident that analogy by itself could not be a force in evolution, and the constant substitution of new forms for old ones is one of the most striking features in the transformation of languages. Each time a new formation becomes definitely installed and eliminates its rival, something is actually created and something else abandoned, with the result that analogy occupies a preponderant place in the theory of evolution. This is the point that I should like to emphasise (1974, p. 169). This last passage is certainly a little opaque. The point Saussure wishes to emphasise has, I think, a number of elements. One is that analogy, as he says, depends on the models provided by the larger system, not just individual invention. In this respect, it is one more lesson in the need to separate language from speaking (1974, p. 165). Another element, though, is that some form of selection takes place. This is in addition to the analogical creation process. So analogy has a preponderant place in evolution in enabling the transition from one language state to another but this is not accomplished by the creation of new forms alone. There is a process of selection involved as well.

Here then we seem to find another more detailed point of analogy. The question then arises, if there is selection, what is the criterion at work? Whitney had no doubt as to the answer, at least in terms of phonetic change. It is, he says a case of mental economy: an avoidance of the effort of memory involved in remembering exceptions and observing them accurately in practice (Alter, 2005, p. 221). Alter notes that although confident that the least-effort principle furnished the motive underlying almost all forms of language change, Whitney conceded that "the details of this working are ... not a little obscure" (2005, p.221). Saussure certainly 
favours Whitney's theory over explanations based on racial factors or those of soil and climate (Saussure, 1974, p. 149). But the difficulty Saussure identifies with the law of least is that we can scarcely determine what is most difficult for each language to pronounce (1974, p. 149) Dipthongs sometimes become monopthongs, for example - but the reverse also seems to occur, perhaps because dipthongs help differentiate elements. The law of least effort would require extensive study, Saussure concludes. It would be necessary to consider simultaneously the physiological viewpoint (the question of articulation) and the psychological viewpoint (the question of attention) (1974, p. 149).

It is important to note the central role analogy plays, in Saussure's view, in the evolution of language. Four fifths of French is Proto-Indo-European, he says, if we think of the substance that constitutes sentences but the words that have been transmitted without analogical change would occupy less than the space of one page $(1974$, p. 172). More than this, though, the stability of certain forms - their conservation - is just as much the work of analogy as their transformation. The most systematically integrated forms are those that are most analogically productive - and these forms are themselves reciprocally produced by their products. Saussure uses the example of agunt which survived almost intact from prehistoric period through Latin to the beginning of the romance period. The form did not change because ag- and -unt regularly appeared in other series and the support of these forms preserved agunt (1974, p. 172). Unity and divisibility are somehow combined in the sign: A word is apprehended simultaneously as a unit and a syntagm (1974, p. 172). The sign is simultaneously synthesized as a unit and dispersed through the system.

In summary then, we see that the Neogrammarians were very much opposed, as Saussure reflects, to the idea that language was a thing that leads a life of its own outside of and 
above human beings (Brugmann, in Alter, 2005, p.224). As Saussure says: Language was considered a specific sphere, a fourth natural kingdom; this led to methods of reasoning that would have caused astonishment in other sciences $(1974$, p. 4). But this critique is directed specifically at the life cycle thesis and in support of its replacement by the doctrines of uniformitarianism and analogy as a creative force. Saussure, in particular, has no desire to throw the biological baby out with the vitalist bathwater. It is necessary, he says to maintain a metaphorical middle ground. When we consider his extraordinary vision of analogy as both a transformational and a conservative force - of a stability that is no less vibrant than change - we can see why he might take this view. Referring to the advent of the Neogrammarian school of linguistics on which his own work is based, Saussure says: One no longer dared say, "Language does this or that" or "life of language" since language is not an entity and exists only within speakers. One must not go too far, however, and a compromise is in order. Certain metaphors are indispensible. To require that only words that correspond to the facts of speech be used is to pretend that these facts no longer perplex us. This is by no means true, and in some instances I shall not hesitate to use one of the expressions condemned at that time (1974, p. 5, footnote).

\section{Section 4: Further points of analogy}

- The order of the Course hides the importance of Saussure's engagement with contemporary accounts of common ancestry and family trees of languages - the most obvious point of analogy between linguistic and biological evolution. 
- Saussure's position rests on a deeper commitment to evolutionary change - one that allows for no enduring material element that could be immune to such change.

- The question then arises whether this understanding of linguistic evolution could be a closer match to the processes of biological evolution as we now understand them. There are certainly reasons for thinking it is.

- Apart from supporting similar forms of origin and descent this understanding of linguistic evolution also, for example, provides for a more specific and suggestive analogy between master genes and word roots.

I've suggested that one way in which Saussure's position in relation to the biological "metaphor" or analogy is obscured in favour of a conventionalist view of language is the order in which the original editors, Ballye and Sechehaye, have arranged the book of Saussure's Course of lectures. The sequence of Saussure's teaching is stated in the quotation given at the start of this chapter and reflected in the order of lectures in the original third Course in general linguistics. It seems that in the third Course of lectures, the conception of the arbitrary nature of the sign that is central to the discussion of language and linguistic value is introduced following a lengthy and comprehensive consideration of all the random and sometimes fortuitous forms of change that occur in the evolution of languages, including a whole chapter devoted to the diversification of languages over geographical space and time. 
Indeed Saussure's most forceful exposition of what I am calling "system arbitrariness" - the potentially all pervasive character of evolutionary change - occurs in what is now the last chapter of the Course. This chapter - Chapter V of Part V - is one that the editors say they have taken from elsewhere because, while it is not concerned with retrospective linguistics, (the subject of the remainder of Part V), it forms an apt conclusion to the book. In fact, the chapter does seem to have to do with retrospective linguistics - but, more importantly, it forms an apt introduction, from the evolutionary point of view, to Saussure's theory of language. Underlying the whole of Part V is this question: how can evolutionary deductions - what we might call retrospective predictions - be made from arbitrary systems and what are the limits of that process?

The fundamental problem, identified in Chapter $\mathrm{V}$, is the all pervasive character of change ... no family of languages rightly belongs once and for all to a particular linguistic type. To ask the type to which a group of languages belongs is to forget that languages evolve; the implication is that there is an element of stability in evolution. How is it possible to impose limitations on an activity that has none? (1974, p. 229). The chapter identifies a principle of evolution: When we assume that there are permanent traits which neither time nor space can change in any way we clash head-on with the fundamental principles of evolutionary linguistics. No characteristic has a right to permanent existence; it persists only through sheer luck $(1974$, p. 229) $\ldots$ any characteristic that is preserved in time may also disappear with time (1974, p. 230). He also notes that a trait of the prototype may not appear in some of the derived languages. The reverse is equally true. It is not unusual even to find that the common traits of all the representatives of a family do not appear in the original idiom (1974, p. 230). Saussure is seeking to rebut simplistic conceptions of phylogenetic inheritance in language. He concludes in the last paragraph of the chapter: We now realize that Schleicher was wrong in looking upon language as an organic thing 
with its own law of evolution but we continue, without suspecting it, to try to make language organic in another sense by assuming that the "genius" of a race or ethnic group tends constantly to lead language along certain fixed routes (1974, p. 231-232). Saussure is concerned to avoid any superficial linguistic-biological analogy - particularly those associated with $19^{\text {th }}$ Century 'scientific racism' of the kind espoused by his older brother Leopold (Joseph, J., in Sanders, 2004, p. 69) - but to do so from the basis of a deeper commitment to the evolutionary character of language. That permits the inclusion of no essential element or "genius". That, in turn, is connected to the conception of internal linguistics and the exclusion of any external factor in evolution. This is the fundamental idea of this course: the true and unique object of linguistics is language studied in and of itself (Saussure, 1974, p. 232). This concluding statement echoes the same proposition from very near the beginning of the book in which Saussure asks what the object of linguistics might be. It can be seen either as a bookend, as did Saussure's editors (Bouquet, S., in Sanders, 2004, p.207), or as an earlier stage in a sequence of thought.

The question arises, then, whether this deeper understanding of linguistic evolution is likely to be a closer match to the processes of biological evolution as we now understand them. There are certainly reasons for thinking it is. Part 5, for example, argues that diachronic linguistics does not proceed in one direction only through time. A key point in this discussion is that while the common original language, Proto-Indo-European - the mother language of Greek, Latin and Sanskrit - was able to be reconstructed retrospectively from Sanskrit, Sanskrit did not develop earlier chronologically than Greek or Latin. It developed later but preserved certain original forms of the mother language that were lost in the subsequent evolution of Greek and Latin. Because it was the oldest 
document of Proto-Indo-European, they promoted Sanskrit to the rank of prototype. To imagine that Proto-Indo-European engendered Sanskrit, Greek, Slavic, Celtic, Italic etc is one thing; to substitute one of these languages for Proto-Indo-European is something else entirely. The glaring mistake of the earliest scholars had varied and far reaching consequences ... (1974, p. 215). Here, then, is another more detailed point of analogy with one of the truisms of contemporary evolutionary theory as opposed to a Victorian understanding. The latter supposed a single linear process of evolution, a 'great chain of being' as it was often called. Tennyson, for example, abjured humanity to Move upward, working out the beast and let the ape and tiger die (Tennyson, 1849, p. 118). Now it is understood that the overall form of evolution is bush like, with earlier forms - including transitional forms - co-existing with later ones. This is something Saussure also contemplates at the level of linguistic analogy, as we have seen, with the later rival co-existing with the form it seeks to supplant. He also notes the persistence of vestigial characteristics in linguistic forms: elements that endure because they become peripheral to the current of evolutionary change (Saussure, 1974, p. 173).

As we have noted, common origin is the most explicit point of analogy and this is the issue which Saussure tackles in Part V of the Course and Chapter V in particular. It dates at least from Schlegel. Darwin's work sharpened awareness of the analogy amongst linguists - but he himself was also acutely aware of it. Cavalli-Sforza writes: In 1863 the German linguist August Schleicher published a tree showing the origins of the Indo-Europeans very much like the one we would draw today using modern methods. The ties between biology and linguistics were evident at once. Schleicher was certainly influenced by Charles Darwin's use of trees to explain the theory of organismal evolution. In "On the Origin of Species" Darwin clearly stated that if we knew the tree of biological descent of the human groups, we could extract the tree relating languages (2000, p. 166). Saussure was clearly aware, first of all, of theories of common 
origin. At the age of fifteen, after he had learned Greek to add to his French, German, English and Latin, Saussure wrote an "Essay on Languages" in which he argued that all languages have their root in a system of two or three basic consonants.(Culler, 1986, p. 21) Saussure said of himself: The idea that with the help of one or two Sanskrit syllables - since that was the main idea of the [Pictet's] book and of all contemporary linguistics - one could reconstruct the life of people who had disappeared, inflamed me with an enthusiasm unequalled in its naivete. (Davies, A.M., in Sanders, 2004, p. 14). In the mature theory, however, the pursuit of one common origin is abandoned. Historical linguistics has become a matter simply of tracing common origin as far as possible. As with many biologists, Saussure is relaxed on the question of whether there could be a single source of language: Besides diversity within related groups, then, there is absolute diversity - differences between languages that have no recognizable or demonstrable kinship ... a good example is Chinese with respect to the Indo-European languages (1974, p. 192).

Word roots, however, suggest a more subtle area of analogy with gene based evolution. Saussure says: The root is the irreducible element common to all words of the same family. (1974, P. 186) This element was also called the "material" as opposed to the "formal" element of word formation, the latter being inflections of various kinds including prefixes and suffixes such as verb and noun endings. Roots are, arguably, the oldest heritable units in a family of languages. Saussure continues: But any subjective and synchronic analysis separates material elements only by considering the share of meaning that matches each element and the root is in this respect the element in which the meaning common to all related words reaches the highest degree of abstraction and generality (1974, P. 186). This may be reflected within a root - the more reduced the radical is the greater the likelihood that its meaning will become abstract. Thus zeugmation suggests a little team, zeugma any team whatsoever and zeug - the indefinite notion of yoking or harnessing (1974, P. 186). This concept of 
abstraction is certainly suggestive. Recent work mapping genes has identified very abstract and very ancient genes functioning at the highest level of commonality. These are "master genes". The so-called "Tinman" gene, for example, is responsible for the initial production of the heart in embryological development and is common to animals as diverse as humans, fish and fruit flies (Zimmer, 2000). The gene may have come from the first marine creature that modified a system for circulating water over gills. Now it is the necessary trigger for further specifications of the heart by clusters of genes that vary across these families of animal. What is intriguing about this point of analogy is the relativity of abstraction it suggests. The most basic element undergoes a kind of semantic ascent in evolution due to the subsequent specifications or inflections that attach to it.

This kind of insight of Saussure's into word roots comes from his insistence that grammatical elements can only be defined in evolutionary terms, as the ongoing result of changing paradigmatic and syntagmatic relations, rather than by distinct grammatical structures. This is something we saw in his discussion of grammar in Chapter 2 of this thesis, where he pushes further into an evolutionary perspective than the Neogrammarians had done. Part of this insistence is, of course, Saussure's view that no element is immutable, including the "material" element of any sign. Indeed, when he talks of "radical arbitrariness" we may hear in this term an evocation of the mutability of the root. There may be some that have not changed up to this point, says Saussure - word roots in the Semitic family of languages seem particularly stable, for example - but that does not mean they will not change in the future. In general, everything that time has done, time can undo (Saussure, 1974, p. 231). 


\section{Section 5: Saussure pushes deeper into the analogy}

- The wholly arbitrary nature of language and the lingustic sign does not, Saussure argues, result in language being best understood as a convention.

- Rather, it distinguishes language from other conventional, social institutions that are all based in varying degrees on the natural relations of things $(1974$, p. 75$)$ and is responsible for the manner and complexity of linguistic evolution.

- Arbitrariness means that language changes, or rather evolves, under the influence of all the forces which can affect either sound or meanings. It exposes the linguistic sign to change because that change, whatever its origin, always result in a shift in the relationship between the signified and the signifier.

There is no easy resolution, then for Saussure, between conventionalism and a more naturalistic approach. We have seen that Whitney helps Saussure repudiate the life cycle thesis. The story is a little more complicated than this however. For what came along with the life cycle thesis, especially as it was co-opted by theological interests, was the notion that the rapid early development of language in its Edenic phase is only explicable by the "natural significancy" of its terms (Alter, 2005, p. 59). That is why, despite having the authority of Webster's dictionary definition behind him, Whitney had been forced to defend the arbitrary nature of the sign along with the other principles that were so influential in the establishment of the Neogrammarian school. Once again I am indebted 
to Stephen Alter for this account: First writing on this subject in 1839, Gibbs said that this thesis [natural significancy] although neglected of late, was assuming its place once again as "one of the deepest and most important doctrines in philology ... In order to explain the existence of language, it is not enough that man has the organ of speech, that he has sensations and ideas, and that he has a desire to communicate them to others; but it is also necessary that sounds should have a natural adaptedness to express the particular sensations and ideas (Alter, 2005, p. 59). The doctrine can be traced back to Epicurus and re-emerges as late as the 1850s as a kind of audio-resonance theory, most notably in Muller's work (Alter, 2005, p. 89). Epicurus wrote: names ... were not at first deliberately given to things, but men's natures according to their different nationalities had their own peculiar feelings and received their peculiar impressions, and so each in their own way emitted air formed into shape by each of these feelings and impressions, according to the differences made in the different nations by the places of their abode as well. (Epicurus, Letter to Herodotus 75-6, trans. Bailey, 1926, quoted by Joseph in Sanders, 2004, p.68)

Saussure's intuition is one that follows quite naturally from Whitney's work: that the very arbitrariness of the sign is tied not to a simple contract or convention but to the evolution of language, when that evolution is rightly conceived. But Saussure wants to push further down this line of thought - and hence, I would suggest, go deeper into the linguistic biological analogy. In one chapter of the Course in particular, he wrestles with the tension inherent in connecting arbitrariness - associated with Whitney's conventionalism - with historical evolution. This is the chapter of the Course entitled "Immutability and Mutability of the Sign". It is here that we find the tribute to Whitney and his insistence on the arbitrary nature of the sign - together with the view that Whitney did not "follow through" on his insight. Saussure's argument in this chapter is a complex one but might be outlined as follows: 
a. The signifier, though to all appearances freely chosen with respect to the idea that it represents, is fixed not free with respect to the linguistic community that uses it.

b. That is not because the community by some simple contract or convention agrees on signifiers and imposes them as a law. It is, rather, because language is only ever experienced as an inheritance, as the product of historical forces - the deck is always already stacked.

c. But that doesn't get us very far as an explanation. Even inherited, traditional institutions can change radically, and language does not do that. What Whitney does not see is that the radically arbitrary nature of the particular social institution that is language separates that institution out from others. Other social institutions - even those as apparently arbitrary as fashion - are all based in varying degrees on the natural relations of things $(\mathbf{1 9 7 4 ,}$ P.75). The arbitrariness of language is responsible for its characteristic evolution, both the mutability and immutability of signs.

d. Signifier arbitrariness creates the continuous, gradual yet exhaustive nature of linguistic change. It exposes the sign to change because change, although it can originate through a myriad of forces that affect either sound or meaning, always results in a shift in the signifier-signified relation.

e. This kind of arbitrariness is closely connected with time. The thing which keeps language from being a simple convention that can be modified at the whim of interested 
parties is not its social nature. Rather it is the action of time combined with the social force (1974, P. 78).

In the last part of the chapter, Saussure returns explicitly to the language-speech distinction he made in the introductory lectures. He illustrates this framework very simply with a circle for language connected to a square for the community of speakers or speech. He presents this diagram - essentially the conventionalist position - and then presents his own position by modifying the diagram by the addition of an arrow to represent time mediating between the two.

The argument represents both a deeper positive analogy with biological evolution but also a certain negative analogy. It is an advance from conventionalism toward the linguistic-biological analogy because of its commitment to "the action of time" in combination with the social force and the way in which that works in the relation between speech and language. But the analogy is limited by the move Saussure makes in c. above to install signifier-signified arbitrariness at a deeper level of abstraction than evolutionary forces such as the syntagmatic and paradigmatic relations he describes as the mechanism of language. Signifier-signified arbitrariness allows for an explanation, he contends, of both mutability and immutability. The sign is immutable because it is arbitrary in the sense that there is no reasoned argument that can be adduced to persuade a community of speakers to change it. It is mutable because, conversely there is no reason why it should not change. 
The problem is that this conception of arbitrariness as the separability of the signifier assumes a pre-existing signified and a fixed structure of reference. If there is a pre-existing opposition between signifier and signified there must be a pre-existing delimitation of both the signified and the signifier. The premise of the arbitrary nature of the sign is inescapably a conventionalist premise. But Saussure wants to argue that it is the gap between the signifier and the signified that accounts for the mutable nature more precisely, perhaps, the labile nature - of the sign. As it is a product of both the social force and time, no one can change anything in it and on the other hand the arbitrariness of its signs theoretically entails the freedom of establishing just any relationship between phonetic substance and ideas. The result is that each of the two elements in the sign maintains its own life to a degree unknown elsewhere, and that language changes, or rather evolves, under the influence of all the forces which can affect either sound or meanings (1974, P. 76). All change, whatever its origin, results in a shift in the signifier-signified relation, i.e. a semantic change. This is given emphasis more than once. Regardless of what the forces of change are, whether in isolation or in combination they always result in a shift in the relationship between the signified and the signifier (1974, P. 74). Language is powerless to defend itself against the forces which from one moment to the next are shifting the relationship between the signified and the signifier. This is one of the consequences of the arbitrary nature of the sign (1974, P. 76). The question is whether the opposition of signifier and signified is itself evolving along with other relations of opposition and association - or whether it stands apart from those relations as the fixed, structural cause of their evolution. I will consider this question in more detail in the last chapter of this thesis. Whatever the mechanism involved, though, Saussure commits in this chapter to a much more systematic process of the evolution of signs than conventionalism would allow. To that extent he goes deeper into the linguistic-biological analogy. 


\section{Section 6: The missing unit}

- Saussure finds it very difficult to identify a unit of linguistic evolution and this may be considered both a point of analogy and of contrast.

- Cavalli-Sforza is more certain on both sides of the analogy, comparing words with genes and noting a strong similarity in terms of "variability".

- Lexical diffusion aligns with Saussure's conception of the creative role of analogy and Saussure's account of this process is more supportive of the linguisticbiological analogy than that of Cavalli- Sforza.

Another point of analogy with biological evolution - and perhaps a point of contrast is the difficulty in identifying any unit of evolution. Perhaps the best known confrontation with this question in biology is marked by Richard Dawkins' discussion at the beginning of "The Selfish Gene" (Dawkins, 1976). Dawkins argues by a process of elimination that it can only be genes themselves that are the unit that is selected in evolution, a view which now enjoys widespread support (Cone, J.A., 2006). Saussure experiences the same difficulty but, crucially, is unable to reach any resolution. First, the object that linguistics studies seems to be a function of the scientist's viewpoint on speech rather than an object capable of determining that viewpoint. Second, having settled on language or languages as the object of linguistics, it is impossible to identify the unit within language undergoing evolutionary change. It could be words but it appears that it can also be 
combinations of words or subsections of words. As I described in the first chapter, Saussure opts for a certain level of abstraction - preferring to speak wherever possible of the terms of language, since a term is what belongs to a system.

But this does not seem to have allayed Saussure's anxiety - and sometimes despair - at ever being able to demonstrate "what sort of object language is" (Culler, 1986, p. 24) Of course, Saussure is not able to consider any analogy with genes as the heritable unit of evolution since a genotypic model was not developed until the 1920s. Saussure could only have been familiar with Darwin's pre-Mendellian, phenotypic model of inheritance: "pangenesis". Pangenesis holds that body cells shed gemmules, which collect in the reproductive organs prior to fertilization. Thus every cell in the body has a 'vote' in the constitution of the offspring (Pangenesis, Wikipedia, 2008).

For Cavalli-Sforza the analogy is very much one that is constituted between words and genes. One way in which it applies at a more detailed level concerns their variability: I have already mentioned that there are some words that change very little over time and space, either in their phonology or meaning: they are especially useful for establishing relationships between languages that have been separated. Unfortunately, these words are rare. At the opposite extreme are the highly variable words, the ones that have a high mutation rate. Highly variable genes have a great number of alleles; similarly highly variable words have a great number of synonyms. They can be found in a thesaurus. For example, there are many synonyms for the word "drunk" ... the same is true for the word "penis". Studying the variation of words would certainly offer interesting psychological information (Cavalli-Sforza, 2000, p. 197). It is not clear whether Saussure considers the variability of words but he does consider their productivity. That productivity occurs through analogy - and that is tied to decomposability. Words can be rated for capacity to engender other words to the extent to which they themselves are 
decomposable... each language has both productive and sterile words in varying proportions ... An Esperantist has unlimited freedom to build new words on a given root (Saussure, 1974, p. 166). Productive forms are "stored" within languages' paradigmatic and syntagmatic relations. Following on from what we might call Saussure's language-speech-time model we find a more analogous role for speech. Speech is the means of transmission and replication of the language within the community of speakers, as that community is defined geographically and as it continues over time. This means that: Speech is continuously engaged in decomposing its units and this activity contains not only every possibility of effective talk but every possibility of analogical formation (Saussure, 1974, p. 166). At the same time: Any [analogical] creation must be preceded by an unconscious comparison of the materials deposited in the storehouse of language where productive forms are arranged according to their syntagmatic and associative relations (Saussure, 1974, p. 166). For Saussure terms can be preserved in one of two ways. Either the term is at the very centre of the evolutionary current and highly productive. Or, as in the case of a place-name, it is preserved because it is on the periphery of the language as an evolving entity. It is in the intermediate area between these two zones that terms are most subject to evolutionary transformation.

What Saussure thinks of as the productivity of words may be closer to what Cavalli-Sforza calls "lexical diffusion". But then we encounter a marked difference in interpretation, with Cavalli-Sforza appearing to reflect the influence of Chomsky's theses of the native and mental character of basic grammatical structure: We could not leave this subject without mentioning the most interesting aspect of linguistic evolution - lexical diffusion, whose importance was demonstrated by William Wang ... Lexical diffusion does not refer to the way an innovation spreads from one person to another, but to the effect that the change in one word may have on the other words in one person's vocabulary. This is especially important because it also tells us about the working of the brain which seems to operate from a set of rules. Although each language 
preserves many grammatical, phonological and syntactical irregularities, there is a tendency for homogenization and extension of rules (Cavalli-Sforza, 2000, p. 203). Saussure's approach seems more helpful in explaining the linguistic biological analogy: We have seen (p.195) that the innovation was due to an accident which was not only material but also negative, the elimination of the $a$ in betahus. Everything occurred outside the mind and in the realm of sound changes, which readily impose a tight yoke on thought and force it into the special way that the material state of signs opens to it. ... language is not controlled directly by the mind of speakers $(1974$, p. 228). We may also note that Cavalli-Sforza's example in this case supports Saussure's analysis of the complexity of the syntagmatic and paradigmatic forces whose build up results in analogical formations. It seems that it could not be as simple as Whitney suggests with regard to the assimilative effect of the majority of cases on the minority: English verbs are in the process of becoming more regular as time passes. Another example is the differentiation of verbs and nouns by the position of the accent: the word "present" is a noun if the accent is on the first syllable, and a verb if on the second syllable. In 1570 there were only three examples (outlaw, rebel, record). Between 1582 and 1934 they grew steadily from 8 to 150 (Cavalli Sforza, 2000, p. 203).

Cavalli-Sforza Sforza suggests, however, that with regard to the complexity in the transformation of linguistic terms we may be reaching the limit of the analogy with biological evolution: We must note a significant difference between biological and genetic mutation. A genetic mutant is generally very similar to the original gene since one gives rise to the other with only a small change. Words vary in more complicated ways. The same root can vary phonologically from language to language and it can also change meaning (2000, p. 197). The question remains, perhaps, as to whether this difference is due to the accelerated rate of linguistic transmission and hence the accelerated rate of linguistic evolution - rather than to a difference in mechanism. 
Finally, it seems important to note a certain echo between the assumption articulated by Cavalli-Sforza that Linguistic evolution is a special type of cultural evolution (2000, p. 150) and Saussure's desire to situate language within semiology, the broader study of the life of signs in society. This echo persists despite the fact that Cavalli-Sforza does not describe the relationship between linguistic and cultural evolution in any detail. The feeling of similarity persist, perhaps, because Saussure ties the perception of language as one of many semiological systems to internal linguistics, to the study of language in itself (1974, p. 16). As we shall see below, for Saussure what belongs to internal linguistics is what tends to support the linguistic-biological analogy.

\section{Section 7: The negative analogy and the demarcation between internal and external linguistics}

- Saussure consistently characterizes the elements that negate the empirical application of the linguistic-biological analogy as external to language studied in and of itself.

- Language in Saussure's account has an “inner organism” capable of evolving independently of external factors which may, however, retard that evolution.

- Anything that causes evolutionary change in language belongs to this inner organism, to internal linguistics. In effect, it is anything that arises from the free interaction of language and speech. This unhindered interaction of language and 
speech is the empirical condition under which the linguistic-biological analogy holds.

- The initial points of analogy identified at the start of this chapter are all consistent with the definition of internal linguistics.

The first point of negative analogy is the most obvious and has been alluded to already: languages evolve much more quickly than genes: Genetic mutations are rare, and transmission from one individual to another occurs only from parent to child, while linguistic changes are much more frequent and can pass also between unrelated individuals. As a result languages change more quickly than genes. In effect, if a word can resist change for 1,000 years a gene can remain substantially unchanged for million and even billions of years (Cavalli- Sforza, 2000, p.150). For Cavalli-Sforza, linguistic evolution is a special type of cultural evolution because cultural transmission, replication and exchange - and their arbitrary imperfections - are the medium of linguistic evolution. This process, he says, is similar in many ways to the transmission and replication of disease organisms as modeled in epidemiology. This is due to the inclusion of horizontal as well as vertical, intergenerational transmission. That, in turn, suggests that linguistic evolution will accelerate to a much greater rate than hitherto imagined due to the current development of information and communication technology.

As we explore the negative analogy further, however, we find something startling. We find that Saussure has assigned the positive and negative analogy clear, separate categories. Those categories are the categories of internal and external linguistics respectively. Everything that is consistent with biological evolution belongs to "the inner 
organism" (Saussure, 1974, p. 21) or the internal elements of language and is studied by internal linguistics. That includes some diachronic elements and all synchronic elements. The proper objects of external linguistics, on the other hand, are those external forces and mechanisms that interfere, we might say, with the effects of "time" or natural evolution on languages. In this sense, the internal/external opposition is prior to the diachronic/synchronic distinction. For the internal elements of language are identified in turn with the unique and proper object of linguistics: language studied in and of itself.

Cavalli-Sforza Sforza writes: Nevertheless, there are several major sources of divergence between genetic and linguistic trees. One language can be replaced by another in a relatively short time. In Europe for example, Hungarian is spoken in the geographic centre of many Indo-European branches: Slavic, Germanic, and Romance; but it belongs to the Finno-Ugric branch of Uralic ... at the end of the ninth century A.D., the nomadic Magyars left their land in Russia, crossed the Carpathians and invaded Hungary ... the conquest resulted in a Magyar monarchy, which imposed its language on the local Romance speaking population. The number of conquerors was large but did not constitute the majority of the population - perhaps less than $30 \%$ of the total. The genetic effect of this conquest was therefore modest ...(2000, p. 151). Language replacement through conquest is just one means by which linguistic and biological evolution can diverge. Cavalli-Sforza goes on to examine these in more detail - and Saussure also provides a parallel summary in his discussion of external linguistics, largely in terms of the relations between language and political history. For example: Great historical events like the Roman conquest have an incalculable influence on a host of linguistic facts. Colonisation, which is only one form that conquest may take, brings about change in idiom, by transporting it into different surroundings ... The internal politics of states is no less important to the life of languages; certain governments (like the Swiss) allow the co-existence of several idioms; others (like the French) strive for linguistic unity (1974, p. 20). Saussure also identifies as belonging to external linguistics ... all the points 
where linguistics borders on ethnology, all the relations that link the history of a language and the history of a race or civilization $(1974$, p. 20$)$.

In the broadest terms, I suggest, Saussure identifies external factors with the traits that attach language to the other social institutions - those that are more or less voluntary $(1974, \mathrm{p}$. 17). With regard to phonetic change in particular, the key problem that Saussure sees in what he classifies as external factors is that there is no apparent explanation for why they should act at one time rather than another. There is no account of what occurs to unleash a change whose general cause has existed for a long time. Climatic influence, racial predisposition, and the tendency toward least effort are all permanent or lasting. Why do they act sporadically, sometimes on one point of the phonological system and sometimes on another (Saussure, 1974, p. 150)? Saussure distinguishes these factors from exchange between populations that can be classified as part of internal linguistics: Did earlier populations introduce some of their own articulatory habits into the new language on adopting it? This is admissible and quite natural. But if the imponderable forces of race etc. are called in anew, the pitfalls described earlier reappear (Saussure, 1974, p. 151).

Again, in parallel with the points of negative analogy noted by Cavalli-Sforza, Saussure cites the relations between language and ... all sorts of institutions (the Church, the school etc.) All these institutions in turn are closely tied to the literary development of a language, a general phenomenon that is all the more inseparable from political history $(1974$, p. 20). Saussure also consigns everything that relates to the geographical spreading of languages and dialectical splitting to the realm of the negative analogy. He says: Finally everything that relates to the geographical spreading of languages and dialectical splitting belongs to external linguistics. Doubtless the distinction between internal and external linguistics seems most paradoxical here, since the geographical phenomenon is so closely linked to the existence of any language; but 
geographical spreading and dialectical splitting do not actually affect the inner organism of an idiom (1974, p. 22).

A very close parallel develops as Saussure justifies this exclusion: Take as an example the borrowing of foreign words. We observe from the outset that borrowing is not a constant force in the life of a language... More important still, a loan word no longer counts as such whenever it is studied within a system; it exists only through its relation with, and opposition to, words associated with it, just like any other sign $(1974$, p. 21 - p. 22). Likewise, Cavalli-Sforza: Even though the phenomenon of borrowing words from other languages, especially from neighbours, is well established the most studied evolutionary trees give the impression that a language changes in ways that are largely independent of changes taking place in other languages. This is a prerequisite for the applicability of tree analysis $(\mathbf{2 0 0 0 ,}$ p. 194). Chapter $\mathrm{V}$ of the Introduction to the Course is entitled "Internal and External Elements of Language" and here Saussure marks out the positive and negative analogy at some length. Throughout the chapter, language as a system is equated with language as an organism - and indeed as a "living" organism as Saussure refers to it elsewhere. He begins the chapter: My definition of language presupposes the exclusion of everything outside its organism or system - in a word, of everything known as "external linguistics". Saussure asks: Some have maintained that the foregoing issues simply cannot be separated from the study of language proper... Just as the inner organism of a plant is modified by alien forces (terrain, climate, etc) does not the grammatical organism depend constantly on the external forces of linguistic change $(\mathbf{1 9 7 4}, \mathbf{p . 2 0})$ ? He answers this question in the following way: I believe that the study of external linguistic phenomena is most fruitful; but to say that we cannot understand the internal linguistic organism without studying external phenomena is wrong (1974, p. 21). He concludes the discussion: One must always distinguish between what is internal and what is external. In each instance one can determine the nature of the phenomenon by applying this rule: everything that changes the system in any way is internal $(1974$, p. 22). 
Saussure's remarks on loan words provide the clue to what he means here, I think, by "changing the system". It is a question of whether relations of opposition and association - syntagmatic and paradigmatic relations - change around any supposed innovation. That, in turn, is a question of whether the innovation can be analogical whether the speaker taps into the constellation of signs around any given sign as "a build up of forces" for evolutionary change. A newly formed word like in-decorable already has a potential existence in language; all its elements are found in syntagms like décor-er 'decorate', décoration 'decoration', pardon-able 'pardonable' ... inconnu 'unknown', etc. and the final step of realizing it in speaking is a small matter in comparison with the build-up of forces that makes it possible (1974, p. 166).

Where there is such a change, a certain internal freedom is in play. External factors are those that, by definition, do not cause such change but can only inhibit it: Immobility the relative fixation of an idiom - may have an external cause (the influence of a court, school, an academy, writing, etc.) which in turn is positively favoured by social and political equilibrium. But if some external upheaval that has affected the equilibrium of the nation precipitates linguistic evolution, that is because language simply reverts back to its free state and follows its regular course. The immobility of Latin of the classical period is due to external facts; the changes that it later underwent, however, were self generated in the absence of certain external conditions (Saussure, 1974, p. 150). It seems that external factors can only stymie the process of evolutionary change, not participate in it. They impose limitations on "an activity that has none". In effect that is to say that they don't arise from the relation between a language and the population that supports it. They don't arise from the free interaction - perhaps we should say "embodied" or even "voluntary" interaction - of language and speech. That relation seems to come about through the activities of speakers who are at once inside the language, familiar to an automatic or unconscious degree with its storehouse of forms, as 
well as outside it at the very fringe of speech that exceeds language (Saussure, 1974, p. 165). These are the conditions under which resonant innovations can be produced. Those conditions can be met by both native speakers and speakers from outside the language whose interaction with the language is genuinely creative - or procreative. It may be noted, too, that the initial points of analogy identified at the start of this chapter are all consistent with this definition of internal linguistics and the free interaction of language and speech. 


\section{The Life of Language:}

\section{Saussure and Evolution}

\section{Chapter 4: The philosophical appropriation of Saussure's theory}

\section{Section 1: The theory and the analogy}

- The conditions under which the linguistic-biological analogy holds are the conditions which Saussure says define internal as opposed to external linguistics: they provide for the free interplay, without external interference or imposition, of language and speech.

- Saussure thus succeeds in outlining a common evolutionary framework for two apparently quite different semiological systems. There is, however, also a contrary tendency in his thought. This is exemplified in his view that language can be distinguished from other semiological systems by the wholly arbitrary nature of its signs.

- There is a material or natural substratum to many sign systems, says Saussure. Language alone, because it has a signifier that has no natural connection to the signified, functions as a system of pure values. 
In the previous chapter I explored the analogy between biological and linguistic evolution in more depth - both historically and in its contemporary form - and examined how Saussure's work can be situated in relation to that analogy. The aim of this examination was to provide a more detailed and profound answer to the first of the guiding questions of this thesis: to what extent is Saussure's theory of language a theory that underpins and explains the linguistic-biological analogy? Providing a deeper answer to that question enables us to provide an answer to the second of our guiding questions: to what extent should Saussure's theory be one that explains and supports the analogy? That question is the particular subject of this chapter. The answer to this second question, though, continues to emerge very much in parallel to the answer to the first question. And it leads on to the third question with which we are concerned: a consideration of what the answers to these first two questions suggest about the philosophical appropriation of Saussure's theory.

What have we learned so far, then, about Saussure and evolution? As long as each system is allowed to evolve freely then the linguistic-biological analogy will hold, even to the extent that it can form the basis of successful empirical analysis and prediction. What does "evolve freely" mean? It means that there is free interaction between speech and language - between individual innovation and collective conservation - without external interference or imposition. These are the empirical conditions under which the analogy holds as described by Cavalli-Sforza and they are the same as those under which Saussure says we may observe the inner organism of language. It may be that the rate of evolution differs in each system. But that difference appears to correspond to differing rates of transmission - that is, differing rates of interaction of speech and language. These 
differences also occur within biology, between genomes, with viruses representing a certain limit of evolutionary acceleration. The language-speech framework - by which I mean the language-speech-time framework Saussure defines and illustrates diagrammatically in the Immutability and Mutability of the Sign (Saussure, 1974, p. 71) is, then, a common evolutionary framework. This is, first of all, how Saussure's theory explains the linguistic-biological analogy.

The unfettered interplay of speech and language that forms the subject of internal linguistics can also be described as an ideal for Saussure. It is the condition of the fully semiological life (1974, p. 76) he envisages for Esperanto, for example. It is at once an evolutionary and a democratic ideal, consistent with such descendants of his theory as Jurgen Habermas' conceptions of communicative rationality and democratic participation (Habermas, 1987). Saussure is concerned with what we might describe as a self transforming process enacted in the relationship between communities of speakers and their systems - between the speech that lies within the language system and the speech that lies beyond it. The fully semiological life is also though, as we will see below, a theoretical ideal that is not quite fully realized in the theory itself.

For while Saussure succeeds in outlining a common framework for two apparently quite different semiological systems, there is, too, a contrary tendency in his thought. We have encountered this from a number of angles, the most acute of which has arisen in our discussion of his argument in the Immutability and Mutability of the Sign. This is Saussure's view that language can be distinguished from other semiological systems by the arbitrariness of its signs - where arbitrariness means the lack of any natural 
connection between the signifier and the signified. There is a material or natural substratum to many sign systems, says Saussure. In economics, for example, land has a natural value. Language alone, because it has a signifier that has no connection to the signified, functions as a system of pure values.

There is a real ambivalence in Saussure's teaching on this point. For it is precisely the arbitrariness of language that he contends makes it the most characteristic of all semiological systems. Signs that are wholly arbitrary realize better than the others the ideal of the semiological process; that is why language, the most complex and universal of all systems of expression, is also the most characteristic; in this sense linguistics can become the master-pattern for all branches of semiology although language is only one particular semiological system (Saussure, 1974, p. 68). That contention suggests that the particular arbitrary relation between the signifier and the signified in language just reflects a deeper arbitrariness - what I call "system arbitrariness" - shared by all systems. Language makes the material medium of any system visible, as Saussure puts it, as just a substance to be put to use (1974, p. 118).

So there is this tension. On the one hand Saussure articulates the popular - indeed we could say culturally embedded - conception of language as a freely willed human construction. This view depends on the lack of natural connection between the signifier and the signified - the separability, let us say, of one from the other. As Muller highlighted, this view cannot explain how languages evolve in a manner that is analogous to natural forms of evolution. On the other hand, we have Saussure's theory of systematic values in which the signifier and signified are inseparable. We would expect an account 
of sign systems on this basis to be consistent across human-made and natural systems. Accordingly, this aspect of the theory is consistent with the linguistic-biological analogy.

\section{Section 2: Distinguishing between two forms of arbitrariness}

- I suggest that Saussure's theory should support the linguistic-biological analogy. I therefore contend that we need to distinguish between two forms of arbitrariness - signifier arbitrariness and system arbitrariness or material discontinuity - that Saussure tends to conflate.

- Despite appearances, signifier arbitrariness is consistently at odds with system arbitrariness. Signifier arbitrariness is defined by the lack of a natural connection between the signifier and the signified. System arbitrariness, by contrast, entails the inseparability of signifier and signified within the system.

- More specifically, in opposing the natural significancy thesis, Saussure appears to assume the necessity of signifier difference when its possibility would suffice. It is only the necessity of signifier difference that is inconsistent with system arbitrariness and the linguistic-biological analogy.

- Whitney's insight that opposition plays a delimiting role within systems fuels Saussure's desire to link the difference between signs in a system to the difference between the signifier and the signified in a sign. Nevertheless, there are compelling reasons to recall that the "decoupage" or the cutting out of signs is 
solely the result of the evolving syntagmatic and paradigmatic relations that constitute the linguistic system.

In considering the extent to which Saussure's theory supports the linguisticbiological analogy, then, we can say that the theory supports the analogy insofar as Saussure proposes that language is a system of pure values. But it does not support the analogy insofar as Saussure conceives of the purity of a system of values as measured by the arbitrariness of its names or signifiers rather than by the free interaction of language and speech. I want to argue that Saussure's theory should support the analogy and so in what follows I will argue that we must distinguish between two forms of arbitrariness that Saussure consistently conflates. One is signifier arbitrariness. As Saussure puts it, the choice of a given slice of sound to name a given idea is completely arbitrary $(1974$, p. 113). It is the arbitrariness of the signifier as opposed to the signified. The other form of arbitrariness is what we might call "system arbitrariness". This is the arbitrariness of the signifier and the signified together, of the whole sign. Saussure is invoking this system arbitrariness when he says, for example, that language only happens to use sound images as its medium leaving aside some physiological questions, language could just as easily have developed as a system of manual signs.

The distinction between the two forms of arbitrariness can certainly appear subtle and connecting the two has proved a persuasive strategy for Saussure. Buried within their conflation, however, are some powerful contradictions. We can see this as soon as we begin to look more closely into each form of arbitrariness. 
System arbitrariness is also what I have called "material discontinuity". In Saussure's view, historical linguistics reveals a new class of phenomena (1974, p. 231) without any fixed units, identities or objects on which a science can be based. Instead, these phenomena manifest a material discontinuity in which change is all pervasive and permanence results from sheer luck. (Saussure, 1974, p. 231) The material medium of a sign system is arbitrary in the sense of being irrelevant to its systematics because there are no material elements that transcend the mechanism of evolutionary change. To prove that language is a system of pure values, says Saussure, it is enough to consider the two elements involved in its functioning. Not only is thought before language a vague uncharted nebula but the phonic substance is neither more fixed nor more rigid than thought. It is equally plastic (1974, p. 112). For that reason, neither are thoughts given material form nor are sounds transformed into mental entities. The somewhat mysterious fact is rather that "thought-sound" implies division, and that language works out its units while taking shape between two shapeless masses (Saussure, 1974, p. 112). Saussure is saying that there is no indivisible material element - no element that cannot be "cut up" or "sliced" for redistribution - through the ongoing, evolutionary mechanism of language. There is nothing that pre-exists linguistic value or could form the base for it. This is system arbitrariness or material discontinuity.

Now consider signifier arbitrariness - particularly the distinctive arbitrariness of the signifier as opposed to the signified that Saussure says we encounter in language. How can we recognize the lack of "natural connection" between the signifier and the signified if we don't first of all suppose that there is some material basis to the signified, that it is in some way a natural object? The signified must have a nature in itself. It cannot be solely a product of relations of association and opposition, a value emanating from the 
system (Saussure, 1974, p. 117). It must somehow be an isolable object, capable of being listed in an ontology in no particular order or arrangement. Otherwise the nature of the signified would just reflect the nature of its system - and that nature would always be shared by its systematic signifier.

Likewise, Saussure could not assign different signs within the same system - or different systems of signs - differing degrees of arbitrariness if we did not assume preexisting natural objects as signifieds and some gap between these and their signifiers. This assumption is essential to signifier arbitrariness and to the conventional - and conventionalist - view of language.

The separable signifier, then, assumes a separable signified, both laterally in relation to other signifieds and vertically in relation to its signifier. As Whitney says we have our idea and then we get a name for it (Alter, 2005, p. 72). But Saussure has this strong desire to connect up these two contradictory conceptions: signifier arbitrariness and all pervasive evolutionary change or system arbitrariness. The well known passages in which he rejects onomatapeia as an explanation for the origin of certain signs provide a further example. It is an accident of their evolution, says Saussure, that certain signifiers such as glas sound like their signifieds - in this case, the knell of a bell. Originally there was a separation of the signifier and the signified. Yet as Derrida argues (Derrida, 1974) there is a significant contradiction lurking here. The natural connection between the signifier and the signified in glas is said to be an evolutionary accident. But isn't its origin as an arbitrary sign equally then an evolutionary accident? If arbitrariness is just the evolutionary, accidental character of the bond between signifier and signified, though, we 
will be unable to discern by any essential feature of that bond whether any sign is arbitrary as opposed to natural. And if a natural connection in the signifier-signified relation is just as arbitrary as a lack of natural connection in the signifier-signified relation how can we appeal to signifier-signified difference as the source of arbitrariness in the system - or as the source of the distinctive evolution of the linguistic system, as Saussure wants to do?

To put the issue another way, we may recall that Saussure is rebutting the natural significancy thesis. That thesis assumes that there is a natural or necessary connection between the signifier and the signified. But, in logical terms, the negation of the necessity of sameness in the signifier-signified relation is not the necessity of difference in that relation: it is the possibility of difference in that relation. That possibility is consistent, in turn, with the possibility of sameness in that relation. Saussure does not need to argue that signifier-signified difference is the original - and originating - condition of the sign. And indeed he should not, if he is to adhere to the uniformitarian principle. The conditions at work in the past must be essentially the same as those at work in the present. The possibility of signifier-signified difference together with signifier-signified sameness is such a condition.

Yet Saussure very often seems to hold to the view that signifier-signified difference is a necessary condition of linguistic systems. That is at odds with the all pervasive potential for change in linguistic systems, their purely contingent character. It is also at odds with any analogy between the evolution of linguistic systems and natural systems, including the linguistic-biological analogy. Simply, it is not signifiers or signs, 
considered in isolation, that are arbitrary. It is systems. The sign is evolving within a system that is evolving. It is the system's paradigmatic and syntagmatic relations that are responsible for every aspect of the sign - all its relations of similarity and difference, its division from other units and the division of units within it. The evolution of those relations is entirely arbitrary in the sense that it has no perduring, necessary element.

If this were not the case - if evolutionary change in language were not potentially all pervasive - then there might be some fixed external structure or criterion, transcending sign systems, by which we could judge whether isolated signs were wholly or partially arbitrary. As it is, the fact that signs exist only within arbitrary systems makes that judgement impossible. So while it seems natural to think of the arbitrariness of a system as being expressed in the arbitrariness or otherwise of the signs that make up that system, if we do this then, precisely, we elide the evolutionary mechanism of language. And, in doing that, we elide what language has in common with other sign systems.

The conflation of signifier and system arbitrariness is also evident in Saussure's argument in the Immutability and Mutability of Signs. It is a matter, says Saussure, of "following through" on Whitney's principle of the arbitrary signifier and seeing that this distinguishes it from all other social institutions and is responsible for the manner and complexity of linguistic evolution. This is despite the fact that Saussure knows that semantic evolution is essential to linguistic evolution and Whitney is explicit that the signified or idea exists prior to its signifier. It is as if, for Saussure, the evolution of language depends on signifier arbitrariness and that sign systems would otherwise be 
immobile. Needless to say, the linguistic-biological analogy directly challenges this assumption too.

But Saussure also attempts to forge the connection between material discontinuity and necessary signifier arbitrariness from the other side of the pairing, from the side of material discontinuity. He is encouraged, no doubt, by some divergent views of Whitney's on semantics. This can be seen in a particular passage in the Course. Alter tells us that Whitney, especially in his 1875 book "The Life and Growth of Languages", offers a new interpretation of the familiar distinction between "material" and "formal" elements in language. In his first book he set forth the standard view that material elements (such as the full in fully) had descended from a language family's root words and so had retained their independent significance. Formal elements, the theory ran, had emerged with the development of inflective grammar and expressed grammatical elaboration only; they had no independent meaning. Although he never abandoned this orthodox Boppian theory, Whitney introduced in his mid career writings the idea that the material and formal aspects of language actually exist in a reciprocal relationship on a strictly synchronic plane. He also expanded the realm of the "formal", even to the point of implying that no truly independent "material" elements exist. He gave as examples paired terms such as brook:brooks and man:men. The semantic difference between the members of these pairs, he said, was generated purely "by contrast". Even the primary term, brook was itself "formed", because it received its ability to express singleness of number "not by a [positive] sign, but by the absence of an otherwise necessary sign to the contrary (Alter 251-2).

When we look at the corresponding passage in Saussure's Course we find Saussure asserting a correlation between the arbitrariness of signifiers and the differential delimitation of signs. Since one vocal image is no better suited than the next to what it is commissioned to express, it is evident, even a priori, that a segment of language can never in the final 
analysis be based on anything except its noncoincidence with the rest. Arbitrary and differential are two correlative qualities. The alteration of linguistic signs clearly illustrates this. It is precisely because the terms $a$ and $b$ as such are radically incapable of coming to consciousness - one is always conscious of only the $a / b$ difference that each term is free to change according to laws that are unrelated to its signifying function. No positive sign characterizes the genitive plural in Czech zen; still the two forms zena: zen function as well as earlier forms zena: zenb; zen has value only because it is different $(1974$, p. 118).

Again, Saussure slides from the arbitrariness of the signifier - the vocal image - to the arbitrary segmentation of language, the delimitation of signs that include the signified. Terms evolve holistically through the syntagmatic and paradigmatic mechanism of language and they do this independently of their signified, says Saussure, because they are not motivated by their signified. Yet the point is that signifieds are inseparable from signifiers in this process. Signifieds evolve as well. That means that the concept of signifier arbitrariness is no longer applicable.

But Saussure's intuition is that if the absence of a sign can function as a sign - and if only oppositions are capable of coming to consciousness in language - then that seems at once to explain the absence of any continuous material element in the evolution of sign systems and to connect back to the opposition of signifier and signified. The system is one of differences - and it is that way because of the radical arbitrariness of the signifier. "Arbitrary and differential are two correlative qualities". The gap between signs is the same gap as that between names and objects. The separation of the signifier from the signified is correlated with the delimiting difference or opposition between signs. Every evolutionary change in signs can be conceived as a shift in the relationship between the 
signifier and the signified. Signifier arbitrariness is tied to material discontinuity - and by that means to the free evolution of sign systems, to internal as opposed to external linguistics. The three concepts are knotted together in this quotation, for example: Not only are the two domains that are linked by the linguistic fact shapeless and confused, but the choice of a given slice of sound to name a given idea is completely arbitrary. If this were not true the notion of value would be compromised because it would include an externally imposed element (Saussure, 1974, p. 113).

Yet once we incorporate this important insight of Whitney's - that opposition is systematic - we have another reason to distinguish between signifier arbitrariness and system arbitrariness. The choice of one material medium as opposed to another for a system is arbitrary. The choice of one sound in opposition to another to name a given idea within the system is not entirely arbitrary just because opposition is systematic. The sound in question must be sufficiently similar to others to be a part of the system and sufficiently different to be non-coincident with other signs.

Certainly it is tempting to equate the arbitrariness of sound as the medium for language with the arbitrariness of a particular sound in language as the medium for a particular idea. But particular sound-ideas are values that emanate from the medium. Saussure often fails to make this distinction partly, we could say, because he often fails to make the distinction between absolute and relative difference. The delimiting differences within the language system - more properly termed oppositions - that individuate values are not absolute but relative in the sense that they are held within associative relations. The absence of a mark in Saussure's example functions on the basis of the sameness of every other feature of these two signs. Its significance depends on both aspects. These 
associations between signs may be as broad as the similarity that makes a sound a part of a language rather than background noise. It may also be that a sign consists "most precisely" in being what other signs are not. Signs are defined most generally, we can say, by similarity or association - they are defined most specifically by opposition. In between they are defined by the alternation of association and opposition. At the most precise level the opposition must be between signs that are also most similar, as Saussure and Whitney's examples of singular/plural oppositions shows. The rule of non coincidence or non contradiction they follow at the most precise level, is then, correspondingly strict. It is not difference as such, not absolute difference that carries significance. To reach the level of precision at which a value is ultimately defined by opposition requires a complex interplay of syntagmatic and paradigmatic relations, relations of association and opposition - as illustrated by Saussure's "somnolent" and our "paramedic" examples in chapter 2.

Semantic variation is proof, says Saussure, that instead of pre-existing ideas we find in language only values emanating from the system. Those values may well be partly delimited, in the manner we've described, not by their positive content but negatively by their relations with other terms of the system (Saussure, 1974, p. 117). But if the relation between signs is solely or absolutely differential - or if it is arbitrary in the sense that signifiers are thought to be arbitrary in opposition to their signifieds - then signs are also separable from each other. And if they are separable they are isolable and non-systematic. Saussure's conception of decoupage or the cutting out of units of meaning runs the same risk. If this process is supposed to be absolute or arbitrary in the manner that the signifier 
is arbitrary then we elide the mechanism of language and the systematic character of signs.

\section{Section 3: Why Saussure's theory should support the analogy}

- Conflating signifier and system arbitrariness generates two opposing models of language. This is one good reason why Saussure's theory should be interpreted so as to support the linguistic-biological analogy.

- There are other reasons however, why signifier arbitrariness should be unhooked from system arbitrariness.

- These include freeing the theory from the contradictions and aporia outlined in the immediately preceding section and the empirical support that the theory then gains from the analogy. It also opens the possibility of a fuller philosophical appropriation of Saussure's theory.

The linguistic-biological analogy directly challenges, then, this conflation between signifier and system arbitrariness in Saussure's theory. This is reflected in the way that the conflation plays out in Saussure's theory. It is responsible, for example, for Saussure's conception of relative as opposed to absolute arbitrariness. In this conception, the systematic is partially superimposed on the arbitrary. Signs are originally isolated, absolutely arbitrary or differential - and language is by nature chaotic (Saussure, 1974, p. 131). The mind contrives to introduce a degree of rationality (Saussure, 1974, p. 131) in the form of a 
system that limits or partially transforms this absolute arbitrariness. Relations within the system are purely those of similarity and analogy. Systematic signs are signs that are productive of other signs by these means. The system is distinctively evolutionary and diachronic. Signs that remain outside the system - or below it, as it were, as the system's raw material - remain isolated, wholly arbitrary, unproductive (Saussure, 1974, p. 166).

In fact, in pursuing the connection between signifier and system arbitrariness Saussure generates two opposing models of language. In one model, he describes a static or synchronic, crystalline structure of differences. In this structure, the arbitrariness between the signifier and the signified is responsible for both the mutability and immutability of signs. The real evolutionary mechanism - the mechanism of language that Saussure also describes - is elided. This tends to be the dominant reading of Saussure's theory. The uniquely arbitrary character of the signifier in language is the ground on which synchronic linguistics is separated out from diachronic linguistics.

In the other model - that of relative arbitrariness - the system is constituted solely by relations of similarity and analogy on a base of simply named objects. This system is essentially diachronic. In both scenarios Saussure fails to identify the ongoing evolutionary mechanism of language with its signifying structure. In that mechanism, syntagmatic and paradigmatic relations - sameness and difference - work together to create meaning. Indeed, it may be that what we are here calling "linguistic system" is just what Heidegger calls the "originary being together of identity and difference", (Heidegger, 1969). But instead, Saussure ends up advancing two models of language, one based on relations of difference and one based on relations of sameness or analogy. 
The linguistic-biological analogy drives a wedge, then, between the two senses of the arbitrary that we find in Saussure's theory. Material discontinuity or system arbitrariness is consistent with the analogy - signifier arbitrariness contradicts it. If Saussure's theory is to support the analogy - and vice versa - then system arbitrariness must be unhooked from signifier arbitrariness. As we saw above, "material discontinuity" also names the absence of what are technically called material as opposed to formal elements in language and the delimitation of signs by opposition. It is consistent with what Saussure is striving to capture when he declares that everything comes down to the fact that language is a form not a substance (1974, p. 113).

On the other hand, in striving to unite signifier and system arbitrariness, Saussure's theory ultimately splits into two contradictory models. That in itself is a good reason to say that Saussure's theory should be one that supports the linguistic-biological analogy. At this point, though, we may take a step back and review a number of reasons why the theory should support the analogy.

- First, system arbitrariness goes to the heart of what Saussure is trying to achieve in his theory - an account of the forces that are universally and permanently at work in language evolution. In accordance, in particular, with the uniformitarian thesis Saussure wants to identify the ongoing evolutionary mechanism of language with its signifying structure - to describe these as one and the same thing. 
- Second, if Saussure's theory is consistent with the linguistic-biological analogy then that analogy, in turn, provides considerable empirical support for his theory.

- Third, the extent to which Saussure's theory supports the analogy is the extent to which it is freed from the contradictions and aporia that flow from uniting signifier arbitrariness with material discontinuity. I have discussed some of these aporia above: the signifier is both separable and inseparable from the signified; the relation between the signifier and the signified is not necessarily differential just not necessarily the same; two contradictory models of system emerge, one based on relations of difference and the other on relations of sameness; "cutting out" is conceived as the mechanism rather than just an effect of language evolution.

I hope that these three reasons have been explored to some extent already in this thesis. They certainly encourage us to go on and separate out signifier arbitrariness in Saussure's theory and rely solely on system arbitrariness. But that also opens the possibility of a fuller philosophical appropriation of Saussure's theory - and this is a fourth reason why Saussure's theory should be read as a theory that underpins and explains the linguistic-biological analogy. In the following section I want to explore the possibility of such a fuller appropriation in more depth. Then I suggest that, crucially, this requires an alternative account of signifier arbitrariness - one that is consistent with, rather than contradicting, systematic value. 


\section{Section 4: The fourth, philosophical, reason for separating out signifier} arbitrariness.

- The philosophical appropriation of Saussure's theory is limited by the fact that simple arbitrary naming - and, therefore, pre-existing extra-linguistic objects appear to continue along side systematic value.

- A popular approach to locating simple, individual naming in relation to value which consists in grafting simple naming onto the language-speech oppositionmay be developed further by reference to Saussure's conception of systematic latitude.

- This may, as Laclau and Mouffe suggest, help explicate the seemingly intractable philosophical problem of the relationship between a material base and an ideological superstructure.

The philosophical implications of Saussure's theory all have to do with semantics: semantic variance over communities of speakers and semantic evolution over time within a community of speakers. Saussure foregrounds this phenomenon, first brought to light by historical linguistics, by making it a principle that the ideas or objects referred to in language do not exist prior to or outside the structure of reference in language. This semantic immanence or semantic relativism has a clear philosophical implication: it offers an alternative model of ontology. The limit we encounter in the philosophical appropriation of Saussure's theory, however, is the co-existence of simple naming with 
linguistic value. If the name or signifier is arbitrary as opposed to the object it names or signifies then that object must lie outside language as a system of signifiers. There must be an extra-linguistic world. The theory is not, we might say, "fully ontologised". It can always be relegated to the realm of "language" as opposed to "reality".

In the sections above I've highlighted some points at which we can see Saussure striving to connect these two concepts: the arbitrariness of names with system arbitrariness. I've also argued that his theory will not cohere on this basis. Indeed it divides into two contradictory models. The theory only hangs together if we can interpret Saussure's talk of the choice of a given slice of sound to name a given idea $(1974$, p. 113) as referring simultaneously to the arbitrariness of the signified as well as of the signifier.

This division in Saussure's theory also arises from the fact that Saussure is attempting, in a quite single minded fashion, to establish a theory of linguistics not a philosophical semantics. As a consequence, the object to which he refers is very often a linguistic object, the object of study for linguistics. It is not any and every object - the "world" to which a philosophical semantics refers as it continues the broader philosophical project of metaphysical enquiry. Likewise, the facts to which Saussure refers are "the facts of speech" - not all facts, not facts as such. This difference can be observed at many points. As we have noted, when Saussure describes the material discontinuity he finds in diachronic linguistics he contrasts this with systems of value that still have some material basis, such as economics. Likewise, language is thought to be the most exemplary of sign systems just because it doesn't maintain a fixed material basis as other semiotic systems may do - as fashion does with regard to certain parameters set by 
the human body, for example. Or, when discussing linguistic identity, Saussure cites objects like the $8.25 \mathrm{pm}$ Geneva-to-Paris train or a certain street: These, he says, can change in every material respect while remaining the same because their circumstantial or contextual definition - their delimitation - remains the same. These objects are contrasted by Saussure with an object such as his stolen suit which persists across different circumstances or contexts by virtue of a certain inert, material identity (Saussure, 1974, p. $108-$ p. 109)

Again, the arbitrariness of signifiers is illustrated by the fact that the same object - a cattlebeast - has different names on different sides of a geographical border. But linguistic value is illustrated by the English word mutton because it names something different from the French word mouton. It is as if two different kinds of objects existed in the world - some with a kind of internal, inherent essence and others with a purely external, relative essence.

So long as Saussure's synchronic or structural linguistics is appropriated to the social sciences this issue can be parenthesized. For in the social sciences, it may be said, we are not studying a natural, material object but objects that are, broadly speaking, human values - despite a desire at times to include natural scientific objects within these social scientific accounts. In these areas Saussure's influence has, of course, been profound. But a full philosophical appropriation requires a different approach. One way of dealing with the appeal to signifier-signified arbitrariness in Saussure's theory is to accept that Saussure's linguistics continues to maintain some element of simple naming or signification alongside value. It is certainly possible to justify readings that suggest 
that value and signification co-exist peacefully. Saussure says of a word that: Being part of a system, it is endowed not only with signification but also and especially with a value, and this is something quite different. A few examples will show clearly that this is true. Modern French "mouton" can have the same signification as English "sheep" but not the same value and this for several reasons particularly because in speaking of a piece of meat ready to be served on the table, English uses mutton and not sheep (1974, p. 115). As Joseph notes: This discussion has troubled many commentators (for a selection, see the long note 231 of the de Mauro edition of the Cours) because when it comes to "meaning" (sens or signification), Saussure reverts to the ordinary way of talking about words and things that he has dismissed as "nomenclaturism" and that his whole concept of the signe linguistique aims to supersede (Sanders, 2004, p. 66).

But if we maintain the co-existence of simple naming alongside linguistic value Saussure's theory is not very different, as we will see, from Gottlob Frege's theory of Sense and Reference (Frege, 1997). In Frege's theory, sense - the mode of determination of the object of reference - co-exists with simple names and objects of reference. For many interpreters the problem is compounded if we think of the very doctrine of arbitrariness itself as depending on a nomenclaturist view of signification. Such a concern marks one major divergence in post-Saussurean linguistics, with the Russian linguist Roman Jakobson contending that the theory of arbitrariness is in blatant contradiction (Holdcroft, 1991, p. 52) to the conception of linguistic value. Saussure introduces the concept of arbitrariness by saying that: "the idea of 'sister' is not linked by any inner relationship to the succession of sounds s-o-r which serves as its signifier in French; that it could be represented equally by just any other sequence is proved by differences among languages and by the very existence of different languages: the signified 'ox' has as its signifier ' $b-o-f$ ' on one side of the border and 0-k-s (ochs) on the other (1974, p. 68). Jakobson, quite reasonably, contends that what is good for the sheep should also be good for the ox: the scope of the word "boeuf" and 
that of the word "Ochs" do not coincide. (Holdcroft, 1991, p. 52) As a consequence Jakobson supports the view articulated by Benveniste: the connection between the signifier and the signified is not arbitrary; on the contrary it is necessary (Holdcroft, 1991, p. 52).

Of course, the scope of these terms could coincide. They could be the same values just by coincidence or chance. We don't have to maintain that there are no coincidences of value between systems to maintain that languages consist solely of systematic values. But differences in values between systems are certainly evidence of the systematic character of signs.

A popular view attempts to reconcile signification and value by "grafting" them on to Saussure's speech/language distinction. Signification, it is said, belongs to speech and value to language. (Holdcroft 1991, Joseph in Sanders, 2004, Culler, 1986). Joseph describes the strategy in this way: But as Burger (1961) concluded, the discussion makes sense if we graft the value/meaning distinction onto that between langue, the mental system and parole, what people actually do with language. 'Meaning' is then to be understood in the ordinary way, as the use we make of spoken words to denote things, actions, qualities and so on, whereas 'value' is what is intrinsic to mental signs that makes it possible to use spoken words in this way (Sanders p. 66). This account seems quite implausible since it contradicts semantic variation and evolution and assumes pre-existing "things, actions, qualities and so on". However associating simple naming with speech doe shave the appeal of suggesting that simple naming can be conceived originally as individual naming. It seems that an innovative individual speech act of naming could be thought of as signification, prior to its adoption or rejection by the group - prior to its becoming, or failing to become, a value within the system. That leads 
on to a more developed conception of systematic latitude as a way of comprehending arbitrary naming - a conception I outline below.

A somewhat different approach is evident in a text such as Ernesto Laclau and Chantale Mouffe's seminal apology for Post Marxism, "Post Marxism without Apologies" (Laclau, E. \& Mouffe, C., 1990). Here the authors contend that the object is discursively constituted in its being or essence (1990, p. 104) - but distinguish the being of an object from its existence. The existence of an object is a necessary pre-condition of its having a being but as a member of a certain community, I will never encounter the object in its naked existence - such a notion is a mere abstraction (1990, p. 104).

Even if we don't think of language as a system of naming, however, there are at least two problems that arise from any approach that maintains the co-existence of simple naming and systematic value. The first is that a philosophical appropriation of Saussure's theory demands an account of language in relation to all kinds of object. We need one story about how language relates to the world and cannot leave one form of reference - or one kind of object of reference - outside that account. Objects such as Gross National Product or Saussure's stolen suit are signifieds like any other. They have an inseparable relation to their signifiers and form a sign - a linguistic value - just as certainly as the signifieds of linguistics. If this were not the case the signifieds of linguistics would be pure values only in the sense that they are the object of this exclusive discipline. The question of their relation to any object outside linguistics - their semantic value - would remain unanswered. The signifieds of linguistics must be the signifieds of language. So, while it is Saussure's disciplinary fervour that helps propel his theory toward its radical 
conclusions, the sign - even as the object of study of linguistics - must be universal because it must be capable of including any object as its signified.

The second problem is that, sooner or later, any political or social scientific theory circles back to its metaphysical base. For example, if we look again at Laclau and Mouffe's article we see that Saussure's theory seems to offer a solution to the vexed question of the relation between a material base and an ideological superstructure: One possible way of understanding this embeddedness of ideas in the material conditions of society would be in terms of signifying totalities. The 'state' or 'ideas' would not be self constituted identities but rather 'differences' in the Saussurean sense, whose only identity is established relationally with other differences such as 'productive forces', 'relations of production', etc. The 'materialist' advance of Marx would have been to show that the area of social differences which constitutes the signifying totalities is much wider and deeper than it had been supposed hitherto (1990, p. 110).

But we have already seen that a purely differential linguistic system depends on yoking material discontinuity to signifier arbitrariness - and signifier arbitrariness presupposes a natural, isolable signified. Likewise, we have seen above that the distinction between a material "existence" and a linguistic "being" or value is maintained in Laclau and Mouffe's theory at a more abstract, fundamental level. So contemporary Critical Theory often evinces this dilemma: do we engage with a wholly articulable construct? Or does some natural, bare life remains below such structures, a material remainder? The difficulty associated with the first horn of this dilemma is that pure, differential values begin to feel weightless and arbitrary in a negative sense. The difficulty encountered on the second horn is that matter or existence includes something a-priori impenetrable and mysterious - a component in which systematic values seem bound to be stowed out of 
sight. Either way, the tension between the original assumptions of signifier arbitrariness and the systematic role which Saussure seeks to assign it remains highly problematic particularly in the elevation of difference as such to a structural principle.

\section{Section 5: Systematic latitude - an alternative to signifier arbitrariness}

- If we do not want signifier arbitrariness to contradict Saussure's evolutionary systematics, we need to give an account of simple naming as an effect of system arbitrariness - effectively reversing Saussure's strategy.

- New signifiers can be added to pre-existing systematic values in a process that extends or elaborates those values so long as they do not contradict pre-existing values.

- That is because systems of linguistic value have a limit which coincides with the limit of the interests of their community of speakers. From the point of the system further elaborations are arbitrary in that they only have to obey a rule of noncontradiction.

If the co-existence of signification and linguistic value is not an option, then, what are we to do with simple naming? While the linguistic-biological analogy offers very strong encouragement to rely solely on systematic value, it does not address the content of what is, as we saw at the beginning of this thesis, a widespread and longstanding intuition. In particular, we would not want to re-enact the battle that Whitney fought on behalf of 
signifier arbitrariness against the linguistic-biological analogy in the form of the doctrine of natural significancy and linguistic natural theology. In fact, we are accustomed to think of the gap between the name and the object as the gap between the subject and the object - and in this sense as the source of both human freedom and human limitation. As Frege put it: No-one can be forbidden from using any arbitrarily producible event or object as a sign for something else (1892, p. 152). What we need, rather, is a satisfying account of signifier arbitrariness on the basis of system arbitrariness. We want to show signifier arbitrariness as an effect of material discontinuity, not the other way around - reversing, in some sense, Saussure's strategy. That, I think, is quite possible if we adapt one of Saussure's own concepts to the task.

For the systematic delimitation of objects leaves what Saussure calls a certain latitude between points of convergence (1974, p. 119). Saussure highlights the latitude between these points with respect to the pronunciation of phonemes in speech and the form of letters in writing. Phonemes are above all else, opposing, relative and negative entities (1974, p. 119). As long as one phoneme does not cross the boundary with another, individuals and groups have considerable freedom in their formation. This freedom is evidenced in idiolects and, to some extent, in dialects. Here I want to suggest that the same latitude accounts for simple naming. Systematic latitude could be the best explanation for a certain nominal discretion that speakers enjoy and the best way of resolving the issues around the apparent co-existence of systematic value with simple naming.

First, we need to acknowledge that there are objects that are pre-existing in relation to acts of naming. That seems undeniable. Persons, pets, body parts - all can be "dubbed" 
according to our fancy. The question is, are these pre-existing objects isolated or systematic? We assert that they are systematic. They are always already signs. And the nature of a sign is the nature of its system. But once the system has defined the object in accordance with its needs it then leaves plenty of latitude for further variation and elaboration, both by individuals or by groups. The system may require that Fido's name is registered, for example - or that the name on our passport corresponds to that on our birth certificate. It is systematic to that extent, as the system brings out the desired differentiation at the desired point (Saussure, 1974, p. 132). But this leaves wide latitude as to what that name shall be. Indeed, whenever we think of simple arbitrary naming we do so by considering the signified in isolation - thereby, paradoxically, taking its systematic definition for granted. Once that definition is assumed, we are left with the latitude that remains, a certain broad nominal discretion.

So it is with Saussure's example of a substitute chess piece. The substitute for the original only has to be different from the other pieces says Saussure - it is necessary only that it not blur its identity with other pieces (1974, p. 110). But as we've seen earlier, this is only true once the substitute has had its systematic properties conferred upon it: that is, it is deemed capable of certain moves in relation to the other pieces. With respect to those systematic properties the original piece resists, as Saussure puts it, any arbitrary substitution (1974, p. 72). At the risk of mixing our ludic metaphors the substitute chess piece has to become part of the same stacked deck $(\mathbf{1 9 7 4}$, p. 71) in which the original participated. There then remains a certain latitude or margin of arbitrariness as to its other properties, a latitude whose boundaries are set by a weak rule of non-contradiction, of consistency or compatibility. It is only necessary that the substitute not be confused with other pieces 
that have other systematic properties. In this sense the substitute piece must only be different. But it is equally vital to observe that the piece's systematic properties are not themselves merely a result of this piece being different from the other chess pieces.

Saussure's innovation is to show that the object, before any apparently arbitrary name is conferred upon it, is defined in a purely contingent - and therefore arbitrary system of associative and combinatorial relations. That system is the subject of an evolutionary continuity which has the potential to transform any and all aspects of the objects within it. Whatever name we use for an object such as rose it may indeed still possess its definitional properties, such as its sweet smell. But this definition is systematic. That is the most - and the least - that Saussure needs to claim. Indeed, in Juliet's exclamation - that which we call a rose by any other name would smell as sweet (Shakespeare, 1597, Act 2, Scene 2, lines 44-45) - all the systematic work is already done at another level. In using a rose as a signifier for Romeo, Juliet has taken him from a system of blood ties and arranged marriages into one of erotic desire and romantic aspiration. In saying deny thy father and refuse thy name (Shakespeare, 1597, Act 2, Scene 2, lines 33-34), she acknowledges that those two acts - obedience to the law of the father and attachment to the family name - are inseparable. "Romeo" as a linguistic value is a scion of the house of Montague, a young man with a certain destiny. Once we name him as a rose then we are free to call that rose whatever we want. But at the deeper level Juliet has dramatically exceeded the latitude allowed by the dominant system. Her substitution of the value "rose" for "Romeo" elicits a corresponding resistance. 
Similarly, we can easily imagine objects without their names when we imagine them one by one, in isolation. But if we divest all objects of names then we lose the systematic definition of objects. We are confronted with an unmanageable disorder something like the writhing, gravity-less reality Sartre describes his protagonist experiencing in his novel Nausea, when he loses all names (Sartre, 1949). In this sense, the freedom of naming is a latitude delimited by the system.

The objects in question may, by chance, be quite stable parts of a system. They don't have to be changing. Or change could affect just the periphery of an object. It is rather that evolutionary change makes the character of objects as values in a system visible - and the all pervasive nature of evolutionary change makes the character of objects as values in a pure system of values visible. The change in question may be quite dramatic, as is the case when the Morning Star and the Evening Star turn out to be one object, the planet Venus - or the planet Pluto not to be a planet at all. But the system delimits objects, as I've put it, from the outside in so that changes in definition may occur just at the edges of the object - and be very gradually evolving.

Further, we must note that signs that appear discretionary may become essential as systems evolve and vice versa. The Higgs Boson seems at present to be a sign comprising a discretionary and a definitional element respectively. But there may turn out to be different types of Higgsian Boson - or conversely the Higgs Boson could turn out to be a chimera and the Higgs element be lost altogether. 
We do also need to correctly identify the system of delimitation of an object. Unless we realize that Juliet is using "Romeo" as a metonym for "Romeo Montague", for example, then her challenge Wherefore art thou 'Romeo'? (Shakespeare, 1597, p. 33) - her placing of speech marks around a linguistic value - lacks any force. More subtly, an irrational reaction by an individual to an event or object may suggest that it has significance in some inter-subjective system, preserved in that individual, that is not apparent to others in the community. Equally, an anomalous empirical value - the advance in the perihelion orbit of Mercury observed around the beginning of the $20^{\text {th }}$ Century, for example - may suggest that the underlying system of values is not yet fully or correctly delimited.

Sometimes the latitude at the limit of the system, formed by this rule, is quite specific and narrow. But it still appears as a margin of arbitrariness. A good example can be found in late $19^{\text {th }}$ Century Germany. In this case, when the government conceived the project of further integrating the Jewish community into German society it provided lists of permitted units of meaning - "gold", "silver", "braun", "stein", "berg" - to Jewish citizens which they were free to combine at will to form German names. These were names that would be consistent with - but did not infringe upon - the existing system of identities.

The fundamental point is that systems are relative to communities of interest. It is not that simple naming exists on top of systematic value. Rather, it is the case that the interests of the community - and with these, the needs of the system - have a certain limit. From the point of view of those interests and their system what lies beyond that 
limit need only comply with a weak rule of non contradiction. That rule defines the latitude allowed by the system - and that latitude may appear to the system as the arbitrariness of names.

Again, Frege applies that principle of the freedom of naming I have quoted him describing earlier when he sets about inventing symbolic logic. This, as he sees it, is simply a system of names economical enough to bring complex relations between large units of meaning within the circle of the mind's eye i.e. within the limits of our concentration within which they can be compared, connected and contrasted. But the key question with any such artificial language is whether it remains within the latitude of the system it seeks to compress - or whether it generates a distinctive semantics. Is it consistent with - or does it contradict - the system it claims to translate?

Names may be proscribed on the basis that they are blasphemous and this may vary between cultures. It is clearly considered blasphemous to use "Jesus" as a name for one's children in Anglophone cultures but it is popular to do so in Hispanic cultures, for example. Of course, names that are not consistent or that contradict the systematic delimitation of the object named may deliberately be used by groups to challenge the existing system of values. Obvious examples are the use of terms like "gay" or "queer" by a minority group. This re-enacts Juliet's strategy. The appeal to arbitrariness hides the project of transformation. The new name is not seen as arbitrary by the system to just the extent that the system resists its own transformation. But the arbitrariness of names - a certain margin of freedom - is itself a value within the system. So a small group can use one part of the system as the basis for a demand for consistency throughout the system 
and, in so doing, punch above its weight. Language is supporting us against language, we could say.

To summarise, re-articulating simple, arbitrary naming as systematic latitude involves the following elements:

1. Linguistic systems are located within a speaking circuit and so are co-extensive with their community of speakers - which we may also think of as their community of interest.

2. The degree of precision in the delimitation of values in a system is likewise defined by the interest of its community of speakers.

3. Binary oppositions form the boundaries of systems - values are delimited most precisely by their binary opposition. This leaves a certain latitude for further delimitation by other communities of interest. That delimitation - in the first instance, by association - follows a rule of non-contradiction.

4. Relative to the relevant system and community of interest, this further elaboration or delimitation has the character of arbitrary naming.

5. Systems or values may be further elaborated or delimited on this basis to the level of an individual speaker. 
6. Truth is an expression of systematic preference at the most precise level of systematic delimitation.

With reference to this sixth point, I am invoking the inchoate Saussurean theory of truth briefly described in chapter 2 .

\section{Section 6: Testing systematic latitude}

- We can test the six point proto-theory in a preliminary way by seeing how it explains two of Frege's puzzles. For example, Frege's identity problem can be accounted for by evolution in the systematic relations of sameness and difference that constitute objects.

- Our inability to substitute co-referential names in opaque contexts can be also be explained - primarily by the co-extension of specific systems of value with specific speakers, something that, paradoxically, these contexts make transparent.

- Subtleties, such as the way that values within a sentence may vary with their varying oppositional relations, are also able to be accounted for.

There are some basic tests that can be applied to the six point proto-theory outlined above. In this section I want very briefly to outline how the adaptation of the concept of systematic latitude to simple naming might work in these test cases. 
The tests I have in mind are those identified by Saussure's contemporary Gottlob Frege, particularly in his article, On Sense and Reference (1997, p. 151). The similarities between Frege's concept of sense and Saussure's concept of linguistic value are notable. Perhaps they are most obvious in this formulation by Frege: The sense of a proper name is grasped by everybody who is sufficiently familiar with the language or totality of designations to which it belongs (1892, p. 153). The differences between the theories revolve around the role of simple naming. If we think of Saussure's theory as involving a peaceful co-existence of simple naming with value then there is in fact little difference between the two. In both theories, however, the relations between these three elements: the simple name; the sense or value associated with that name; and the object named, are highly problematic. What we are concerned with here is whether an account of simple naming as systematic latitude can deal in any plausible way with some of the challenges that Frege identifies for his theory.

The first of these challenges is Frege's identity problem. The problem goes like this: if the meaning of a name is just the object it names what do we learn from identity statements such as "The Morning Star is the Evening Star"? How do these seem to be "synthetic" or informative about the world we live in - at least when we affirm them as true? For it would seem that such a sentence could tell us only one of two things. First that the convention we follow in the use of names is that the "Evening Star" is interchangeable with the "Morning Star". They can both be used to name the same thing. Alternatively the sentence could be telling us that the two objects named are the same, one thing. The problem is that in neither case does the sentence tell us anything new about the world. In the first case it tells us something about the conventions we use to 
name the world. If it is true it will be so analytically - that is, by virtue of the meaning of the terms used. In the second case, if the meaning of names is the thing they name - and this sentence is true - then the thing these two names name must already be one thing. All the identity sentence can tell us is that the object named is identical with itself. That is also an analytic - not a synthetic - truth.

How does Saussure's theory - including the account of simple naming we have outlined above - deal with this challenge? The sentence tells us that two values that were previously opposed - the "Morning Star" and the "Evening Star" - are now identified. This can only be due to the evolution of the system in which these values are found. That evolution will involve a redistribution of the relations of sameness and difference - the syntagmatic and paradigmatic relations - that constitute values in the system. The informative identity sentence is not telling us, in this case at least, of an elaboration to the system that some individual or group is undertaking, within the scope of the latitude of the system, such that these names are interchangeable. Neither, on the other hand, is the sentence telling us that the Planet Venus - which happens to be the one object in question - is the same as itself. It was never simply the same as itself but was always constituted as a value within a system of sameness and opposition. It was never an isolated object. Its essence was always extended through the system - as was that of the Morning Star and the Evening Star. The Planet Venus is now a different value, as are the Morning Star and the Evening Star. If the sentence is true it is because we judge that these new values are parts of our overall, preferred system of values. 
We might object the values of these names certainly appears to have changed - but doesn't that just concern, as Frege would say, the cognitive value associated with the name? Their referent - the Planet Venus - continues to hurtle through space in just the way that it has in the past and will in the future. I think the answer to this objection is that things may indeed be said to exist prior to our knowledge of them. They cannot ever, though, be said to exist as absolute singular things whose definition had nothing to do, however simply, with any of the other things around them. No man is an island - no island is an island either. For Frege, the opposite is the case - the referent is precisely a particular, unique object named by a singular term. Certainly, Saussure can allow that we observe isolated phenomena. But he can also point out that those observations have to be systematically reproducible before we begin to take them seriously and consider them a challenge to any existing system of objects.

The second test of Frege's that I want to consider concerns what Frege called subordinate clauses but which are now more often known as propositional attitudes, opaque contexts or intentional contexts. These are sentences of the kind: 1) Lois knows that Superman can fly. They are so named because they tell us about Lois Lane's attitude to the proposition Superman can fly. Or, similarly, they are opaque in that the relation between the name and its referent is obscured by the mediation of an intentional verb such as knowing, believing, seeing etc. The problem is that if the meaning of names is just their referent then the name Clark Kent, which has the same individual as its referent as Superman, should be substitutable in sentence 1) without that affecting its truth. However, says Frege, that does not seem to be the case in examples of this kind. Lois knows Superman can fly but it is not true to say that she knows Clark Kent can fly. 
Intuitions differ on this last point. Scott Soames feels truth is preserved through such substitutions (Soames, 2002). Frege does not. In these cases, says Frege, what we normally think of as the cognitive value or sense associated with a name becomes its referent - partly just because it is the sense that determines the truth of a sentence of this kind and what determines the truth of a sentence must be the referent. The sense of the name Superman is different for Lois from the sense of the name Clark Kent. As a consequence truth, is not preserved when one name is substituted for the other.

The explanation provided by our proto-theory is clearly going to run along similar lines to Frege's account. For in the proto-theory all objects are always in an intentional relationship to a community of speakers, down to the level of the individual speaker. In this sense, sentences of this kind may be seen as transparent contexts because they specify the speaker or community of speakers involved. By this means they specify the system in which the signified is found. In normal contexts that system is opaque because it is unconsciously assumed - at the very moment that we take the referent to be an isolated object. The account offered by the proto-theory is very simple, then. In Lois' system Clark Kent and Superman have different values. One value includes the ability to fly. The other does not. The two terms are not substitutible therefore, while preserving truth.

As I've said, from the point of view of our proto-theory, in normal contexts the system involved is assumed. Soames' account then depends simply on assuming that the system in which a sign has value is always the most comprehensive or knowing system 
available. It ignores elaborations or partialisations of that system - and with it the pleasures of dramatic irony that drive the superman stories.

An encouraging aspect of the proto-theory is that it seems to be able to account for examples in which both intuitions about the substitutability of co-referential expressions - the Soamesian and the Fregean - appear to be combined. Consider the sentence: 2) Lois knows Clark can fly but she doesn't know he has x-ray vision. Let us suppose that this sentence is uttered by one of two interlocutors playing a supporting role in the Superman story. Is truth preserved in substituting Clark for Superman in this case? Is there, in other words, an appropriate latitude allowed by the system?

Let us note to begin with that the latitude at the boundary of the system is defined by its ultimate binary opposition - and truth expresses the preference of the system at that level. If the ultimate opposition in this sentence is taken to be the opposition between two attributes possessed by a super being - the power of flight and x-ray vision - then the truth of the sentence will depend on Lois's knowledge of those powers alone. Does she know that Superman can, if he wishes, see through her clothes? If not, the sentence is true. The interlocutors are then free to add their own conspiratorial nuance to the sentence by calling Superman Clark. The sentence will be true regardless of what name they give this super being because of the latitude the system's ultimate opposition leaves. But if we judge the ultimate opposition in the system to lie between the values Clark and Superman which values include their differing dress, comportment and public identity - then the sentence will be false. If, for example, the actor speaking the line emphasises or "hits" the 
word Clark instead of the word fly, that will mark a different ultimate opposition - despite the apparent absence of the opposing sign Superman - and entail a different truth value.

So the proto-theory promises to have explanatory power at the most subtle level at which interested individuals and communities of speakers interact. To sum up: there are objects that exist prior to being named - but they are systematically delimited objects. The apparently arbitrary character of names derives from the latitude that delimitation by opposition leaves. That latitude is a weak restriction of non-coincidence or noncontradiction. To be true or authentic is to be a part of the system that is used as the criterion of truth or authenticity.

\section{Section 7: Metaphysical implications}

- The linguistic-biological analogy requires a re-articulation of signifier arbitrariness as systematic latitude and gives the speech-language frameworkthe evolutionary framework the two systems have in common - the central explanatory role.

- Metaphysically, this common evolutionary framework can be seen as an alternative response to what Aristotle calls "substantial change". It is an alternative to the material continuity Aristotle described, which ultimately secures the natural object opposite the human subject. 
- If we pursue this alternative, the subject-object relation - which is paradigmatically aligned with the arbitrariness of the signifier-signified relation - gives way to a speech-language relation as our basic metaphysical framework.

In the first part of this chapter I have argued that signifier arbitrariness needs to be strongly distinguished from material discontinuity. Signifier arbitrariness is not the reason that Language has the strange, striking characteristic of not having entities that are perceptible at the outset and yet of not permitting us to doubt that they exist and that their functioning constitutes it (Saussure, 1974, p. 107). And this feature - material discontinuity - is not a trait that distinguishes language from all other semiological institutions (Saussure, 1974, p. 107). It is a trait that unites semiological institutions so long as they are free to evolve. As we have seen with respect to language and at least one other semiological system in which signifier arbitrariness does not feature, these systems will evolve in similar ways so long as there is free interaction between language and speech. It is not that the sign is necessarily motivated in one system and necessarily unmotivated in the other. It is, rather, that the presence or absence of any specific motivation for a sign is irrelevant to its evolutionary systematics.

In the second part of this chapter I have, therefore, argued that signifier arbitrariness needs to be removed from the mechanism of the system itself and relocated, as systematic latitude, at the interface of language and speech. It is here, at the edge of the system, that the freedom that Saussure envisages for the Esperantist is located - in the complex relationship between innovation and the system that both enables and limits that 
innovation. It is in maintaining the play in this relationship that the linguistic-biological analogy is sustained. If Saussure can conceive of all evolutionary change in language as a shift in the relationship between signifier and signified it is just because the latitude at the boundary of the system which accounts for the appearance of signifier arbitrariness changes with any change in the system itself. By maintaining the free play in the relationship between language and speech, the semiological ideal - the life of language becomes accessible to all sign systems.

In the second part of this chapter I have also started to use what I have called the "inchoate theory of truth" that we find in Saussure - and this, too, is structured around the speech-language relationship. In fact, the fuller philosophical appropriation of Saussure's theory appears to involve a kind of transition or translation of problems into a speechlanguage framework as the means for their solution. One way of understanding this process - and perhaps all there is room to say further with regard to the way in which the linguistic-biological analogy opens the prospect of an alternative explanatory framework - is to point out that this common evolutionary framework is an alternative response to substantial change.

That is, it is an alternative to the Aristotelan account of the object as an individual substance (Aristotle 1998). That substance reveals itself in an open space - it presences itself in a space of disclosure. Saussure's object - the sign - is encountered within a system. The Aristotelean substance has its origin in itself. The Saussurean value has its origin in an evolving system of sameness and difference. The Aristotelean substance has an internal essence, an enduring being in itself that can stand in opposition to its 
accidental properties and ephemeral surroundings. The Saussurean object has an external essence that changes with changes in its surroundings. The Aristotelean substance is individual. The Saussurean value is infinitely divisible.

The Aristotelean substance has an underlying material continuity that transcends changes in its essential nature. That material substratum secures the object - it holds the place of the object - opposite an intentional human subject that refers to such objects by arbitrary names. But diachronic linguistics and its "new class of phenomena" compels Saussure to think beyond this framework - to think of systematic, evolutionary continuity in place of material continuity. As we saw in Saussure's example of the terms agunt and zeugma this systematic continuity includes not only the outward ripple of innovation and change but the inward ripple of conservation and stability that secures core, material elements - ancient elements - by mean of a present process. The object then ceases to have its ground or origin in its unique nature - and language ceases to be a question of how an autonomous human subject, undifferentiated as to being collective or individual, succeeds in referring to such objects over a relation of difference. Instead, language becomes the question of how objects are constituted as values by individuals and communities of speakers using interdependent, systematic relations of association and opposition, sameness and difference.

Unhooking system arbitrariness - that is, the lack of a natural or material base to evolutionary change - from signifier arbitrariness allows the speech-language framework to slide into position as our most basic assumption in place of the subject-object framework. If we don't think of the signifier-signified relation as necessarily a relation of 
difference then we can conceive of speech - and speakers - as occupying a space of possibility in which they may, like our interlocutors in the Superman stories, be simultaneously within a specific communal system and outside it. The interaction between the individual will and the collective will is conceived as more fundamental more original, we might say - than the opposition between a free human subject and a pre-determined natural object. I've argued that the freedom of arbitrary naming in fact reflects the changing boundary between the speech that lies within a particular linguistic system and the speech that lies beyond it. In that relation we find the means of innovation, elaboration, concentration and transformation. That, at least, is the evolutionary innovation that this analogy - the linguistic-biological analogy - suggests. 


\section{List of References}

Alter, S. G. (2005). William Dwight Whitney and the Science of Language. Baltimore: John Hopkins University Press.

Aristotle, (1998). Metaphysics. Tancred-Lawson, H. (trans.). London: Penguin

Barthes, R. (1968). Elements of Semiology. New York: Hill and Wang

Belsey, C. (2002). Critical Practice ( $2^{\text {nd }}$ ed.). New York: Routledge

Cavalli-Sforza, L.L. (2000). Genes, Peoples and Languages. Seielstad, M. (trans.), New York: North Point Press.

Culler, J. (1986). Ferdinand de Saussure (2 ${ }^{\text {nd }}$ ed.). New York: Cornell University Press

Cone, J. (2006). Review of the Thirtieth Anniversary edition of the Selfish Gene Times Literary Supplement retrieved 5 May 2009 from http//tls.timesonline.co.uk/article/0,25350-2225739,00.html

Dawkins, R. (1976). The Selfish Gene. Oxford: Oxford University Press

Derrida, J. (1974). Glas. Leavey, P. \& Rand, R. (trans, 1978) Lincoln: University of Nebraska Press

Emmeche C., Kull K., Stjernfelt F. (2002). Reading Hoffmeyer, Rethinking Biology. Tartu: Tartu University Press. Quoted on Biosemiotics, Introductory Page and Starting Site. Retrieved 10 June 2009 from http://www.zbi.ee/ uexkull/biosem.htm

Frege, G. (1997). On Sinn and Bedeutung. Translated from the German by Black, M. in Beaney, M. (Ed.), The Frege Reader (p. 151- p.171)., Oxford, Massachusetts: Blackwell.

Gadet, F. (1986). Saussure and Contemporary Culture. Elliott, G., (trans.), (1989). London: Century Hutchinson.

Godel, R. (1957). Les Sources manuscrites du Cours de linguistique generale de Ferdinand de Saussure. Geneva: Droz

Habermas, J. (1987). The Theory of Communicative Action. Vol 2. Lifeworld and System: A critique of Functionalist Reason. McCarthy, T., (trans.) Boston: Beacon Press

Harris, R. (1987). Reading Saussure. London: Duckworth.

Heidegger, M. (1969). Identity and Difference. Stambaugh, J. (trans) Chicago: University of Chicago Press 
Holdcroft, D. (1991). Saussure Signs, System and Arbitrariness. Cambridge: Cambridge University Press.

Laclau, E. \& Mouffe, C. (1990). Post-marxism without apologies. In Laclau, E. New reflections on the revolution of our time (p. 97 - p. 132). London: Verso (Original work published 1986)

Pangenesis, Wikipedia, Retrieved 8 July 2008, www.wikipedia.org

Prothero, D. (2008). Evolution: What the fossils say and why it matters. Columbia University Press discussed in New Scientist 1 March 2008, p. 35

Sanders, C. (Ed), (2004). The Cambridge Companion to Saussure. Cambridge:

Cambridge University Press.

Sartre, J.P. (1949). Nausea. Alexander L. (trans.) Norfolk, Connecticut: New Directions

de Saussure, F. (1974). Course in General Linguistics. Bally, C. \& Sechehaye, A. in collaboration with Reidlinger, A. (Eds.), Baskin, W., (trans.). Glasgow: Fontana/Collins.

de Saussure, F. (1911). Lecture of 30 June 1911. Student notes, retrieved 20 June 2009 from http://www.marxists.org/reference/subject/philosophy/works/fr/saussure.htm

Shakespeare, W. (1597). Romeo and Juliet. Blakemore Evans, G. (Ed.) (1984) Cambridge: Cambridge University Press.

Smithyman, K.S. (1978). Dwarf with a Billiard Cue. Auckland: Auckland University Press

Soames, S. (2002). Beyond Rigidity: The Unfinished Semantic Agenda of 'Naming and Necessity'. Oxford: Oxford University Press

Sturrock, J. (2003). Structuralism ( $2^{\text {nd }}$ ed.).London: Blackwell

Tennyson, Lord A., (1849). In Memoriam AHH, CXVIII . Retrieved 1 June, 2009, from 190 http://en.wikisource.org/wiki/In_Memoriam_A._H._H.Collected Poems

White, S.K., (2000). Sustaining affirmation: The strengths of weak ontology in political theory. Princeton: Princeton University Press.

Zimmer, C. (2000). The Hidden Unity of Hearts. Natural History Magazine, April 2000 retrieved 10 May 2009:

http://www.naturalhistorymag.com/master.html?http://www.naturalhistorymag.com /features/0400_feature1.html 
The Life of Language:

Saussure and Evolution 